\title{
DESIGN AND SIMULATION OF PASSIVE THERMAL MANAGEMENT SYSTEM FOR LITHIUM-ION BATTERY PACKS ON AN UNMANNED GROUND VEHICLE
}

\author{
A Thesis \\ Presented to \\ the Faculty of California Polytechnic State University, \\ San Luis Obispo
}

\author{
In Partial Fulfillment \\ of the Requirements for the Degree \\ Master of Science in Mechanical Engineering
}

by

Kevin Kenneth Parsons

December 2012 
(c) 2012

Kevin Kenneth Parsons

ALL RIGHTS RESERVED 


\section{COMMITTEE MEMBERSHIP}

TITLE:

AUTHOR:

DATE SUBMITTED:

COMmitTeE CHAIR: Thomas J. Mackin, Ph.D., Professor of

COMMITTEE MEMBER: Kim A. Shollenberger, Ph.D., Professor of

COMmitTeE MEMBER: John Dunning, Ph.D.
Mechanical Engineering

Mechanical Engineering

Design and Simulation of Passive Thermal Management System for Lithium-ion Battery Packs on an Unmanned Ground Vehicle

Kevin Kenneth Parsons

December 2012 


\begin{abstract}
Design and Simulation of Passive Thermal Management System for Lithium-ion Battery Packs on an Unmanned Ground Vehicle
\end{abstract}

Kevin Kenneth Parsons

The transient thermal response of a 15-cell, 48 volt, lithium-ion battery pack for an unmanned ground vehicle was simulated with ANSYS Fluent. Heat generation rates and specific heat capacity of a single cell were experimentally measured and used as input to the thermal model. A heat generation load was applied to each battery and natural convection film boundary conditions were applied to the exterior of the enclosure. The buoyancy-driven natural convection inside the enclosure was modeled along with the radiation heat transfer between internal components. The maximum temperature of the batteries reached $65.6^{\circ} \mathrm{C}$ after 630 seconds of usage at a simulated peak power draw of 3,600 watts or roughly 85 amps. This exceeds the manufacturer's maximum recommended operating temperature of $60^{\circ} \mathrm{C}$. The pack was redesigned to incorporate a passive thermal management system consisting of a composite expanded graphite matrix infiltrated with a phase-changing paraffin wax. The redesigned battery pack was similarly modeled, showing a decrease in the maximum temperature to $50.3^{\circ} \mathrm{C}$ after 630 seconds at the same power draw. The proposed passive thermal management system kept the batteries within their recommended operating temperature range. 


\section{Acknowledgements}

First, I would like to express my gratitude to Prof. Thomas Mackin for his continual support and advisement throughout the year. I sincerely appreciate all of the discussions and advice he has contributed over the course of the project.

Secondly, I would like to thank Dr. John Dunning for his guidance and contribution of knowledge in electrochemistry. The experiments in this project could not have been performed without the use of the Cal Poly electrochemistry lab equipment. Dr. Dunning was invaluable in providing guidance and support on the use of lab equipment.

Thirdly, I would like to thank Prof. Kim Shollenberger for her guidance, troubleshooting help, and teaching computational heat transfer and fluid dynamics. The computational heat transfer course I had with Prof. Shollenberger has provided me with critical skills for this project and will undoubtedly serve me well throughout my career. 


\section{Contents}

List of Tables $\quad$ ix

List of Figures $\quad$ X

Nomenclature xiii

1 Introduction 1

1.1 Project Aim . . . . . . . . . . . . . . . . . . . 2

1.2 Thesis Organization . . . . . . . . . . . . . . . . . . 3

2 Literature Review $\quad 4$

2.1 Pesaran et al. (1997) . . . . . . . . . . . . . . . . 4

2.2 Onda et al. (2005) . . . . . . . . . . . . . . 8

2.3 Pesaran et al. (2001) . . . . . . . . . . . . . . . . 10

2.4 Al-Hallaj and Selman (2002) . . . . . . . . . . . . . . 12

2.5 Doughty et al. (2002) . . . . . . . . . . . . . . 13

2.6 Maleki and Shamsuri (2003) . . . . . . . . . . . . 14

$2.7 \mathrm{Hu}$ et al. (2010) . . . . . . . . . . . . . . . . 15

2.8 Mills and Al-Hallaj (2005) . . . . . . . . . . . 16

2.9 Rao et al. (2011) . . . . . . . . . . . . . . . . . . 18

2.10 Al-Hallaj et al. (2000) . . . . . . . . . . . . . 21

2.11 Viswanathan et al. (2010) . . . . . . . . . . . . . 22

3 Background $\quad 25$

3.1 Battery Chemistry . . . . . . . . . . . . 25

3.2 Phase Change Materials . . . . . . . . . . . . . . . . 28

4 Computational Fluid Dynamics 29 
$4.1 \quad$ ANSYS Fluent $\ldots \ldots \ldots \ldots$

4.2 Conservation Equations _. . . . . . . . . . . . . . 30

4.2 .1 Continuity Equation . . . . . . . . . . . . . . . 30

4.2 .2 Momentum Equation . . . . . . . . . . . . . . . . . 30

4.2 .3 Energy Equation . . . . . . . . . . . . . . . . . 31

4.3 Buoyancy-Driven Flows . . . . . . . . . . . . . . . . . . . . . . . . . 32

4.3 .1 Boussinesq Model . . . . . . . . . . . . . . . . . . . . . 32

4.4 Surface-to-Surface Radiation Model . . . . . . . . . . . . . . . . . . 33

5 Experiment 35

5.1 Experiment Equipment . . . . . . . . . . . . . . . . . . . 35

5.1.1 Agilent Data Acquisition and Multiplexer . . . . . . . . 35

$5.1 .2 \quad$ LabVIEW Program . . . . . . . . . . . . . . . . . 36

5.1 .3 Infrared Camera . . . . . . . . . . . . . . . . . . 41

5.1 .4 Electronic Load . . . . . . . . . . . . . . . . . . . . . 41

5.1 .5 DC Power Supply . . . . . . . . . . . . . . . . . . . . . 44

5.2 Experiment Procedures and Results . . . . . . . . . . . . 45

5.2.1 Calibration and Heat Capacity . . . . . . . . . . . . 45

5.2.2 Heat Generation Rates - Experimental Method . . . . . . . 53

5.2 .3 Heat Generation Rates - Entropy Method . . . . . . . . . 53

5.2 .4 Uncertainty . . . . . . . . . . . . . . . . . . . 56

6 Computational Fluid Dynamics Model $\quad 58$

6.1 Model Development . . . . . . . . . . . . . . . . . . . . . . 58

6.2 Boundary and Initial Conditions . . . . . . . . . . . . . . . . . 62

6.3 Mesh Development . . . . . . . . . . . . . . . . . . . 65

6.4 Calculation Settings _ . . . . . . . . . . . . . 66

6.5 CFD Results . . . . . . . . . . . . . . . . . 67

6.6 Validation . . . . . . . . . . . . . . . . . . . . . . 72

7 Phase Change Material and Expanded Graphite Model $\quad 74$

7.1 Model Development . . . . . . . . . . . . . . . . . . . . . . . . . 74

7.2 Results . . . . . . . . . . . . . . . . . 78

8 Discussion, Conclusions, and Future Research 81 
8.1 Discussion . . . . . . . . . . . . . . . . . . . . . . 81

8.2 Conclusions . . . . . . . . . . . . . . . . . . . 84

8.3 Recommendations for Future Research . . . . . . . . . . . . . 85

$\begin{array}{ll}\text { Bibliography } & 86\end{array}$

A ANSYS Fluent Model Input Summary 89 


\section{List of Tables}

2.1 Properties used in lead acid battery simulation. . . . . . . . . . 6

3.1 Properties of primary and secondary battery chemistries. . . . . . . 26

3.2 Thermodynamic properties of phase change materials. . . . . . . . . 28

5.1 Front panel details of LabVIEW data collection program. . . . . . . 38

5.2 Constant power discharge rates. . . . . . . . . . . . . 53

5.3 Results of calibration and heat capacity experiments. . . . . . . . 56

5.4 Heat generation during constant power discharges. . . . . . . . . . . . 57

6.1 Radiation material properties. . . . . . . . . . . . . . . . 60

6.2 Thermophysical properties for model materials. . . . . . . . . . . . 62

6.3 Convection film coefficients of the enclosure exterior. . . . . . . . . . 64

6.4 General settings in Fluent. . . . . . . . . . . . . . . 67

6.5 Model settings in Fluent. . . . . . . . . . . . . . . . . . . . . 67

6.6 Solution method settings in Fluent. . . . . . . . . . . . . 67

7.1 Thermodynamic and physical properties of PCM/EG composite material used in simulation. . . . . . . . . . . . . . . . 76

8.1 Temperature comparison of PCM/EG and air simulations. . . . . . . 81 


\section{List of Figures}

1.1 Dimensioned top section view of battery pack. Dimensions in meters [inches]. . . . . . . . . . . . . . . . . . . 2

3.1 Lithium-ion cell structure diagram (ref. [9]). . . . . . . . . . . 27

5.1 Agilent 34972A Data Acquisition / Switch Unit. . . . . . . . . . . 36

5.2 Multiplexer card for Agilent 34972A Data Acquisition / Switch Unit. 37

5.3 LabVIEW front panel for data acquisition program. . . . . . . . . 38

5.4 LabVIEW block diagram of data acquisition program. . . . . . . . . 40

5.5 Flir Thermacam SC300 infrared camera. . . . . . . . . . . . . . . 41

5.6 BK Precision 8515 DC Programmable Load. . . . . . . . . . . . . 42

5.7 Circuit diagram for equipment during battery discharge tests. . . . . 43

5.8 Circuit diagram for equipment to charge the battery. . . . . . . . 43

5.9 BK Precision XLN3640 Programmable DC Power Supply. . . . . . . . 44

5.10 Diagram of experiment setup to measure battery heat capacity and heat generation rates. . . . . . . . . . . . . . 46

5.11 First run of copper cylinder cooling to characterize insulation. . . . . 47

5.12 Second run of copper cylinder cooling. . . . . . . . . . . . . 48

5.13 Third run of copper cylinder cooling. . . . . . . . . . . . . 48

5.14 First run of aluminum cylinder cooling. . . . . . . . . . . . . . . . 49

5.15 Second run of aluminum cylinder cooling. . . . . . . . . . . . . . . 49

5.16 Third run of aluminum cylinder cooling. . . . . . . . . . . 50

5.17 First run of battery cooling. . . . . . . . . . . . . . . 50

5.18 Second run of battery cooling. . . . . . . . . . . . . . . 51

5.19 Third run of battery cooling. . . . . . . . . . . . . . . 51 
5.20 Battery voltage during constant power discharges and open-circuit voltage approximation. . . . . . . . . . . . . . . . 52

5.21 Battery current during constant power discharges. . . . . . . . . . . 52

5.22 Temperature $\left({ }^{\circ} \mathrm{C}\right)$ of battery during one discharge test at each power level. . . . . . . . . . . . . . . . . 5 54

5.23 Heat generation rates (W) for all constant power discharge runs. . . . 54

5.24 Entropy coefficient estimated from heat generation rates and battery discharge characteristics. . . . . . . . . . . . . . 55

5.25 Comparison of measured and predicted heat generation rates (W). . . 57

6.1 Dimensioned front section view of battery pack. Dimensions in meters [inches]. . . . . . . . . . . . . . . . . . . . 59

6.2 Infrared camera image of the heated battery. . . . . . . . . . . 61

6.3 Fluent user-defined function for volumetric heat generation as a function of time from experiment results. . . . . . . . . . . 63

6.4 Isometric view of approximated boundary conditions. . . . . . . . . 64

6.5 ANSYS ICEM mesh of batteries and plastic spacer frames. . . . . . . 65

6.6 Grid independence plot of temperature $\left({ }^{\circ} \mathrm{C}\right)$ versus global mesh size $(\mathrm{m}) .66$

6.7 View of battery temperatures $\left({ }^{\circ} \mathrm{C}\right)$ after 630 seconds at $5 P$ rate. . . 69

6.8 Section view of temperature $\left({ }^{\circ} \mathrm{C}\right)$ contours at vertical middle of battery pack after 630 seconds at $5 P$ discharge rate. . . . . . . . . . . . 69

6.9 Front section view through center of front row of batteries showing temperature $\left({ }^{\circ} \mathrm{C}\right)$ contours at end of discharge at $5 P$ rate. . . . . . . 70

6.10 Isometric view of velocity vectors colored by temperature $\left({ }^{\circ} \mathrm{C}\right)$ for air in the enclosure after 630 seconds under $5 P$ load. . . . . . . . . . . . 70

6.11 Vertical plane of velocity vectors colored by temperature $\left({ }^{\circ} \mathrm{C}\right)$ for air in the enclosure after 630 seconds at 5 P. . . . . . . . . . . . . 71

6.12 Contours of vertical component of velocity $(\mathrm{m} / \mathrm{s})$ for air in the enclosure after 630 seconds under $5 P$ discharge. . . . . . . . . . . . . . . . 71

6.13 Temperature $\left({ }^{\circ} \mathrm{C}\right)$ evolution along horizontal axis through the center of the back row of batteries without PCM/EG. . . . . . . . . . . 72

6.14 Temperature $\left({ }^{\circ} \mathrm{C}\right)$ evolution along longitudinal axis of the middle battery in the back row without PCM/EG. . . . . . . . . . . 73

7.1 Thermal conductivity of PCM/EG composite for various graphite densities (ref. [14]). . . . . . . . . . . . . . . 76 
7.2 Normalized differential scanning calorimetry curve for Rubitherm RT42 paraffin $($ ref. $[14]) \ldots \ldots \ldots \ldots$. . . . . . . . . . . . . 77

7.3 Specific heat $(\mathrm{J} / \mathrm{kgK})$ of the composite combined with effective specific heat due to latent heat of fusion of the paraffin. . . . . . . . . 77

7.4 Maximum temperature $\left({ }^{\circ} \mathrm{C}\right)$ of the batteries in the enclosure over time. 78

7.5 Section view of temperature $\left({ }^{\circ} \mathrm{C}\right)$ contours at vertical middle of battery pack after 630 seconds at $5 P$ rate with the PCM/EG. . . . . . . 79

7.6 View of battery temperatures $\left({ }^{\circ} \mathrm{C}\right)$ after 630 seconds at $5 P$ rate with the $\mathrm{PCM} / \mathrm{EG} \ldots \ldots \ldots \ldots \ldots \ldots$

7.7 Temperature $\left({ }^{\circ} \mathrm{C}\right)$ evolution along horizontal axis through the center of the back row of batteries with PCM/EG. . . . . . . . . 80

7.8 Temperature $\left({ }^{\circ} \mathrm{C}\right)$ evolution along longitudinal axis of the middle battery in the back row with $\mathrm{PCM} / \mathrm{EG} . \ldots \ldots \ldots \ldots$ 


\section{Nomenclature}

$\begin{array}{ll}\text { Symbol } & \text { Description } \\ A & \text { heat transfer area } \\ B i & \text { Biot number } \\ C & \text { constant current rate }(1 C \text { for } 15 \mathrm{Ah}=15 \mathrm{~A}) \\ C_{p} & \text { specific heat capacity at constant pressure } \\ g & \text { gravity } \\ h & \text { enthalpy } \\ \bar{h} & \text { convective heat transfer coefficient } \\ I & \text { current or identity matrix } \\ k & \text { thermal conductivity } \\ L & \text { length } \\ m & \text { mass } \\ n & \text { number of trials } \\ N u_{L} & \text { Nusselt number } \\ p & \text { pressure } \\ P & \text { constant power rate }(1 P \text { for } 48 \mathrm{Wh}=48 \mathrm{~W}) \\ P r & \text { Prandtl number } \\ \dot{q} & \text { heat generation rate } \\ R a_{L} & \text { Rayleigh number } \\ S & \text { standard error }\end{array}$




$\begin{array}{ll}S_{h} & \text { volumetric heat source } \\ t & \text { time } \\ T & \text { temperature } \\ u & \text { uncertainty } \\ U & \text { overall heat transfer coefficient } \\ v & \text { velocity } \\ V & \text { voltage } \\ x & \text { position along horizontal axis } \\ y & \text { position along vertical axis }\end{array}$

\section{Greek Letters}

$\begin{array}{ll}\alpha & \text { thermal diffusivity } \\ \beta & \text { thermal expansion coefficient } \\ \mu & \text { dynamic viscosity } \\ \nu & \text { kinematic viscosity } \\ \rho & \text { density } \\ \sigma & \text { standard deviation }\end{array}$

\section{Subscripts}

$\begin{array}{ll}\text { conv } & \text { convected } \\ \text { eff } & \text { effective } \\ \text { gen } & \text { generated } \\ \text { ocv } & \text { open-circuit voltage } \\ \text { op } & \text { operating voltage } \\ \text { stor } & \text { stored }\end{array}$




\section{Chapter 1}

\section{Introduction}

A 48 volt lithium-ion battery pack was designed and fabricated for use in an unmanned ground vehicle (UGV). The battery pack is assembled from fifteen high capacity cylindrical lithium iron phosphate $\left(\mathrm{LiFePO}_{4}\right)$ batteries $[$ Headway model H40152S, 3.2 V, $15 \mathrm{Ah}, 40 \mathrm{~mm}$ in diameter and $152 \mathrm{~mm}$ tall]. The batteries are supported by plastic spacer frames arranged in a close-packed hexagonal array inside a closed aluminum battery box, Figure 1.1. The battery box panels were welded together to form a trapezoid shaped enclosure. Since the UGV is designed to operate in all-weather conditions, the battery pack must be sealed from the outside environment. Since the batteries generate a significant amount of heat and the sealed enclosure isolates them from the external air, there is concern that the operating temperatures could rise substantially inside the battery pack. The batteries are designed to operate at a maximum temperature of $60^{\circ} \mathrm{C}$.

Though lithium iron phosphate batteries provide the necessary power density required by the $\mathrm{UGV}$, they have high heat generation rates which can limit safe application and battery life $[12,11]$. Vehicle performance and space considerations require the cells to be packed closely together leading to the possibility of high battery 


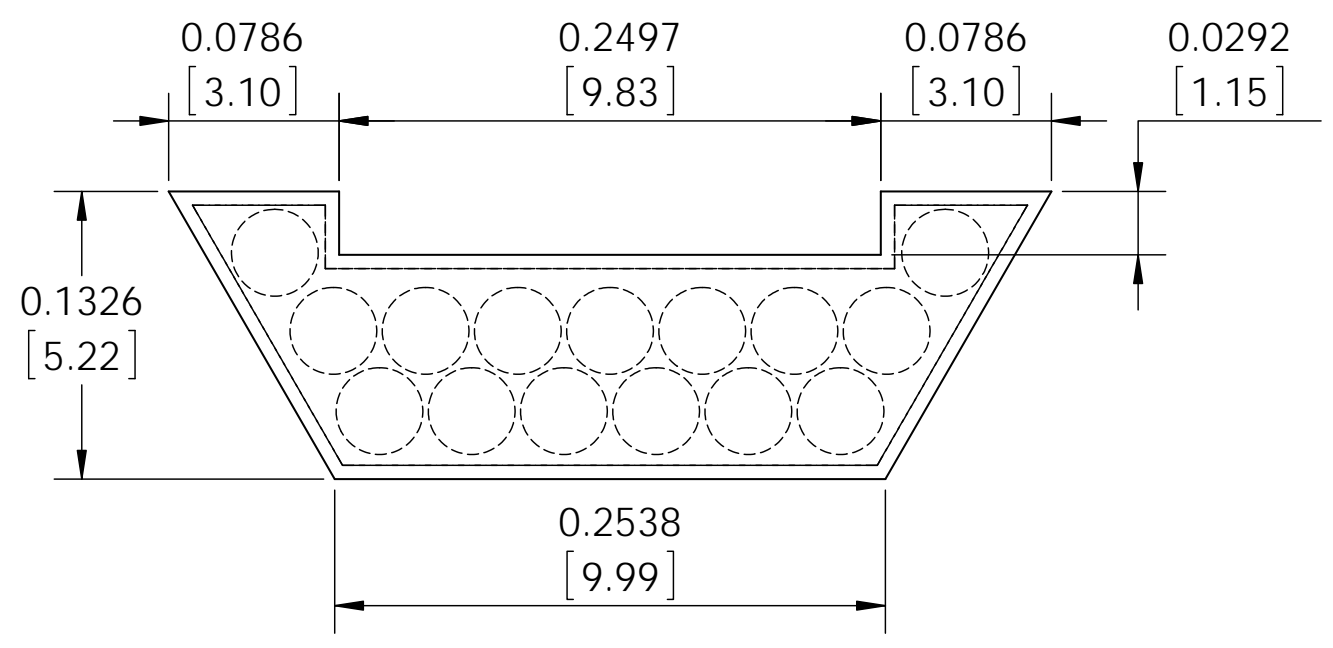

Figure 1.1: Dimensioned top section view of battery pack. Dimensions in meters [inches].

temperatures that degrade battery life and, potentially, lead to thermal runaway [15]. Heat is generated in the cell by two factors; entropy change from electrochemical reactions and irreversible effects such as ohmic heating due to current flow across internal resistance $[16,1]$. Thermal management becomes more critical with larger batteries as surface area to volume ratio decreases with increasing battery size, leading to lower heat transfer rates per unit heat generation rate [20].

\subsection{Project Aim}

The goal of this analysis was to determine the maximum temperatures the batteries would experience under a prescribed high power loading of $240 \mathrm{~W}$ per battery or about $85 \mathrm{~A}$. Since the initial design of the battery pack did not focus on thermal constraints, it was subsequently desired to perform a thermal analysis of the pack to determine the maximum temperatures under the prescribed loading, as well as support design options to control the resulting temperatures. 


\subsection{Thesis Organization}

The thesis is arranged in 8 chapters. Each chapter has its own objective.

- Chapter 1 is the introduction and describes the goals of the project.

- Chapter 2 presents an overview of past research related to thermal modeling of battery packs and thermal management solutions.

- Chapter 3 provides background information on lithium-ion batteries and phase change materials.

- Chapter 4 is an overview of the computational fluid dynamics equations and methods used to simulate the flow in the pack.

- Chapter 5 describes the experiment procedures and results.

- Chapter 6 presents the development and results of the computational fluid dynamics model.

- Chapter 7 presents the development and results of the phase change material and expanded graphite model.

- Chapter 8 discusses the results of the project, conclusions, and recommendations for future research. 


\section{Chapter 2}

\section{Literature Review}

An extensive literature review on battery thermal management is presented in Chapter 2. Battery thermal management poses a significant hurtle in the development of new battery applications. Thermal management solutions and modeling techniques have been researched for many years. The literature review serves to investigate previous research on thermal management solutions, thermal modeling techniques, and thermophysical battery property experiments.

\subsection{Pesaran et al. (1997)}

Pesaran et al. developed a thermal model to predict temperature distributions in battery cells, modules, and packs [16]. Thermal issues associated with electric vehicle battery packs can have a considerable effect on battery performance and lifetime. Temperature variations from module to module can reduce the performance of the entire pack. The study used fundamental heat transfer principles and finite element analysis tools to create temperature distribution models of an electric vehicle battery pack. Additionally, infrared photography and liquid crystal thermography were used 
to obtain images showing the thermal distributions.

Battery pack performance affects the range, power, and downtime of electric vehicles. The optimum operating temperature range is different for each electrochemical couple used in the battery. Generally, higher temperatures improve battery performance due to increased rates of electrochemical reactions. However, the higher temperatures also cause a decrease in the lifetime of the batteries due to increased corrosion rates. If the battery modules can be kept at a uniform temperature then the pack as a whole can operate closer to the desired optimum temperature range. The cells in the pack may have slightly different charge and discharge performances relative to each other if they are at dissimilar temperatures. Overtime this can cause the cells to become unbalanced.

Heat is generated from entropy change due to electrochemical reactions and from Joule's effect, also known as ohmic heating, caused by current flowing through internal resistances. Depending on the operating environment, heat may need to be removed or added to maintain the optimal operating temperature range. Possible thermal management solutions include liquid systems, insulation, thermal storage through a phase-change material, active, or passive approaches. Batteries used in electric vehicles typically have high specific energy whereas batteries used in hybrid electric vehicles typically have high specific power.

The article reviewed previous research from several other authors on battery thermal management. Anderson found that for lead acid batteries, the charge efficiency increases linearly with temperature and lifetime decreases linearly with temperature. Dickinson and Swan showed that temperature gradients between modules reduce the overall pack capacity and recommended maintaining an even temperature distribution across the pack. Wicks and Doane found that both the pack efficiency and maximum operating power increased with temperature from $26{ }^{\circ} \mathrm{C}$ to $65^{\circ} \mathrm{C}$. Barnes employed 


\section{Table 2.1: Properties used in lead acid battery simulation.}

\begin{tabular}{ll}
\hline Property & Value \\
\hline Cells & 6 \\
Voltage & $12 \mathrm{~V}$ \\
Capacity & $12 \mathrm{Ah}$ \\
Dimensions & $0.11 \mathrm{~m} \mathrm{x} 0.16 \mathrm{~m} \mathrm{x} 0.15 \mathrm{~m}$ \\
Heat Generation Rate & $5.83 \mathrm{~W} / \mathrm{cell}, 35 \mathrm{~W} /$ module \\
Cell Core Average Thermal Conductivity & $6 \mathrm{~W} / \mathrm{mK}$ \\
Overall Module Heat Capacity & $900 \mathrm{~J} / \mathrm{kgK}$ \\
\hline
\end{tabular}

a phase change material for cooling and temperature control of lead-acid modules. Lee outlined a methodology for battery thermal modeling. The methodology is based on three equations, a differential equation energy balance, a heat generation equation, and a boundary condition equation based on linear heat transfer between the boundary region and model. Solving the three equations simultaneously results in the temperature distribution in the core over time. Newman and Tiedemann presented equations for a block-shaped three dimensional battery with uniform heat generation and constant wall temperatures. Chen and Evans looked at heat effects in batteries using two-dimensional transient conduction analysis with convective heat transfer at the boundaries.

The approach for this study in particular was to solve the 2D transient heat conduction equation for a set of modules using finite element analysis. If only average battery temperature is of interest then conduction can be ignored and a single temperature can be assumed for each module. Using an iterative process with the energy balance between the module wall and surroundings, the fluid temperature change could be found.

Air was modeled at $25^{\circ} \mathrm{C}$ and a heat transfer coefficient of $35 \mathrm{~W} / \mathrm{m}^{2} \mathrm{~K}$ was applied to all of the battery external surfaces. The convection coefficient used was equivalent 
to modest forced convection with air. Heat generation was assumed to be uniform throughout the core and constant with time. The module core material was assumed to be a single homogeneous material. The thermal properties of the core of the module were estimated as weight averaged values from literature. Cell interconnects were not modeled. A two-dimensional finite element analysis was performed on a single battery. A horizontal cross section of a single rectangular battery at steady state showed a symmetrical temperature distribution with the maximum temperature in the middle and the lowest temperatures at the corners where there was heat loss on both sides. The maximum observed temperature was $45.4^{\circ} \mathrm{C}$. There was a $4.5^{\circ} \mathrm{C}$ difference between the center of the module and the corners of the module and a $3{ }^{\circ} \mathrm{C}$ difference across the polypropylene case surrounding the core of each module. This implied that the thin plastic case imposed a large thermal resistance. If the case had the same thermal conductivity as the core material, then the maximum temperature would have dropped to $41.7^{\circ} \mathrm{C}$ and the maximum temperature difference within the cell would have stayed at $4.5^{\circ} \mathrm{C}$. If the heat transfer coefficient was increased to $100 \mathrm{~W} / \mathrm{m}^{2} \mathrm{~K}$ then the maximum temperature would have dropped to $36.7^{\circ} \mathrm{C}$, but the maximum temperature difference would have stayed the same.

Another two-dimensional finite element analysis was performed on a battery pack consisting of 30 battery modules. Air enters at a mass flowrate of $0.8 \mathrm{~kg} / \mathrm{s}$ from one end of the pack and exits at the other. The pack was insulated on the top, bottom, and sides. One third of the flowrate went down each battery column and the air was equally distributed around each model. An air gap was selected so that the air-side heat transfer coefficient was about $35 \mathrm{~W} / \mathrm{m}^{2} \mathrm{~K}$. The air temperature rose $1.3^{\circ} \mathrm{C}$ as it passed each module and the modules average temperature rose by $1.3^{\circ} \mathrm{C}$ as well. Adding holes between the cylindrical modules caused the steady state temperature to drop from $52.3^{\circ} \mathrm{C}$ to $44.1^{\circ} \mathrm{C}$. Adding the holes between the modules proved to be an effective and recommended design change to the studied battery pack. Temperature 
results were only shown for steady state, but it was noted that the transient analysis exhibited similar trends.

Two thermal imaging techniques were used to collect information about temperature variation in the pack for comparison to the simulation. The two techniques used were infrared photography and liquid crystal thermography. The infrared (IR) imaging technique used a special camera to capture infrared radiation from the batteries. The radiation measurements were converted to surface temperature readings. This technique resulted in a resolution of $0.2{ }^{\circ} \mathrm{C}$. The interconnect sides of the cells generated more heat than the opposite sides of the cells and thus there was a vertical thermal gradient. Infrared photography could be used to look at an unenclosed battery pack, but not an enclosed one. Liquid crystal thermography involved painting the cells with special crystals that change color with temperature. This technique could be used to monitor the cells even in an enclosure as long as the enclosure is transparent. The experiment concluded that a pack with no air flow can reach unacceptably high temperatures and that holes between the cells significantly improved the thermal performance of the pack. For simplified geometries the analytical equation used to show the energy balance could be solved by hand, but realistic geometries must use FEA to solve the equation numerically. Radiation was neglected due to its small contribution to heat transfer relative to the forced convection heat transfer because of the relatively low temperatures below $100{ }^{\circ} \mathrm{C}$.

\subsection{Onda et al. (2005)}

Onda et al. investigated thermal behavior of lithium-ion batteries during rapid charge and discharge cycles [15]. Batteries for electric vehicles generate significant heat during rapid charge and discharge cycles where current levels may exceed the batteries' rating. During these rapid charge or discharge cycles, the cells temperature 
may exceed its design limit. Many institutions are researching lithium-ion batteries due to their high energy and power densities as well as their high charge and discharge efficiencies. As battery size increases, the ratio of heat cooling surface area to power generating volume decreases. As charge or discharge current increases so does the amount of heat generated. This causes the temperature of the battery to rise dramatically. Charge and discharge performance characteristics improve as temperature increases.

A previously created battery thermal model was expanded to be used in rapid charge and discharge simulations. Rapid was defined as when the current exceeded the batteries' rated maximum current. The model was verified by agreement with experimentally measured temperatures. The overpotential resistance, entropy change, and heat transfer coefficient in air were measured. The heat capacity of the battery was measured using a calorimeter. These measurements were used as inputs to the thermal behavior model. The temperature distribution from the model simulation was compared to the measured temperature of the battery cooled under natural convection. The results agreed closely. One dimensional analysis of the battery showed that the radial temperature distribution was nearly constant which was also verified experimentally. The thermal conductivity of the model was assumed to be constant radially.

To measure the heat source factors of the cell at a constant temperature, the cell was charged and discharged while wrapped in thin electrical insulation sheet and immersed in a water thermostat. The cell was charged and discharged twice at the rated condition to erase any previous charge and discharge history. The battery heat capacity was determined using a twin-type calorimeter (Setaram C-80) by increasing the battery temperature from $20^{\circ} \mathrm{C}$ to $90{ }^{\circ} \mathrm{C}$ at a constant rate of $0.4^{\circ} \mathrm{C} / \mathrm{min}$. A curve fit to the data resulted in an equation for the battery heat capacity as a function of cell temperature. The relationship was linear and increased from $37 \mathrm{~J} / \mathrm{K}$ to $39 \mathrm{~J} / \mathrm{K}$ 
from $35^{\circ} \mathrm{C}$ to $85^{\circ} \mathrm{C}$. Lead wires used in the electrical connection of the batteries were shown to promote heat transfer much better than the battery without the wires connected for this small lithium-ion battery. The battery was suspended in air by the lead wires, heated up, and then allowed to cool. This cooling data was used to produce a correction factor for the heat transfer coefficient.

Battery temperature was plotted as a function of radial position at several different times while discharging at $3 C$. The plot shows that the battery temperature decreases by less than $2^{\circ} \mathrm{C}$ from the radial center to the outside. Additionally, the plot shows that the battery reached $75^{\circ} \mathrm{C}$ after 600 seconds at $3 C$ and $101^{\circ} \mathrm{C}$ after 1104 seconds at $3 C$ discharge. Battery temperature was nearly uniform, even during rapid charge or discharge cycles. This indicated that the surface temperature of the battery was representative of the average battery temperature. Temperature measurements were taken by a $0.1 \mathrm{~mm}$ wire diameter thermocouple soldered to the center of the battery surface while the battery was suspended in air by lead wires and cooled by natural convection.

\subsection{Pesaran et al. (2001)}

Pesaran et al. investigated issues and solutions for battery thermal management [17]. Thermal control of batteries in electric vehicles is essential to effective operation in various climates and temperatures. Battery temperature affects the availability of discharge power, energy, and charge acceptance when using regenerative breaking. Ideally, the batteries will operate in a temperature range that optimizes battery performance and life. Temperature variation between modules in the battery pack causes differences in the performance of each module leading to an unbalanced pack and reduced pack performance. 
Thermal imaging techniques and calorimetry were used to measure the thermal characteristics of the batteries. The goal of a thermal management system is to minimize temperature variation between batteries and to keep the batteries in the ideal operating temperature range. The thermal management design must be lightweight and compact. It must not use very much power to perform the thermal management as this increases the battery capacity that must be carried by the vehicle and can increase the heat generation problem further. It must be able to operate in a wide range of both hot and cold climates. It must provide ventilation if the batteries vent hazardous gases. Thermal management systems may make use of air, liquids, insulation, thermal storage, or phase change materials.

The heat generated from the battery under load dictates the type and size of the cooling system required. The heat generation is due to electrochemical enthalpy change and electrical resistive heating. This rate depends on the chemistry type, construction, temperature, state of charge, and discharge or charge profile. A custom built calorimeter at NREL has been used to measure the heat generation from cells or modules under various conditions. Generally, more heat is generated at lower temperatures due to the increased resistance in the cells. Various heat generation rates were recorded for several battery types and various discharge rates.

Heat capacity can be measured by a calorimeter or can be calculated by mass averaging the materials inside the battery. Typical heat capacities for several different battery types are listed. Battery heat capacities were found to range from $650 \mathrm{~J} / \mathrm{kgK}$ to $800 \mathrm{~J} / \mathrm{kgK}$. Module heat generation may not be uniform due to aspect ratio, number of cells, geometry, thermal conductivity of the case, placement of terminals, size, and cell interconnect positions. This indicates that temperature may not be uniform in the module. Temperature over time is plotted for several batteries at different heat generation rates and discharge rates. The temperature rose $12{ }^{\circ} \mathrm{C}$ over the discharge with a heat generation rate of $4.45 \mathrm{~W} /$ cell due to the $2 C$ discharge rate with a specific 
heat capacity of $1019 \mathrm{~J} / \mathrm{kgK}$.

Active thermal management using a fan and air is simpler than liquid cooling systems, but may not be as effective. Since lithium-ion batteries can deliver more power than NiMH batteries, they generate more heat for the same volume and thus need a more efficient heat removal system. Lithium-ion batteries may require a thermal management system due to concerns about safety and low electrical performance at low temperatures.

\subsection{Al-Hallaj and Selman (2002)}

Al-Hallaj and Selman showed that passive thermal management using a phase change material (PCM) based system is viable solution to li-ion battery thermal management [2]. Battery modules were formed from cylindrical lithium-ion cells which were surrounded in a rectangular enclosure. This paper studied the effects of filling the module with a phase change material. The lack of suitably sized batteries is a major obstacle in the development of successful electric vehicles. Lithium-ion batteries would be a great solution if they could be scaled up without having thermal management issues. Lithium-ion cell chemistry is exceptionally well suited to the use of a PCM system. The study concludes that PCM thermal management has great potential for providing effective thermal management without complicating vehicle designs like active systems would.

Lithium-ion cells have excellent performance when operating in ambient temperature conditions, but adverse effects happen when temperatures exceed $65^{\circ} \mathrm{C}$ or drop below $0{ }^{\circ} \mathrm{C}$. Cells are packaged together to form a module and multiple modules are combined to form a pack which provides ample current and voltage. Temperature variation among cells can cause differences in impedance which can amplify capacity 
differences among cells. Capacity differences between cells may cause some cells to be overcharged or over-discharged when the pack is cycled. This effect can lead to premature failure of batteries in the pack. Failure may come in the form of accelerated capacity fading or thermal runaway. Both of these failure modes are related to excessive heat generation in the cells.

In a properly designed PCM system, the PCM does not exceed the constant phase change temperature. Under normal circumstances, the PCM has enough thermal capacity to accept the total heat developed during discharge. The PCM then cools when the pack is charging or no longer in use. Cell heat generation rates were measured for different discharge and charge operating conditions using a calorimeter. The cell typically behaves as a lumped system with uniform temperature. Plots show that temperature does not vary significantly radially through the cylindrical battery except under high cooling conditions where the convection coefficient is between $30 \mathrm{~W} / \mathrm{m}^{2} \mathrm{~K}$ to $100 \mathrm{~W} / \mathrm{m}^{2} \mathrm{~K}$. By taking advantage of the latent heat of fusion of the PCM, the battery pack can be passively cooled and fully enclosed, without any additional moving parts. It was predicted that for a $100 \mathrm{Ah}$ cell in a module under near insulating conditions, the temperature was maintained $8^{\circ} \mathrm{C}$ lower with the PCM than without the PCM. The heat stored in the PCM system can be used in cold environments to keep the battery temperature from getting to low which reduces the need for battery insulation.

\subsection{Doughty et al. (2002)}

Doughty et al. developed thermal models to characterize the response of lithiumion batteries to thermal abuse [4]. The self-heating rates were determined for the cells and then the thermal response was estimated over a variety of conditions. This process was used to isolate the behavior of individual components within the battery. 
Lithium-ion batteries can be divided into two groups. High-temperature batteries for primary power sources that are not rechargeable and ambient temperature lithium-ion batteries which are rechargeable.

Lithium-ion cells typically consist of carbon anodes containing a binder and conductivity enhancing additive, an organic solvent electrolyte with a salt, metal oxide cathodes, conductive graphite, and carbon. Lithium cobalt or a mixed metal oxide is typically used in the cathode. Thermal runaway and gas generation cause the cell to vent and generate significant amounts of heat. One piece of equipment central to this study was the accelerated rate calorimeter (ARC). The ARC measured cell thermal response to increasing temperature in an adiabatic chamber. Some cells experienced thermal runaway at temperatures exceeding $150^{\circ} \mathrm{C}$. Cell aging may also cause a change in the thermal properties and heat generation rates of the battery.

\subsection{Maleki and Shamsuri (2003)}

Maleki and Shamsuri developed a thermal model for a computer battery pack [12]. The notebook computer battery pack was modeled at an ambient temperature of $42^{\circ} \mathrm{C}$ and performed a $55 \mathrm{~W}$ constant power discharge. Temperature rise was primarily due to power dissipation from control electronics during charging and by battery heat dissipation when discharging. Li-ion cells have become a popular power source choice due to their high power density, long lifetime, and practical operating voltage. However, the performance of lithium-ion cells is limited by their heat generation at high current discharge. For safety reasons lithium-ion batteries often have current limiters to restrict heat generation rates.

The heat generation rate of the lithium-ion cell was determined using $\mathrm{Q}=\mathrm{I}\left(\mathrm{V}_{\text {ocv }}{ }^{-}\right.$ $\left.\mathrm{V}_{o p}\right)-\mathrm{IT}\left(\mathrm{dV}_{\text {ocv }} / \mathrm{dT}\right)$ where $V_{o p}$ is the operating voltage and $V_{o c v}$ is the open-circuit 
voltage. The first term is the irreversible heat generation from the internal and polarization impedances in the cells. The second term is the reversible heat generation term from thermodynamic effects. The reversible heat is generally smaller than the irreversible by a factor of 3 or 4 . Heat generation profiles were plotted over time. Various connection arrangements of cells were tested using both parallel and series configurations. Results showed that each cell produced about the same normalized heat regardless of the configuration it was in. This justified measuring the heat generation of one cell and applying it to all cells in the model. Density, heat capacity, and thermal conductivity properties were used as inputs for the model.

To create the thermal model, battery cell heat generation data was measured, then it was assigned to each of the eight cylindrical cells in the pack. Each cell was treated as a cylindrical solid block that generated heat. Conduction on inside of the pack and natural convection on the outside of the pack was modeled. The simulation showed the cells reached temperatures above $60^{\circ} \mathrm{C}$ and non-uniformity in their temperature distribution. Storage for a period of one week at elevated temperatures of $40{ }^{\circ} \mathrm{C}$ to $70{ }^{\circ} \mathrm{C}$ can cause permanent capacity loss of 2 to 10 percent.

\section{$2.7 \quad \mathrm{Hu}$ et al. (2010)}

$\mathrm{Hu}$ et al. developed a novel networking model for predicting battery temperatures without performing additional CFD calculations each time the model is changed [8]. Computer modeling is an invaluable tool to help engineers design better battery cooling systems. A Foster network thermal model of a battery pack was created and compared to a CFD model. ANSYS Fluent CFD software was used to model the flow through a duct that surrounds a single battery. The air came in from one end, then flowed around the cylindrical battery, and exited the opposite end. This was a standard conjugate heat transfer problem in CFD. Constant density and constant 
properties are valid assumptions for air and water cooling systems. CFD solutions may take minutes to hours to solve depending on the mesh size.

A battery module with 16 cylindrical cells from an automotive OEM was simulated using CFD for a given power profile. The CFD model had more than two million computational cells and required approximately two hours of run time on one single CPU. The Foster network method was used to create a thermal circuit model of the pack and cooling system which, after being tuned using CFD results, could be used to accurately determine the results of changes to the system. The Foster network method provided identical results to CFD modeling and could be done in a mere fraction of the time. Heat sources are typically functions of space and time. However, when the Biot number for the cells is small, it is a good approximation to use spatially uniform heat generation. The Foster network method was calibrated by running the CFD solution to generate the step response, but after calibration the Foster network could perform all transient predictions identically to the CFD in a fraction of the time without any additional CFD analysis. The Foster network thermal model could be coupled with a battery electrical model which would be capable of determining the electrical effects on temperature of the battery and the temperature effects on the electrical performance simultaneously. This technique could be used to generate a predictive battery thermal analysis tool for robot vehicle path planning.

\subsection{Mills and Al-Hallaj (2005)}

Mills and Al-Hallaj performed laboratory experiments to characterize the thermal properties of lithium-ion batteries and used them to create a finite element model of a computer battery pack [13]. Lithium-ion batteries typically have higher energy storage densities and are less expensive than other battery chemistries. Li-ion batteries generate significant heat during high power discharges which can shorten their life 
and pose safety hazards. Close packing of the batteries within the pack enclosure leads to high temperatures. Traditional powered cooling systems such as fans are not ideal solutions due to the additional power requirements, weight, and integration complexities. Previous research of Li-ion battery packs has shown that passive thermal management systems utilizing a phase change material (PCM) are a viable solution.

In this article, a passive thermal management system that uses a phase change material was designed and simulated for a lithium-ion laptop battery pack. The problem of low thermal conductivity of the phase change material was significantly improved by adding an expanded graphite matrix to the PCM. The heat generation rate and heat capacity were experimentally measured for various constant power discharges. Simulation of the pack and its six enclosed batteries showed that the volume of the pack had to be doubled to hold sufficient phase change material to keep the batteries below the specified $55^{\circ} \mathrm{C}$ maximum temperature.

The study assumed that the batteries would provide constant power during the entire discharge. The heat generation rate of the battery was determined experimentally. The role of the PCM within the thermal management system was to store the heat generated without significantly raising the temperature of the pack. The latent heat of fusion, melting point, and operating temperature determine the amount of heat stored by the PCM. Paraffin wax was used in this study due to its high specific latent heat, near operating temperature melting point, and low cost. However, paraffin wax has a very low thermal conductivity of $0.2 \mathrm{~W} / \mathrm{mK}$. This limits the rate of heat absorption and dissipation from batteries. This problem was fixed by combining the wax with an expanded graphite matrix which increased the thermal conductivity of the composite PCM/EG.

Simulations were performed using the finite element software PDEase2D solving 
the 2D unsteady heat equation. The thermal conductivity of the batteries was taken from referenced literation, but heat generation and heat capacity were measured through an experimental procedure. Natural convection boundary conditions were applied to the exposed sides of the pack and heat transfer coefficients were applied to the contact sides of the pack. A linear entropy coefficient trend line lead to slightly different heat generation rates than those that were measured, but still had the same overall trend. The predicted and measured values matched within error tolerances except at the end of the discharge cycle. It was suspected that this was due to the behavior of the battery or from the thermal impedance of the Styrofoam washing out the sudden increase in heat generation at the end of the discharge cycle. It was found that increasing the discharge rate significantly increased the total amount of heat generated.

Running the simulation with idealized PCM composite properties, which may be possible to create with advanced fabrication methods, drastically reduced the volume of PCM required keep the batteries under $55^{\circ} \mathrm{C}$. The idealized volume required was reduced to just $9 \%$ more than the minimum pack volume from the natural gaps between the cells. The heat generation measurement techniques used by the study produced highly accurate results. PCM proved to be a good solution as long as the packs can cool off after they are discharged, allowing the wax to return to the solid phase. The PCM thermal management system works well for minimizing temperature swings during brief moments of high power usage.

\section{$2.9 \quad$ Rao et al. (2011)}

Rao et al. created a thermal model of a battery pack utilizing a phase change material and investigated the effects of aging on $\mathrm{LiFePO}_{4}$ batteries [19]. Increasing pressure from oil shortages and environmental pollution concerns has attracted more 
attention to electric and hybrid electric vehicles. Several different battery chemistries are available for EV application such as lead-acid, nickel metal hydride, and lithiumion. Pesaran has found that the optimal operating temperature for these batteries is between $25^{\circ} \mathrm{C}$ and $40^{\circ} \mathrm{C}$. Furthermore, the temperature variation from module to module should be below $5{ }^{\circ} \mathrm{C}$ or charging efficiency and longevity can become degraded. The US National Renewable Energy Laboratory and Illinois Institute of Technology have done considerable research on the topic of automotive battery thermal management. Research has shown that battery thermal management is crucial in the application of EV and HEV for any of the above mentioned battery chemistries. The application of PCM for battery thermal management (BTM) was first demonstrated and patented by Al-Hallaj and Selman (US Patent 6468689 B1 2002). PCM was demonstrated to be a better performing solution than conventional BTM in large scale, high discharge rate, or abusive conditions. A PCM should be nontoxic, noncorrosive, stable, have large latent heat, and high thermal conductivity through use of an expanded graphite or metal matrix. CFD and FEM were recommended for computer modeling. This study and several references cited by it assumed a value for the battery thermal conductivity rather than individually measuring it. The effects of battery aging on the thermal management were studied and results were compared to those of new batteries.

The battery used in this experiment was a $118 \mathrm{~mm}$ x $63 \mathrm{~mm}$ x $13 \mathrm{~mm}, 8$ Ah lithiumion battery with a max anticipated discharge of $4 C$ to $5 C$. Five K-type thermocouples were used with a DAQ system to measure the temperatures of the cells in a 9 cell pack during discharge while surrounded in the PCM. The batteries were discharged at $35 \mathrm{~A}$ or $5 \mathrm{C}$. Battery temperatures reached as high as $76.5^{\circ} \mathrm{C}$. Heat generation rates in the cell during discharge were calculated using $\mathrm{Q}=\mathrm{I}\left(\mathrm{V}_{\text {ocv }}-\mathrm{V}_{\text {op }}\right)-\mathrm{IT}\left(\mathrm{dV} \mathrm{V}_{\text {ocv }} / \mathrm{dT}\right)$.

The effective heat capacity method which treats the phase change process as a temperature dependent change in the specific heat of the PCM was used in this sim- 
ulation. The study created a simulation of aging rectangular $\mathrm{LiFePO}_{4}$ batteries using the CFD software ANSYS Fluent and modeled the phase change material surrounding the batteries. Computational meshes were generated using the preprocessor, Gambit. Computational domain for one single cell was divided into four parts. Nine cells were modeled with a total of 103,253 elements. The following simplifying assumptions were used in the simulation: density change of PCM from solid to liquid was negligible, melting point of the PCM was a constant value rather than a range, specific heat and thermal conductivity of the cell and PCM were constant, the PCM was homogeneous and isotropic, and radiation heat transfer inside the pack was neglected.

Governing equations were solved numerically using the control volume method. The computer model had great agreement with experiment results. More heat is generated as discharge current increases. To demonstrate the effectiveness of the PCM, the pack was first simulated with nothing but air filling the inter-cellular gaps. The simulated temperature of one cell was plotted over time both with and without the PCM filling the gaps in the battery pack. The results show that with the PCM, the temperature of the cell levels off just $5{ }^{\circ} \mathrm{C}$ past the PCM melting point of $50{ }^{\circ} \mathrm{C}$ and stays there at that constant temperature as opposed to increasing almost linearly as seen in the case of no PCM. Increasing the thermal conductivity of the PCM enhances heat transfer into the PCM. All cells were discharged at $35 \mathrm{~A}$ for 720 seconds in the simulation. It was found that lowering the melting point of the PCM and improving its thermal conductivity would be necessary to improve heat transfer. PCM with a melting point below $45^{\circ} \mathrm{C}$ was determined to be optimal for heat transfer. The maximum temperature of the modules reached $50^{\circ} \mathrm{C}$ with the cooling system.

Electrodes were given their own heat generation source and this resulted in significantly higher temperatures at the tops of the cells where the electrodes were. This was in contrast to using purely uniform heat generation methods as assumed in other research. Increasing the PCM thermal conductivity comes at the cost of reduced 
latent heat for a given volume. A well-designed PCM BTM system will have an optimum ratio of thermal conductivity and latent heat of fusion.

\subsection{Al-Hallaj et al. (2000)}

Al-Hallaj et al. performed calorimetric measurements and investigated entropy changes in li-ion batteries [1]. Calorimetric measurements and DC current interruption techniques were used to determine the entropy change during discharge and charge of a Panasonic lithium-ion cell. The entropy coefficient, $d E_{e q} / d T$, the change in open-circuit voltage with respect to temperature, was found to vary from $-.0006 \mathrm{~V} / \mathrm{K}$ to $-.0001 \mathrm{~V} / \mathrm{K}$ from fully discharged to fully charged respectively. Changes in the reversible heat, $T \Delta S$, were claimed to be responsible for the endothermic heat effect observed during discharge of the cells near the 0.23 depth of discharge (DOD). The strong variation in the entropy coefficient near 0.23 was found to be due to the occurrence of a phase change in the cathode and a structural transformation in the graphite anode.

Experiments were conducted inside an accelerated rate calorimeter (ARC). The temperature rise during cycling for several 18650 cells was measured. The cells were discharged at $C / 6$ and a temperature of $35^{\circ} \mathrm{C}$. The ARC setup was used to measure the entropy coefficient of the Panasonic cell. The temperature inside the ARC was increased to specific values and held for several hours to reach equilibrium then the cell open-circuit voltage was measured to estimate the effect of temperature on the cell open-circuit voltage. The open-circuit voltage was assumed to be equal to the $E_{e q}$ of the battery and $d E_{e q} / d T$ was calculated by linear regression of the $E_{e q}$ versus $T$ plots at various depths of discharge.

To study the heat effects that come from structural transformations and phase 
transitions in the cell, electrochemical-calorimetric measurements were taken. The DC current interrupt technique was used in combination with calorimetric measurements during charge and discharge of the cell. The cell was placed inside the ARC and temperature was maintained at $35^{\circ} \mathrm{C}$. The cell was charged for 2 hours then the current was stopped for 3 hours. This sequence was repeated until the cell was fully charged. The same sequence was performed for cell discharge. Temperature, voltage, and current were recorded at one minute intervals. A significant temperature drop was found to occur in the cell near the 0.2 depth of discharge state. Another smaller temperature drop was found to occur in several cells near the 0.95 depth of discharge state. This effect was repeatedly found at operating temperatures of $55^{\circ} \mathrm{C}$ to $70^{\circ} \mathrm{C}$ as well.

In conclusion, a quick endothermic heat effect was observed during the discharge of the Panasonic cell. A substantial entropy decrease was found to occur in the cathode due to a hexagon to monoclinic phase change of $\mathrm{LiCoO}_{2}$, which was then followed by an increase in entropy due to the reverse phase change. The structural transformations characterized by the entropy increase and endothermic reversible heat effect reinforce the observed endothermic spike near the 0.23 depth of discharge state.

\subsection{Viswanathan et al. (2010)}

Viswanathan et al. performed laboratory experiments to determine which battery chemistries minimized reversible heat generation throughout battery discharge and charge [20]. The entropy changes in cathodes materials, anode materials, and complete Li-ion batteries were measured using an electrochemical thermodynamic measurement system (ETMS). $\mathrm{LiCoO}_{2}$ batteries were found to have a much larger entropy change than $\mathrm{LiNi}_{x} \mathrm{Co}_{y} \mathrm{MnZO}_{2}$ and $\mathrm{LiFePO}_{4}$ chemistry batteries. Lithium titanate based anodes have lower entropy change than graphite anodes. Reversible heat 
generation rates, which result from entropy changes, were found to be a significant portion of the total heat generation rate of the batteries. The research study aimed to find the battery electrode materials with low reversible heat generation rates.

The power load on HEV batteries during acceleration and braking is quite high, which requires thermal management systems to dissipate the heat during peak loads. Typical HEV batteries range from $4 \mathrm{kWh}$ to $40 \mathrm{kWh}$. Some applications have the option of active cooling systems, but others do not. Thermal management is critical where active cooling is not available. As the size of the battery increases, the ratio of heat generating volume to heat dissipating surface area increases. This leads to an increase in battery temperatures as battery size increases. Reversible heat generation rates from entropy changes can contribute to more than half of the total heat generation rate. The contribution of reversible heat generation is expected to be higher at lower discharge and charge rates. It is important to quantify the rate of reversible heat generation at various states of charge (SOC). This information can be used in battery thermal management systems to avoid high temperature spikes.

Measurement of reversible and irreversible heat generation in batteries is critical to thermal management. Various combinations of anodes and cathodes can have lower rates of reversible heat generation, by having the anode and cathode entropy changes cancel each other out at various depths of discharge. Rates of irreversible heat generation can be determined from impedance measurements in the cells. Data on entropy changes for $\mathrm{LiCoO}_{2}$ and $\mathrm{LiMn}_{2} \mathrm{O}_{4}$ are readily available, but data on $\mathrm{LiFePO}_{4}$ was limited. In some literature, change in entropy, $\Delta S$, was calculated from $d E / d T$ values.

The ETMS calculates entropy change based on lithium ion exchange. The entropy change corresponds to a reduction reaction which is the discharge reaction for the cathode. Assuming heat for an exothermic reaction is negative then discharge current 
is positive and charge current is negative in sign. In a lithium-ion cell while reduction takes place at the cathode, oxidation takes place at the anode. The total change in entropy for a cell during discharge is the change in entropy from the cathode summed with the change from the anode. Combinations of cathodes and anodes with low full cell entropy changes across all depths of discharge were found. Some combinations were low due to low entropy changes in the cathode and anode and others were low because the entropy changes in the cathode and anode canceled each other out. The irreversible heat generation rate is always exothermic and is given by the current squared times the internal resistance. $Q_{i r r}$ is always negative but $Q_{r}$ can positive or negative. $\mathrm{Q}=\mathrm{Q}_{r}+\mathrm{Q}_{i r r}$. Entropy data for cathodes, anodes, and complete cells was obtained by measuring open-circuit voltage as a function of temperature using the ETMS. Entropy changes were calculated from the slope of the voltage versus time plot. A database of entropy changes for various cathodes and anodes was created by this research. 


\section{Chapter 3}

\section{Background}

\subsection{Battery Chemistry}

A lithium iron phosphate battery $\left(\mathrm{LiFePO}_{4}\right)$, is a specific type of rechargeable lithium-ion battery which uses lithium iron phosphate as the cathode material. Compared to the more common $\mathrm{LiCoO}_{2}$ batteries, $\mathrm{LiFePO}_{4}$ batteries generally have lower energy densities, longer lifetimes, and higher power densities. The batteries store and discharge energy in the form of charged atoms, or ions. The charge and discharge rate of the battery is restricted by the speed that ions can move through the cell. There are several types of lithium-ion batteries including $\mathrm{LiCoO}_{2}, \mathrm{LiMn}_{2} \mathrm{O}_{4}, \mathrm{LiNiO}_{2}$ and $\mathrm{LiFePO}_{4} \cdot \mathrm{LiFePO}_{4}$ batteries avoid the use of Cobalt which reduces costs and avoids environmental concerns. Table 3.1 shows properties for common rechargeable and non-rechargeable battery chemistries.

The safety characteristics inherent to the $\mathrm{LiFePO}_{4}$ chemistry come from the incorporation of phosphates as the cathode material. Phosphates are very stable in overcharge and short circuit conditions and have the ability to withstand high temperatures without decomposing. Phosphates are not prone to thermal runaway and 
Table 3.1: Properties of primary and secondary battery chemistries.

\begin{tabular}{lll}
\hline Chemistry & Cell Voltage $(\mathrm{V})$ & Specific Energy $(\mathrm{MJ} / \mathrm{kg})$ \\
\hline Zinc-carbon & 1.5 & 0.13 \\
Alkaline & 1.5 & 0.50 \\
Lithium & 3.0 & 0.83 \\
$\mathrm{NiCd}$ & 1.2 & 0.14 \\
$\mathrm{NiMH}$ & 1.2 & 0.36 \\
$\mathrm{AgZn}$ & 1.5 & 0.46 \\
NiZn & 1.6 & 0.36 \\
Lead-acid & 2.1 & 0.14 \\
Li-ion & 3.6 & 0.46 \\
\hline
\end{tabular}

will not burn. As a result, $\mathrm{LiFePO}_{4}$ batteries possess safety characteristics that are superior to those of lithium-ion batteries made with other cathode materials. Failure in the form of thermal runaway or premature capacity fading is still possible in lithium iron phosphate battery packs if proper thermal management is not employed.

Lithium-ion batteries work by converting stored chemical energy into electrical energy. Each battery consists of a certain number of voltaic cells with each voltaic cell consisting of two half-cells. The half-cells are connected in series by a conductive electrolyte with anions and cations. One half-cell contains electrolyte and the anode, while the other half-cell contains electrolyte and the cathode. During battery discharge, the anions migrate to the anode and the cations migrate to the cathode. In the redox reaction that occurs, cations are reduced by adding electrons at the cathode and anions are oxidized by removing electrons at the anode [20]. The electrodes do not physically touch, but are electrically connected by the electrolyte. It is possible for two half-cells to use different electrolytes, but they must have a separator to prevent mixing of the electrolyte while still allowing the ions to flow between them. The structure of a typical lithium-ion cell is shown in Figure 3.1.

The voltage developed across the cell's terminals depends on the energy release 


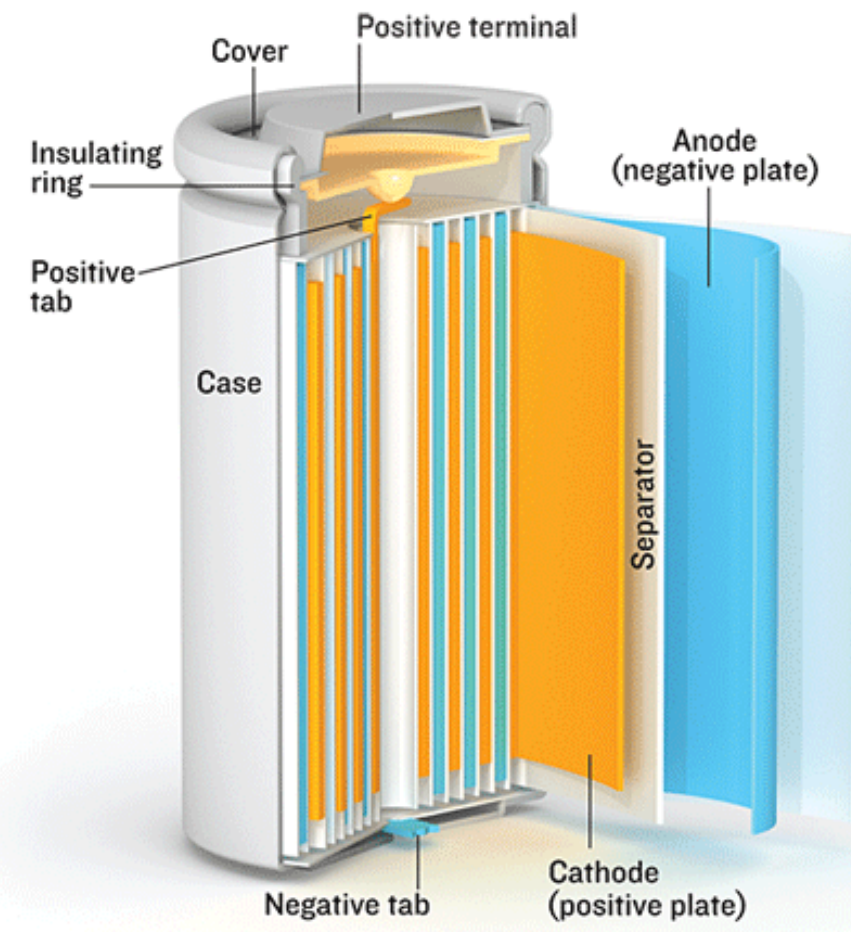

Figure 3.1: Lithium-ion cell structure diagram (ref. [9]).

from the chemical reactions of the electrodes and electrolyte. Each half-cell has an electromotive force (EMF) and the difference between the two half-cell's EMFs determines the battery cell's voltage. The net EMF is the difference in the reduction potentials of the half-reactions. Rechargeable batteries can be recharged by supplying electrical energy to the cell to restore its original composition by reversing the chemical reaction.

Open-circuit voltage is a function of battery temperature and is defined as the voltage across the battery terminals while it is neither charging nor discharging. Due to the internal resistance of the cell, the terminal voltage of the cell during discharge is smaller than open-circuit voltage. Similarly, the terminal voltage is larger than the open-circuit voltage while charging. The internal resistance typically increases under discharge and the open-circuit voltage decreases under discharge. 
Table 3.2: Thermodynamic properties of phase change materials.

\begin{tabular}{llll}
\hline PCM & Melt Point $\left({ }^{\circ} \mathbf{C}\right)$ & Latent Heat $(\mathrm{kJ} / \mathrm{kg})$ & $C_{p}$ Solid $(\mathrm{kJ} / \mathrm{kgK})$ \\
\hline Water & 0 & 333.6 & 2.05 \\
Paraffin & 41 & 174.0 & 2.14 \\
Lauric acid & 44.2 & 211.6 & 1.76 \\
\hline
\end{tabular}

\subsection{Phase Change Materials}

A phase change material $(\mathrm{PCM})$ is defined as a material with a large latent heat of fusion and a desirable melting point which can store or release large amounts of energy. PCMs must be selected such that their melting point is in the operating temperature range of the application. The most commonly used phase change materials are salt hydrates, fatty acids, esters, and various paraffins. Recently ionic liquids were investigated as novel PCMs. PCMs can be classified into three groups: organic, inorganic, and eutectic. Organic PCMs are typically safe, stable, and have a high heat of fusion, but suffer from low thermal conductivity. Paraffin wax, an organic PCM, is a commonly chosen phase change material because of its large latent heat of fusion, stability, and cost. Several common phase change materials and their thermodynamic properties are shown in Table 3.2 .

Thermal-composites is a term given to combinations of phase change materials such as a copper-mesh immersed in a paraffin-wax. The thermal conductivity of the paraffin will be increased by adding the highly conductive copper mesh to the relatively low conducting paraffin, thus increasing bulk thermal conductivity while preserving a large latent heat of fusion. Such hybrid materials are created to achieve specific bulk properties. The desirable bulk properties of the thermal-composite are maximized by combining materials that each have a specific thermal property of interest. If the PCM is required to flow, the solid conducting material must be porous. 


\section{Chapter 4}

\section{Computational Fluid Dynamics}

\subsection{ANSYS Fluent}

The commercially available computational fluid dynamics software, Fluent, by ANSYS, was used to create the fluid flow simulations for this study. The software utilizes the finite-volume method to numerically solve the physical governing equations for the fluid. The mesh for the model was created with ICEM, the preprocessor bundled with Fluent. Fluent offers a wide range of tools to create physics based models for a wide array of applications. The energy equation can be solved to model conjugate heat transfer problems including all modes of heat transfer; conduction, convection, and radiation. Many types of fluid flow problems can be modeled including incompressible, compressible, laminar, and turbulent flows. User-defined functions (UDFs) allow the implementation of new models in addition to the numerous built in Fluent models. User-defined functions are written in the C programming language and compiled using the built-in Fluent compiler. 


\subsection{Conservation Equations}

For thermal fluid flows, Fluent solves the conservation equations for continuity, momentum, and energy. The conservation equations for laminar flow in an inertial reference frame are presented below.

\subsubsection{Continuity Equation}

$$
\frac{\partial \rho}{\partial t}+\nabla \cdot(\rho \vec{v})=S_{m}
$$

Equation 4.1 is the general form of the continuity equation and is valid for both incompressible and compressible flows. $S_{m}$ is the mass added due to various sources and is zero in this case.

\subsubsection{Momentum Equation}

$$
\frac{\partial}{\partial t}(\rho \vec{v})+\nabla \cdot(\rho \vec{v} \vec{v})=-\nabla p+\nabla \cdot(\overline{\bar{\tau}})+\rho \vec{g}+\vec{F}
$$

Equation 4.2 is the general form of the momentum conservation equation. The variable $p$ is the static pressure, $\overline{\bar{\tau}}$ is the stress tensor, $\rho \vec{g}$ is the gravitational body

force, and $\vec{F}$ is the external body force which includes any momentum source or sink terms. $\bar{\tau}$ is given by Equation 4.3. The variable $\mu$ is the dynamic viscosity and $\mathrm{I}$ is the unit tensor.

$$
\overline{\bar{\tau}}=\mu\left(\left(\nabla \vec{v}+\nabla \vec{v}^{T}\right)-\frac{2}{3} \nabla \cdot \vec{v} I\right)
$$




\subsubsection{Energy Equation}

Fluent solves the energy conservation equation in the following general form when the energy equation setting is enabled in the model.

$$
\frac{\partial}{\partial t}(\rho E)+\nabla \cdot(\vec{v}(\rho E+p))=\nabla \cdot\left(k_{e f f} \nabla T-\sum_{j} h_{j} \vec{J}_{j}+\left(\overline{\bar{\tau}}_{e f f} \cdot \vec{v}\right)\right)+S_{h}
$$

The variable $k_{e f f}$ is the effective thermal conductivity, $\vec{J}_{j}$ is the diffusion flux of species $\mathrm{j}$. The first three terms on the right-hand side represent energy transfer due to conduction, species diffusion, and viscous dissipation respectively. $S_{h}$ represents the source or sink term from any volumetric heat sources. E is defined by Equation 4.5 where $h$ is the sensible enthalpy of the fluid, defined by Equation 4.6 for incompressible flows.

$$
\begin{gathered}
E=h-\frac{p}{\rho}+\frac{v^{2}}{2} \\
h=\int_{T_{r e f}}^{T} C_{p} d T+\frac{p}{\rho}
\end{gathered}
$$

In solid regions of the model, Fluent solves the following form of the energy equation:

$$
\frac{\partial}{\partial t}(\rho h)+\nabla \cdot(\vec{v} \rho h)=\nabla \cdot(k \nabla T)+S_{h}
$$

The second term on the left-hand side represents convective energy transfer due to motion of the solid. The terms on the right-hand side represent heat flux due to conduction and volumetric heat sources respectively. 


\subsection{Buoyancy-Driven Flows}

When a fluid is heated and the fluid density varies with temperature, a flow can be induced by the force of gravity acting on the density variations. The buoyancy-driven flow is termed natural convection.

In purely buoyancy-driven flows the strength of the buoyancy-induced flow is measured by the Rayleigh number shown in Equation 4.8.

$$
R a_{L}=\frac{g \beta \Delta T L^{3}}{\nu \alpha}
$$

The variable $\beta$ is the thermal expansion coefficient determined from Equation 4.9.

$$
\beta=-\frac{1}{\rho}\left(\frac{\partial \rho}{\partial T}\right)_{p}
$$

The variable $\alpha$ is the thermal diffusivity determined from Equation 4.10.

$$
\alpha=\frac{k}{\rho c_{p}}
$$

Buoyancy-driven flows with Rayleigh numbers less than $10^{8}$ indicate a laminar flow since transition to turbulence typically occurs over the range of $10^{8}$ to $10^{10}$.

\subsubsection{Boussinesq Model}

Faster convergence can be achieved by using the Boussinesq model. The model treats density as a constant value in all solved equations except for the buoyancy term in the momentum equation.

$$
\left(\rho-\rho_{0}\right) g \approx-\rho_{0} \beta\left(T-T_{0}\right) g
$$


The variable $\rho_{0}$ is the constant fluid density, $T_{0}$ is the operating temperature, and $\beta$ is the thermal expansion coefficient. Equation 4.12 is used to eliminate $\rho$ from the buoyancy term. This approximation is accurate as long changes in the fluid density are small, that is, $\beta\left(T-T_{0}\right) \ll 1$.

$$
\rho=\rho_{0}(1-\beta \Delta T)
$$

\subsection{Surface-to-Surface Radiation Model}

The surface-to-surface (S2S) radiation model was used to account for the radiation exchange in the enclosure of gray-diffuse surfaces. The energy exchange between surfaces depends on geometry, orientation, and distance. These factors are accounted for by a view factor. The S2S model assumes that any absorption, emission, or scattering of radiation can be ignored and that all surfaces are gray and diffuse.

Emissivity and absorptivity of a gray surface is not a function of wavelength. The exchange of radiative energy between surfaces is unaffected by the medium between

them. According the gray-body model, if a certain amount of radiant energy is incident on a surface then a fraction is reflected, a fraction is absorbed, and a fraction is transmitted. Since the surfaces considered in this thesis are opaque to thermal radiation then the transmissivity can be neglected.

Energy leaving a surface is composed of the sum of the emitted energy and reflected energy. Equation 4.13 shows the energy reflected from surface k.

$$
q_{\text {out }, k}=\epsilon_{k} \sigma T_{k}^{4}+\rho_{k} q_{\text {in }, k}
$$

The variable $q_{o u t, k}$ is the energy flux leaving surface $\mathrm{k}, \epsilon_{k}$ is the emissivity of $\mathrm{k}, \sigma$ 
is Boltzmann's constant, $\rho_{k}$ is the reflectivity of $\mathrm{k}$, and $q_{i n, k}$ is the energy flux incident on $\mathrm{k}$ from the surroundings.

Incident energy flux $q_{i n, k}$ can be written as a function of energy flux leaving all other surfaces in view.

$$
A_{k} q_{i n, k}=\sum_{j=1}^{N} A_{j} q_{o u t, j} F_{j k}
$$

The parameter $A_{k}$ is the surface area of $\mathrm{k}, A_{j}$ is the surface area of $\mathrm{j}, F_{j k}$ is the view factor between surface $\mathrm{k}$ and surface $\mathrm{j}$, and $\mathrm{N}$ is the number of surfaces. Equation 4.15 calculates the view factor between two surfaces $\mathrm{i}$ and $\mathrm{j}$. The function $\delta_{i j}$ is equal to one if $d A_{j}$ is visible to $d A_{i}$ and zero otherwise.

$$
F_{i j}=\frac{1}{A_{i}} \int_{A_{i}} \int_{A_{j}} \frac{\cos \theta_{i} \cos \theta_{j}}{\pi r^{2}} \delta_{i j} d A_{i} d A_{j}
$$




\section{Chapter 5}

\section{Experiment}

\subsection{Experiment Equipment}

\subsubsection{Agilent Data Acquisition and Multiplexer}

The Agilent 34972A Data Acquisition / Switch Unit is a versatile data acquisition system that can log signal measurements to a connected computer. The device records thermocouple voltage measurements and automatically converts the measurements to temperatures using the standard NIST tables with either an external, internal, or fixed reference junction. The device accepts all standard thermocouple types including, $\mathrm{J}, \mathrm{K}, \mathrm{S}$, and $\mathrm{T}$. The device is also capable of measuring both $\mathrm{DC}$ and $\mathrm{AC}$ voltage signals. Only voltage and thermocouple measurements were required for the experiments.

Voltage measurement wires and thermocouples were connected to the data acquisition unit through a twenty channel multiplexer. Three T-type thermocouples were screwed into the multiplexer terminals on channels one, two, and three. Two pairs of voltage measurement wires were screwed into the terminals on channels five and six. The multiplexer relay card was inserted into slot one of the Agilent 34972A. Current 


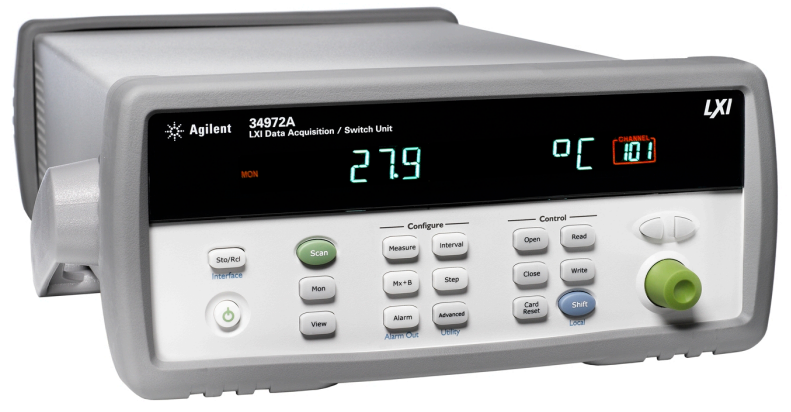

Figure 5.1: Agilent 34972A Data Acquisition / Switch Unit.

was measured using a shunt with an experimentally measured resistance value and the voltage drop across it was measured such that the current through it could be calculated. The second pair of voltage measurement wires were placed across the battery terminals to record battery voltage throughout the discharge.

\subsubsection{LabVIEW Program}

A custom LabVIEW program was written to interface with the Agilent 34972A for data acquisition during the experiments. The program was written to take temperature measurements using the three T-type thermocouples, take DC voltage measurements using the two pairs of voltage leads, split the output readings into their own respective columns, and save them to an excel file with the time stamp. The LabVIEW program used for the experiment data collection uses blocks of code from the "Agilent 34970 Advanced Scan" program, an example program included with the Agilent 34970 LabVIEW driver. The front panel of the LabVIEW program, Figure 5.3, is used to display certain readings, indicators, and input certain variables that shouldn't be hard coded into the program. Details of each part of the front panel are explained in Table 5.1.

Figure 5.4 shows the block diagram used to interface LabVIEW with the Agilent 


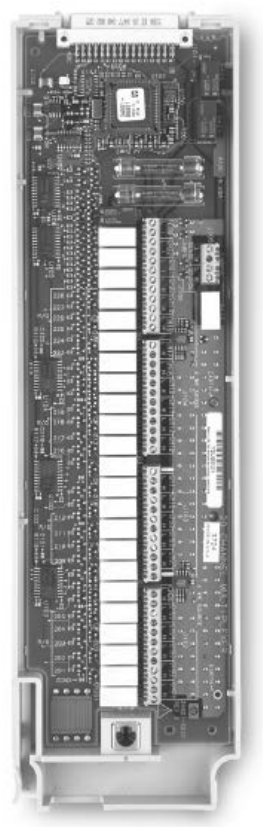

Figure 5.2: Multiplexer card for Agilent 34972A Data Acquisition / Switch Unit.

data acquisition system. The program begins by initializing communication with the Agilent device via the VISA resource name and serial port communication settings. This is done using the Agilent 34970 initialize block which is installed from the Agilent 34970 LabVIEW driver. Communication information from the Agilent device is carried from the initialization block to each additional driver block used in the program such that each block knows how to communicate with the specific Agilent device attached to the computer. The communication signal is represented by the purple line in the block diagram. Additionally, the error outputs of each driver block are carried through to the next successive driver block in series ultimately ending with an error output for troubleshooting feedback with the device. The error signal is represented by the yellow line.

After communication initialization, the signal is carried over to the voltage measurement driver block which accepts configuration inputs and the list of channels to take voltage measurements on. The signal continues to the temperature measure- 


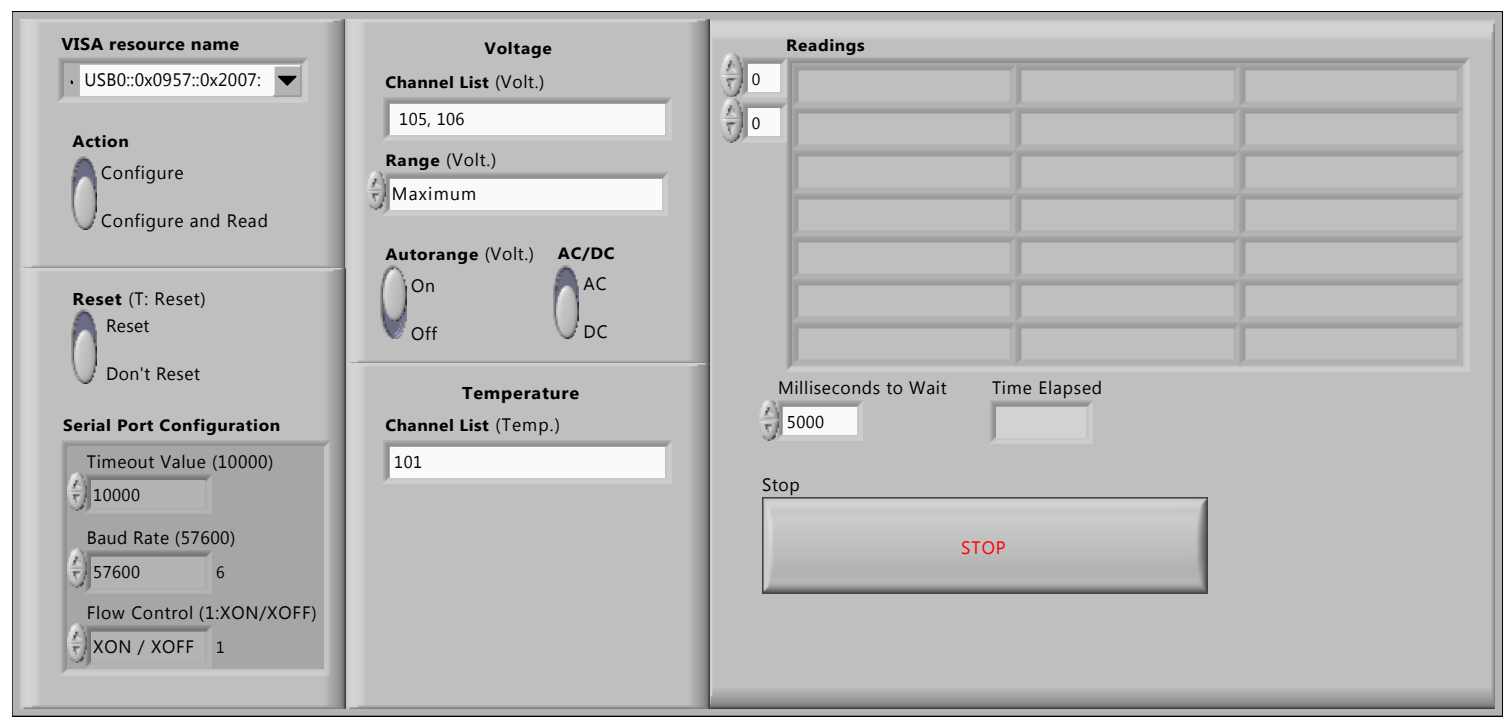

Figure 5.3: LabVIEW front panel for data acquisition program.

Table 5.1: Front panel details of LabVIEW data collection program.

\begin{tabular}{ll}
\hline Front Panel Name & Function \\
\hline VISA Resource Name & Input for the address of the Agilent 34972A. \\
Action & Set the DAQ to configure or configure / read. \\
Reset & Reset the connection. \\
Serial Port Configuration & Settings for the serial port communication. \\
Timeout Value & Time to wait before connection gives up. \\
Baud Rate & Communication rate. \\
Flow Control & Sends XOFF when the receive buffer is full and \\
Voltage Channel List & suspends transmission when XOFF is received. \\
Autorange & List of channels for voltage measurements. \\
AC/DC & Set to automatically determine voltage range. \\
Temp. Channel List & Choose AC or DC voltage readings. \\
Readings & List of channels for temperature measurements. \\
Milliseconds to Wait & Output panel displays the most recent set of read- \\
Time Elapsed & ings. \\
Stop & Delay between each round of readings. \\
\hline
\end{tabular}


ment driver block which accepts configuration parameters of temperature channel list, thermocouple device, T-type, and internal reference junction. A conditional case structure is used to bypass the temperature measurement or voltage measurement configuration aspects of the program if the temperature channel list or voltage channel list is empty. This allows the program to run with an empty temperature or voltage channel list and bypass this aspect of the code without producing an error.

The following sections of code are placed in a loop structure which causes all actions in the structure to be repeated every 5 seconds until the stop button is pressed. Within the loop structure the signal continues to a series of Agilent driver blocks which order the device to switch through the multiplexer's relays to take the previously configured measurements once per loop iteration. This section also handles closing the communications port and handling any errors from the device once the program is stopped. The output of this section is a string of data containing the measured values from the device and their associated channel number. This signal then enters a secondary loop structure which splits the string based on key elements such as commas in order to separate each measurement reading and its associated channel number into its own cell in an array. This array is displayed in the Readings section of the front panel and displays all data collected from each channel for that measurement time. A timer is triggered each time the looping measurement process starts and the initial startup time is subtracted in order to append a timestamp to each set of measurements in the data array. The data array is written to an excel sheet at the location specified in the program. Each row in the excel sheet contains a timestamp and the measured values for each channel specified. Each successive reading is appended to the excel sheet. The main data logging loop continues indefinitely until the stop button is triggered. The excel file must be renamed or deleted after each experiment is performed or else the data will continue to be appended onto the existing file. Each soft coded variable in the front panel is automatically implemented 


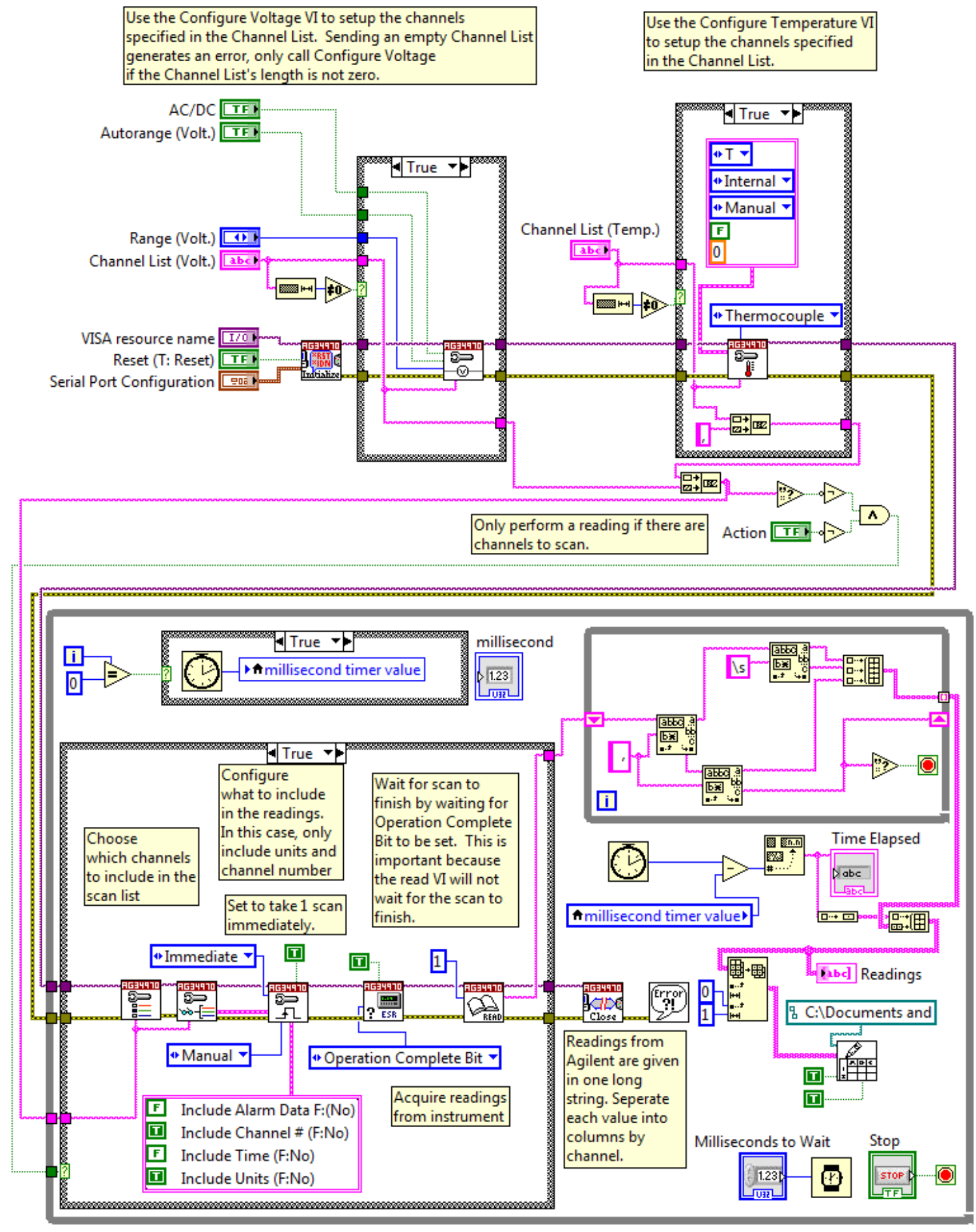

Figure 5.4: LabVIEW block diagram of data acquisition program. 
into the block diagram code each time the program is run. Default values for the front panel variables can be set with the right click menu and all front panel variables will be initialized to defaults each time the program is opened.

\subsubsection{Infrared Camera}

A Flir Thermacam SC300 infrared camera was used to take emissivity measurements for the CFD model. The infrared camera captures all of the radiation from the 7.5 to 13 micrometer wavelengths. Figure 5.5 shows the Flir infrared camera used in the experiments.

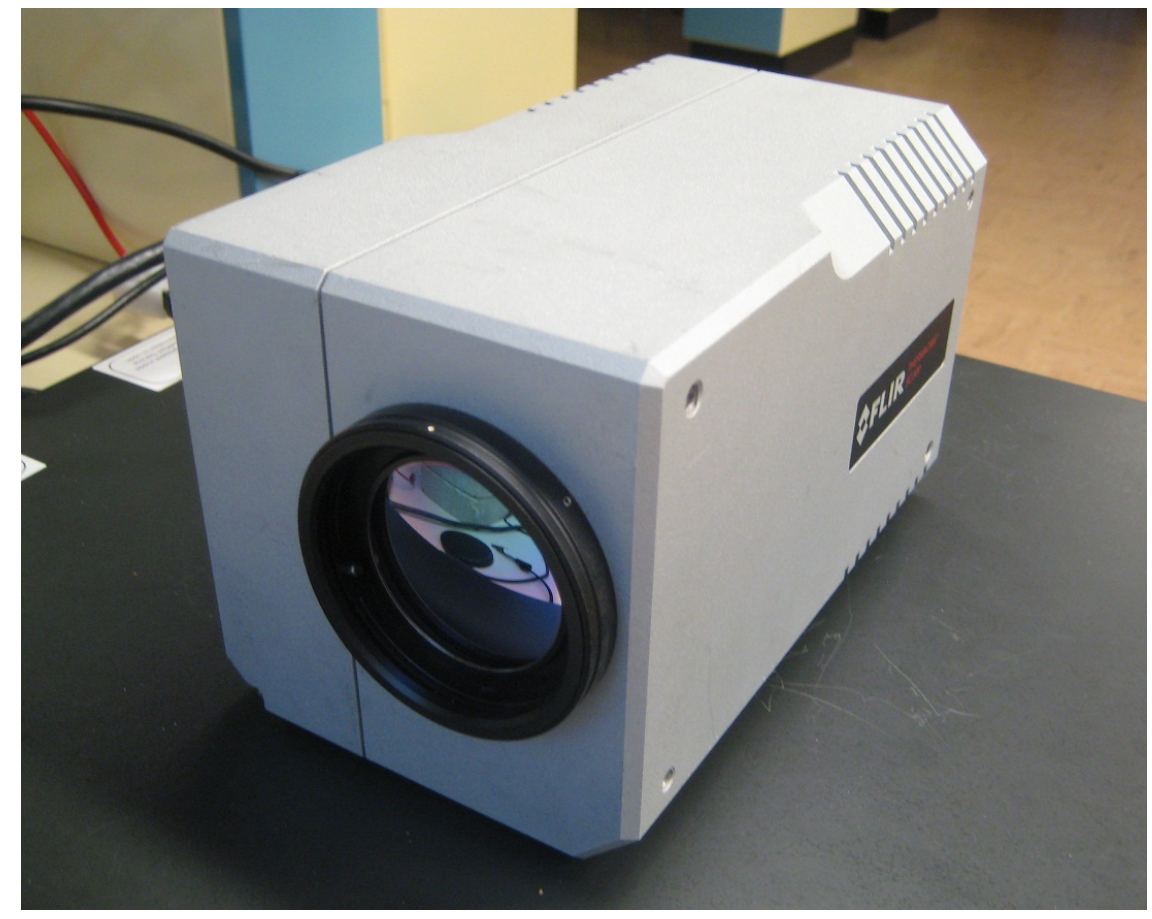

Figure 5.5: Flir Thermacam SC300 infrared camera.

\subsubsection{Electronic Load}

The BK Precision 8518 DC Programmable Load was used to discharge the battery for the experiments. The device is capable of handling up to 1200 watts, 0.1 


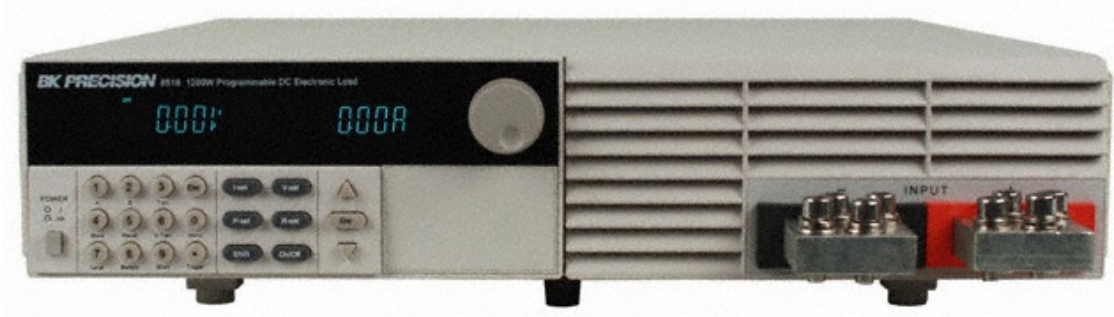

Figure 5.6: BK Precision 8515 DC Programmable Load.

to 60 volts, and up to 240 amps. The electronic load can draw a constant power or constant current from the battery. Both modes were used in measuring the discharge characteristics of the battery. The constant power mode was used during the battery heat generation rate experiments and the constant current mode was used to approximate the battery open-circuit voltage using a slow constant current discharge rate. The device features protective settings, several of which were utilized for this project. The max current setting was adjusted to 150 amps for the tests to ensure that the current from the battery did not exceed the 150 amps max rated capacity for continuous discharge specified in the Headway battery datasheet. All equipment, including the wires and shunt, that were part of the power transmission circuit were capable of handling up to 120 amps as required for the heat generation experiments. The voltage off setting was adjusted to 2 volts so that the load would automatically turn off to prevent the battery from being discharged below the voltage stop point specified in the battery datasheet. The voltage on setting was set to 0 volts to ensure that the load would not automatically turn back on once the voltage off was automatically triggered. 


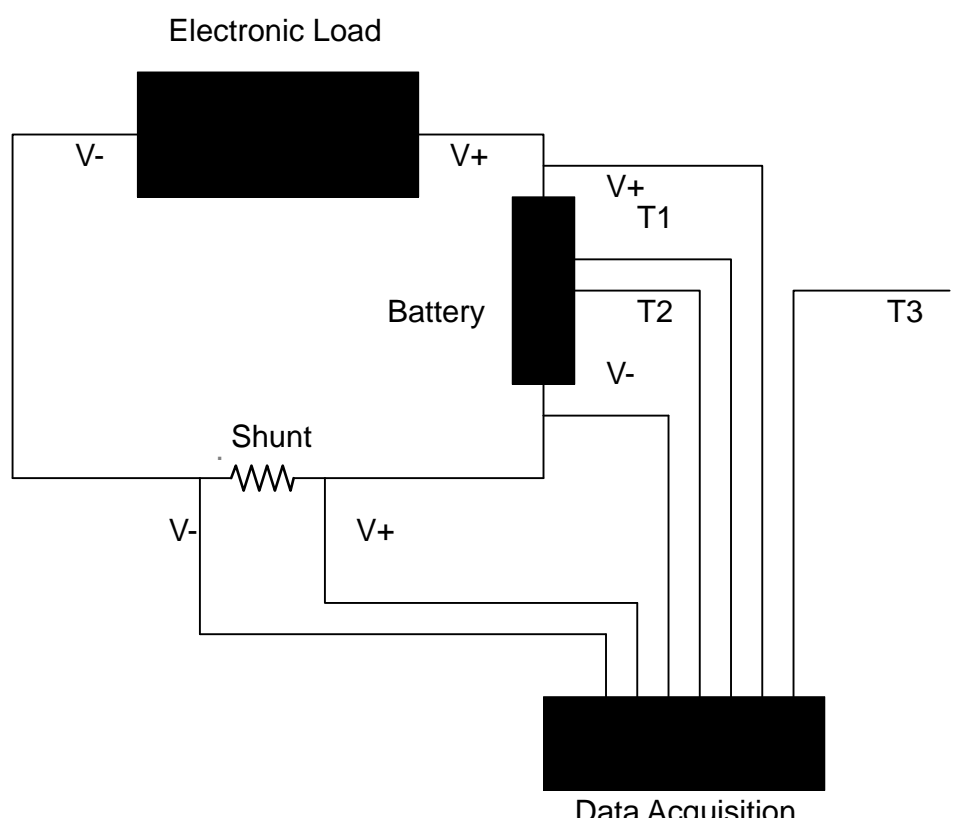

Figure 5.7: Circuit diagram for equipment during battery discharge tests.

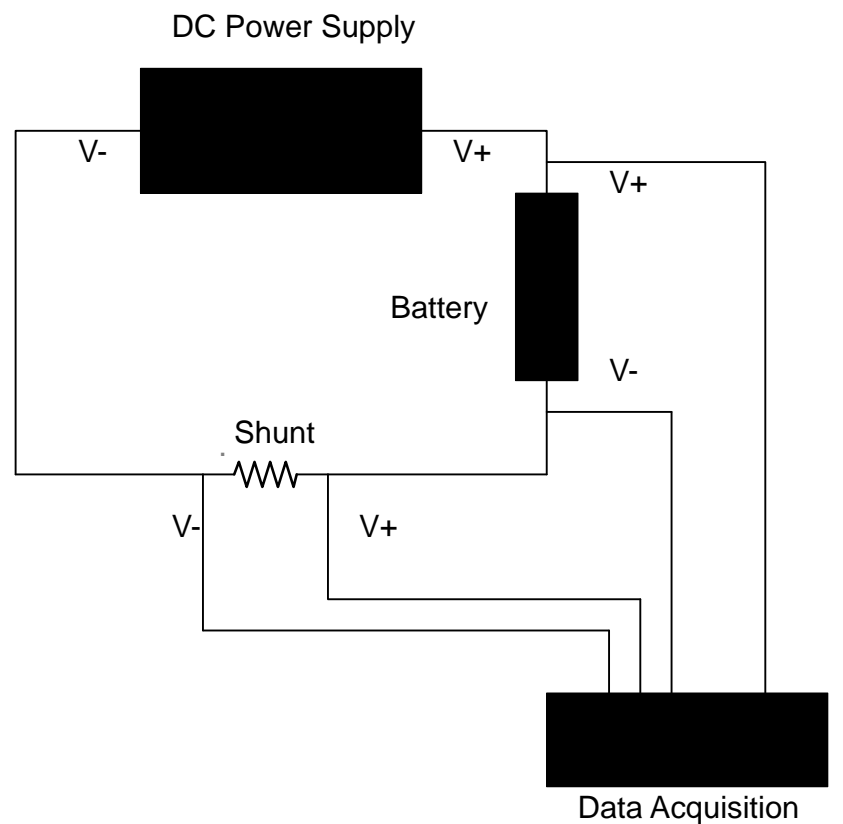

Figure 5.8: Circuit diagram for equipment to charge the battery. 


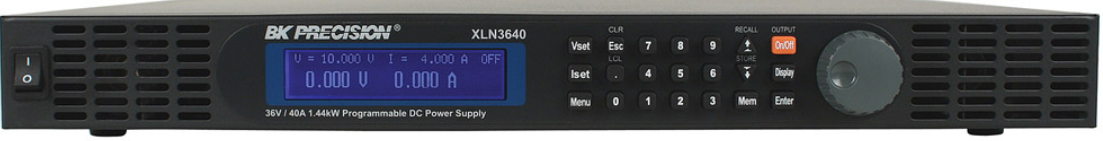

Figure 5.9: BK Precision XLN3640 Programmable DC Power Supply.

\subsubsection{Power Supply}

The BK Precision XLN3640 Programmable DC Power Supply was used to provide a constant current to the Nichrome wire heating coil for the calibration and heat capacity experiments. The power supply is capable of putting out 0 to 36 volts and 0 to 40 amps. A constant current of 1 amp was applied to the heating coil to heat each cylinder up to $60{ }^{\circ} \mathrm{C}$. This process took 30 to 45 minutes depending on the cylinder material. Once the cylinder reached $60^{\circ} \mathrm{C}$ the current was reduced to 0.25 amps. This low current input offset the heat that was lost through the polyurethane foam enclosure and to the ambient air. The current was kept at the low rate to allow each cylinder to remain at $60{ }^{\circ} \mathrm{C}$ for one hour before being turned off and allowed to cool.

The programmable DC power supply was used to charge the battery after each discharge test. The max voltage setting was adjusted to 3.65 volts and the max current setting was adjusted to 20 amps for battery charging. The Headway datasheet specifies a maximum charging voltage of 3.65 volts and maximum charging current of 30 amps. The DC power supply provides a constant current charge to the battery until the voltage across the terminals of the battery reaches 3.65 volts. Then the current tapers off, asymptotically approaching 0 amps. The battery charge was stopped when

the current supply reached 0.1 amps which amounts to 0.66 percent of the battery's rated capacity. The charging process takes about 2 hours. 


\subsection{Experiment Procedures and Results}

The heat generation rates and specific heat of isolated individual batteries were measured experimentally using a technique described by A. Mills and S. Al-Hallaj [13]. These experiments were then used to provide input for the subsequent simulation of the subject 15-cell pack. An energy balance was used to determine the battery heat generation rates as shown in Equations 5.1 and 5.2.

$$
\begin{gathered}
\dot{q}_{g e n}=\dot{q}_{\text {stor }}+\dot{q}_{c o n v} \\
\dot{q}_{g e n}=m C_{P} \frac{d T}{d t}+U A \Delta T
\end{gathered}
$$

Following Mills and Al-Hallaj the battery was insulated in polyurethane foam to reduce convection heat transfer during the experiments. A polyurethane foam block was cut such that the battery could be placed in the center, Figure 5.10. Two metal cylinders, one copper and one 6061 aluminum, were machined to the same cylindrical dimensions as the battery. These cylinders were used to determine the heat loss, or $U A$ value, of the foam insulation block setup. Three T-type thermocouples were used to measure the temperature at the surface of the battery or metal cylinder as well as the external air temperature. An Agilent 34972A Data Acquisition / Switch Unit, BK Precision XLN3640 Programmable DC Power Supply, and BK Precision 8518 Programmable Electronic Load were used for the experiments.

\subsubsection{Calibration and Heat Capacity}

Teflon insulated, 24-gauge, Nichrome heating wire was wound in a helical pattern around the copper and aluminum cylinders and held in place using electrical tape. The copper cylinder was placed into the polyurethane enclosure as shown in Figure 5.10. Two T-type thermocouples were attached on opposite sides in the middle of the 


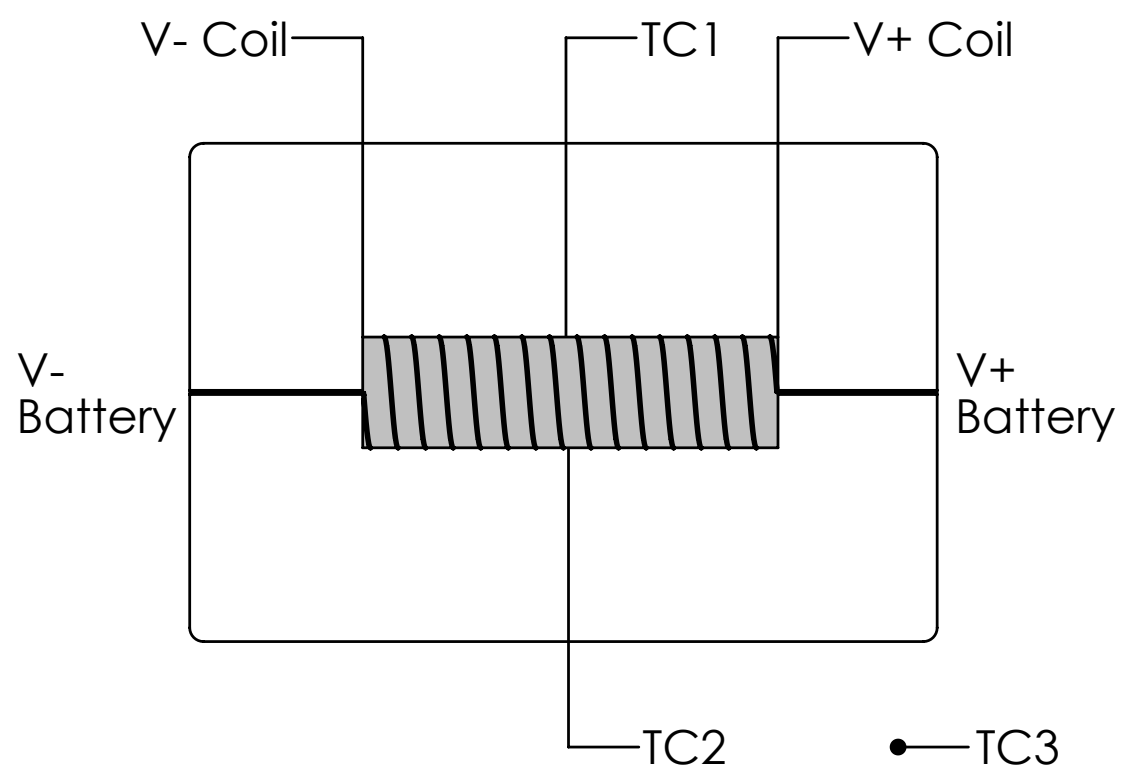

Figure 5.10: Diagram of experiment setup to measure battery heat capacity and heat generation rates.

cylinder. A third T-type thermocouple was placed approximately three feet away from the center of the cylinder to measure the ambient air temperature during the experiment. A DC power supply was used to pass current through the Nichrome wire to heat the cylinder slowly to $60^{\circ} \mathrm{C}$. The current was adjusted to hold the cylinder at the specified temperature for one hour to assure adequate time to achieve a uniform temperature. The heating element was then turned off and the temperature from each thermocouple was recorded every five seconds as the cylinder cooled inside the enclosure. The temperature of the cylinder was taken as the average of the temperatures measured by the two thermocouples attached to it. The ambient air temperature was taken as the average of the recorded ambient temperatures during the cooling process. The cylinder was allowed to cool until it was just $3{ }^{\circ} \mathrm{C}$ above the ambient air temperature. The Biot number of the cylinder was much less than 0.1 due to the relatively high thermal conductivity of the cylinders compared to the small convection coefficient. Solving Equation 5.2 with $\dot{q}_{g e n}=0$ and $B i<<0.1$ leads to the relationship shown in Equation 5.3. 


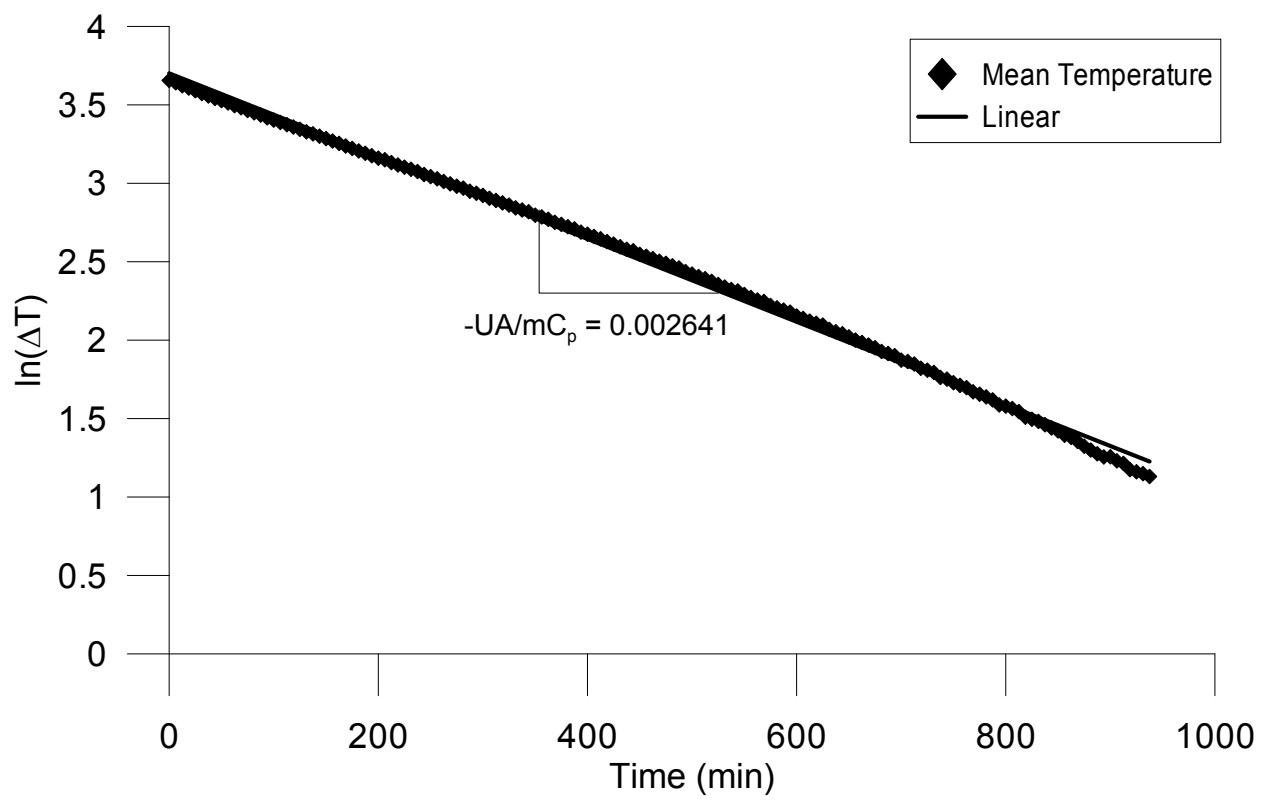

Figure 5.11: First run of copper cylinder cooling to characterize insulation.

$$
\frac{\ln (\Delta T)}{t}=-\frac{U A}{m C_{P}}
$$

The natural log of the temperature difference over time, shown in Figure 5.11 yields a linear cooling trend. The slope of this line is $-U A / m C_{P}$. The heat capacity of the cylinder, $m C_{P}$, is known from the material properties of copper and the measured mass of the cylinder. The $U A$ value of the foam insulated setup was determined from the cooling plot using the known heat capacity of the cylinder. This procedure was performed three times for each of the cylinders to characterize the uncertainty of the $U A$ value, resulting in a $U A$ value of $0.0283 \pm 0.0005 \mathrm{~W} / \mathrm{K}$. The procedure was similarly performed using the battery in place of the metal cylinders to determine the heat capacity of the subject Li-ion batteries. In these experiments the heat capacity, of the battery was found using the slope of the cooling plot with the previously determined $U A$ value of the foam setup providing an experimentally measured specific heat capacity for the batteries of $950 \pm 20 \mathrm{~J} / \mathrm{kgK}$. The calibration results are shown in Table 5.3. 


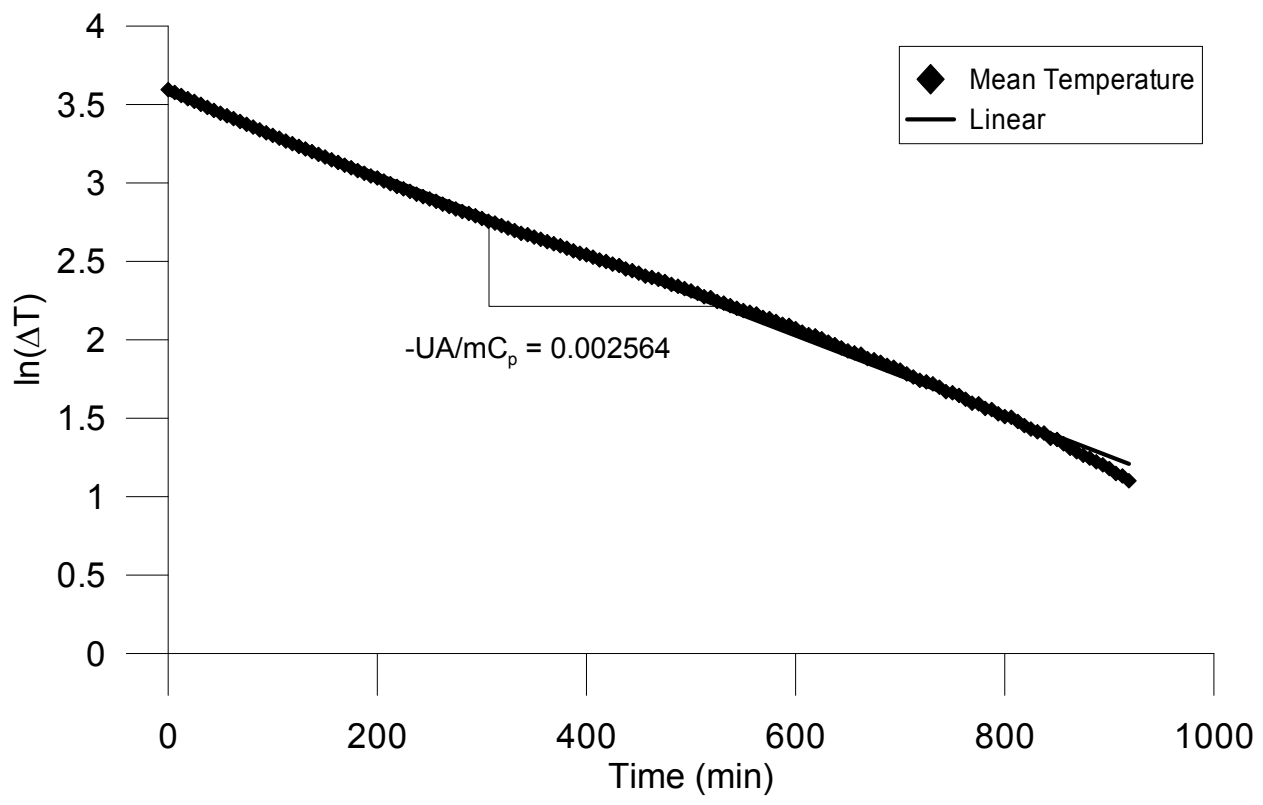

Figure 5.12: Second run of copper cylinder cooling.

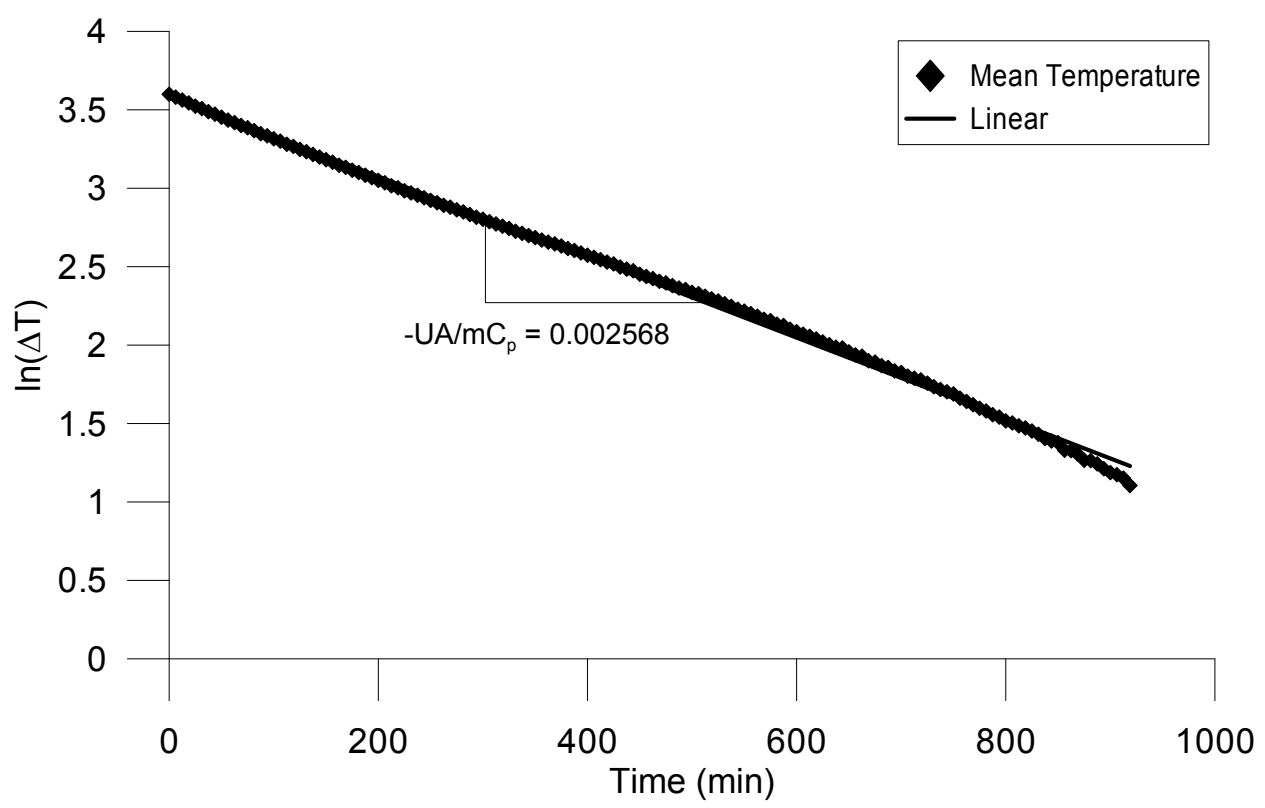

Figure 5.13: Third run of copper cylinder cooling. 


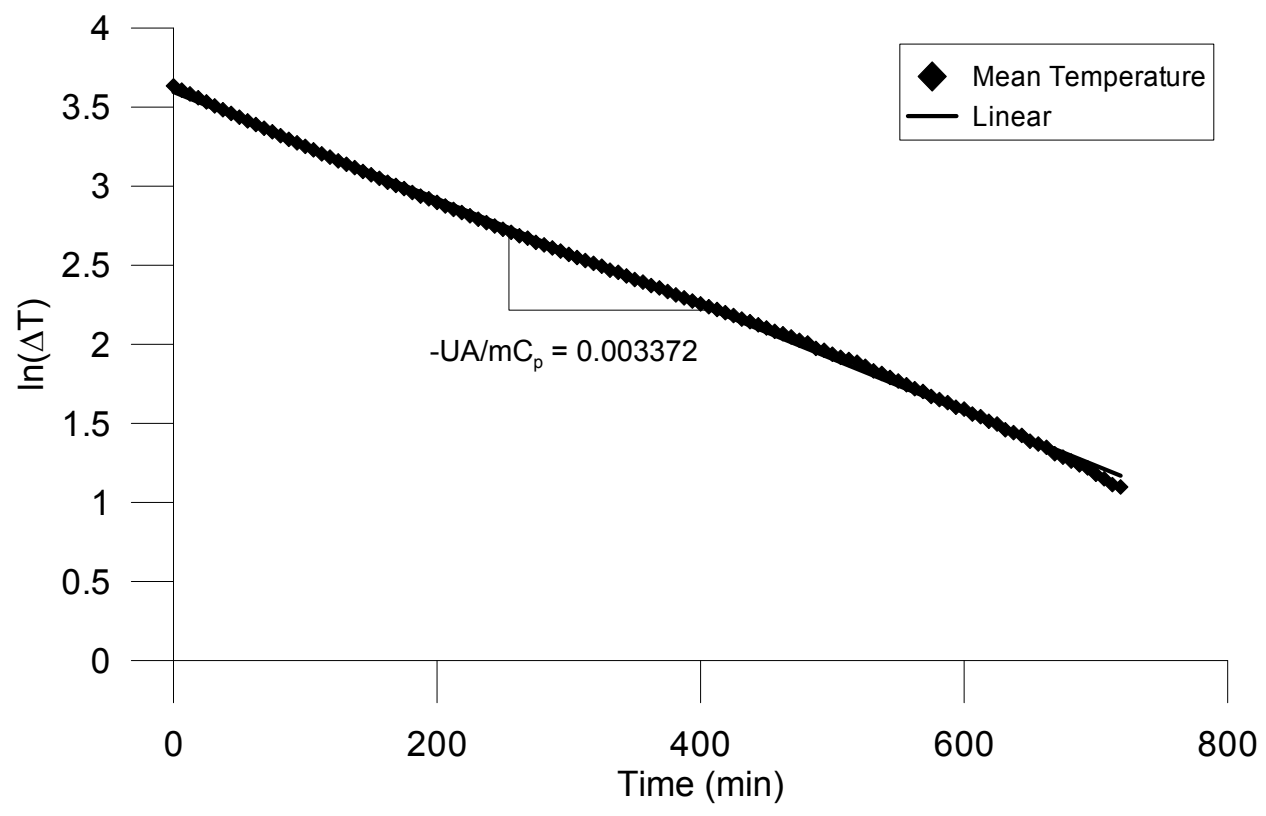

Figure 5.14: First run of aluminum cylinder cooling.

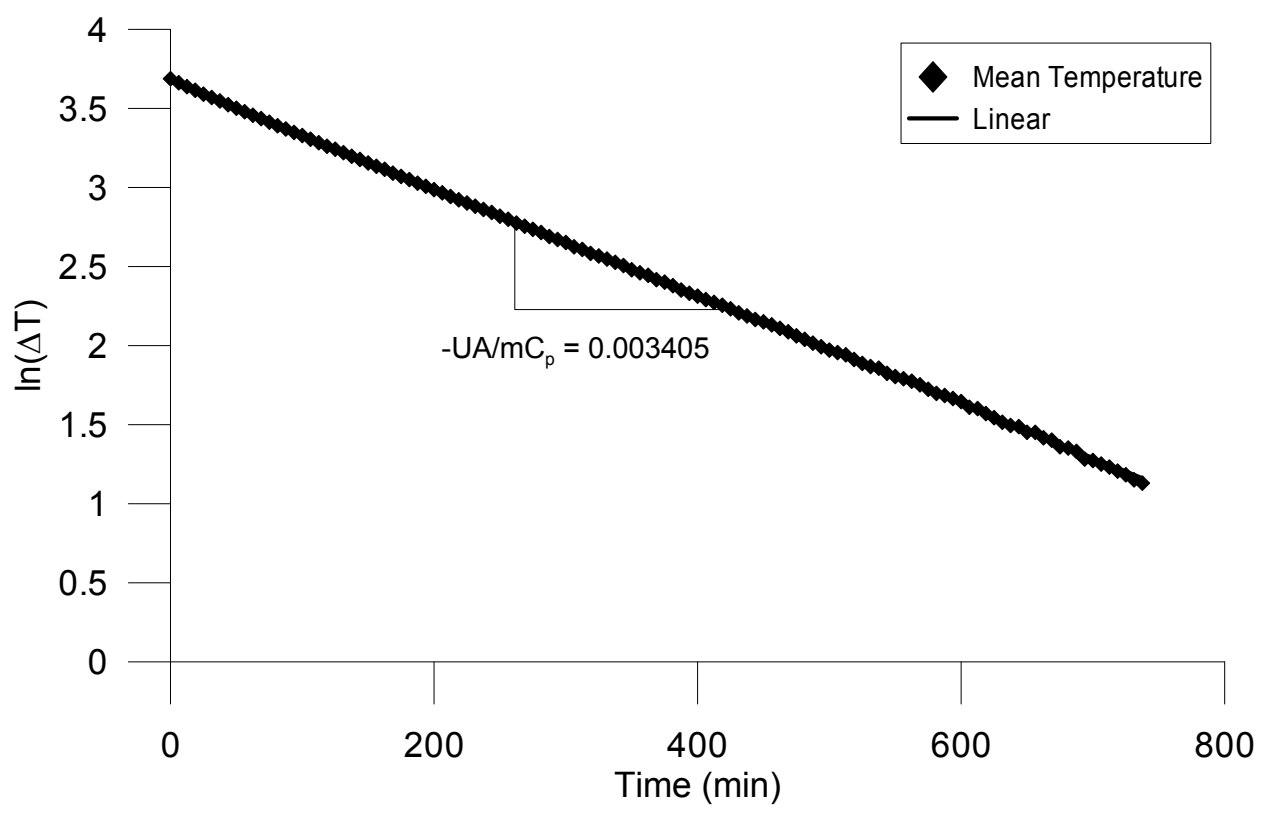

Figure 5.15: Second run of aluminum cylinder cooling. 


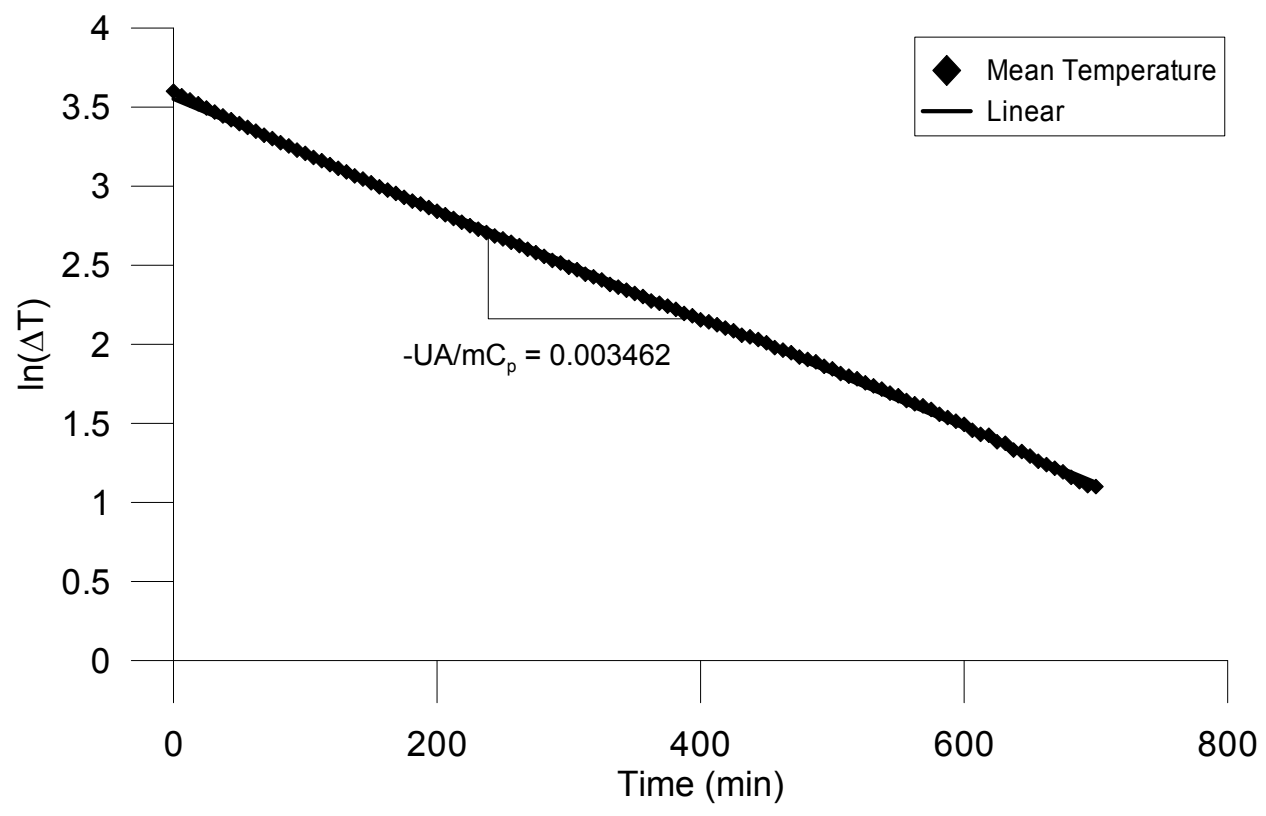

Figure 5.16: Third run of aluminum cylinder cooling.

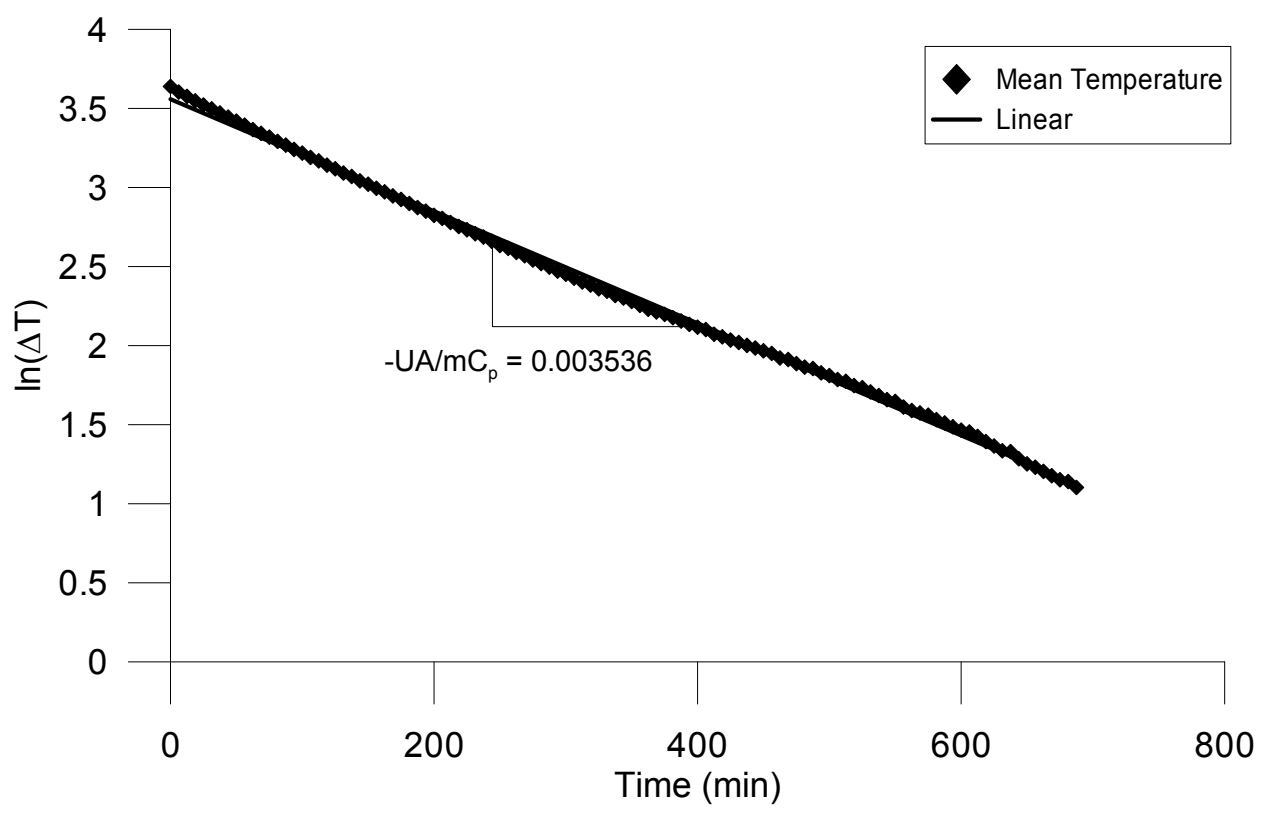

Figure 5.17: First run of battery cooling. 


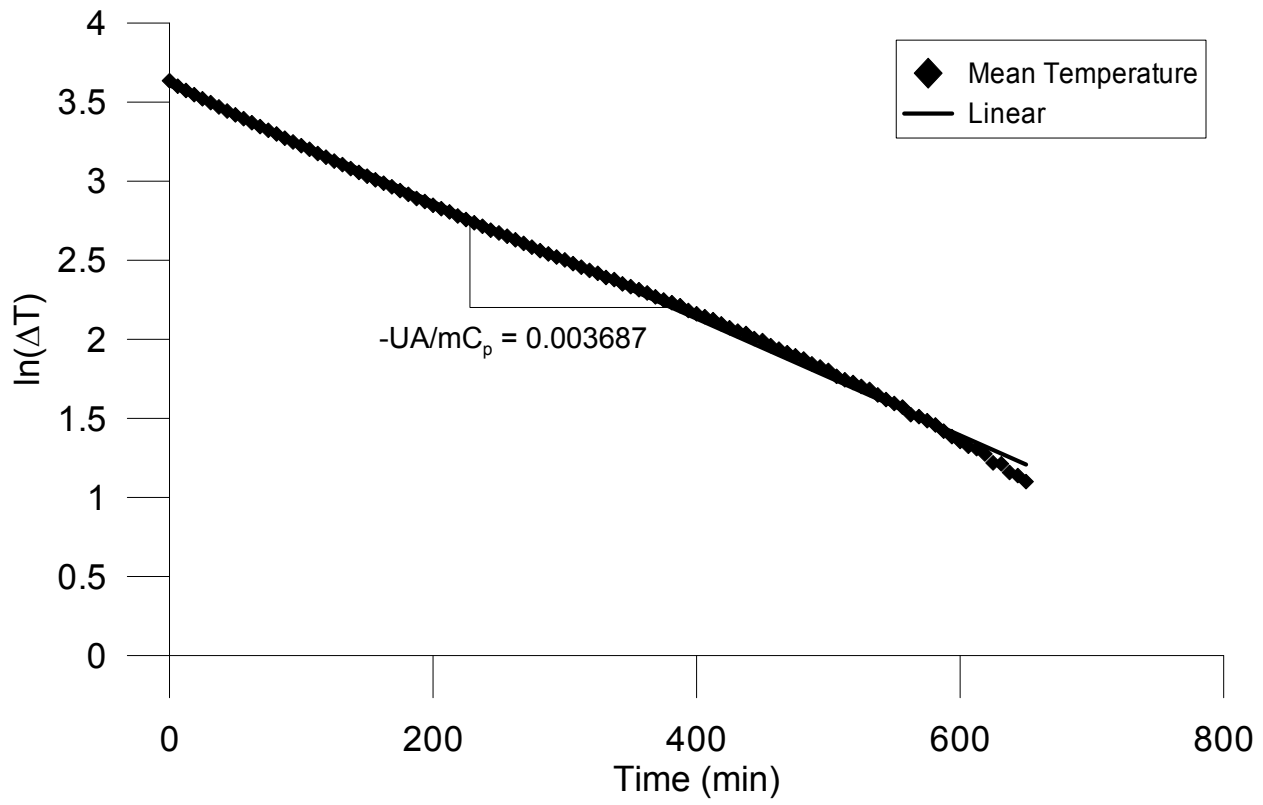

Figure 5.18: Second run of battery cooling.

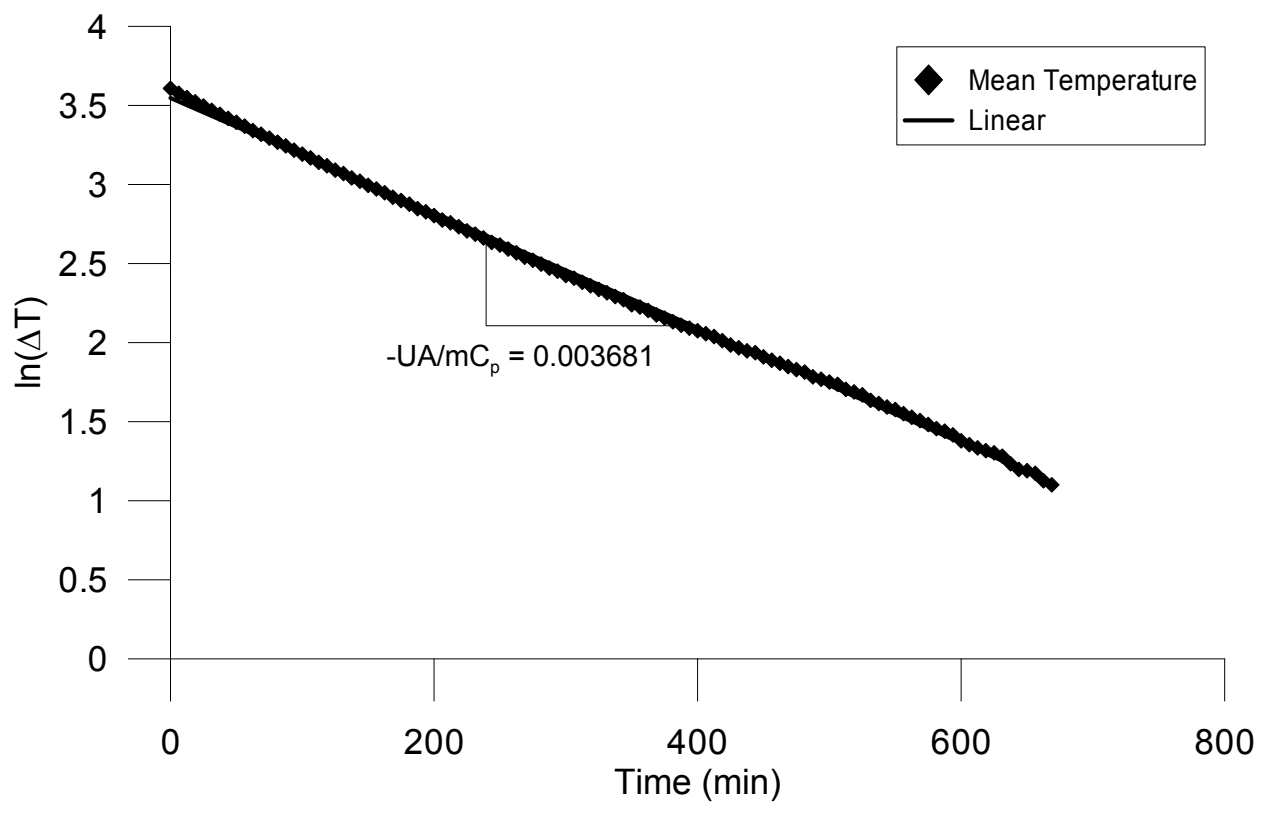

Figure 5.19: Third run of battery cooling. 


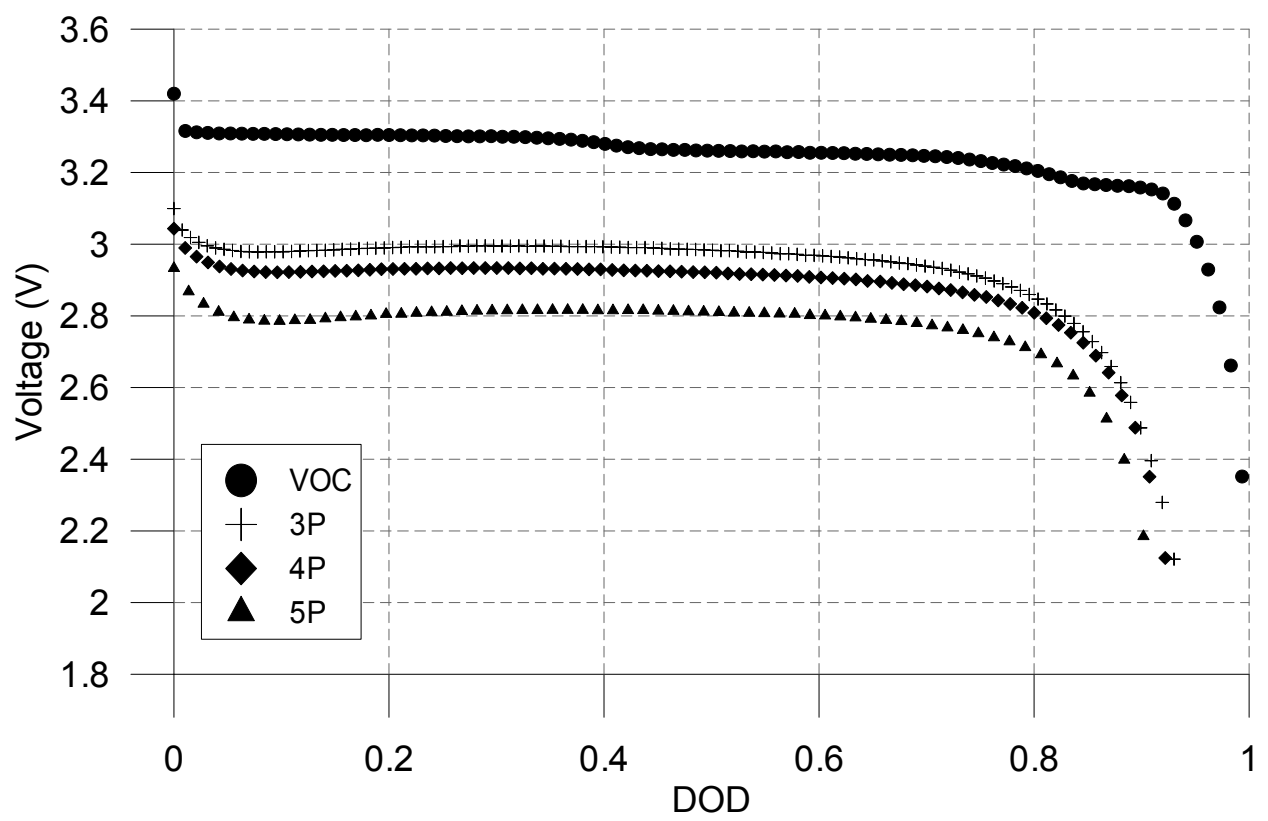

Figure 5.20: Battery voltage during constant power discharges and opencircuit voltage approximation.

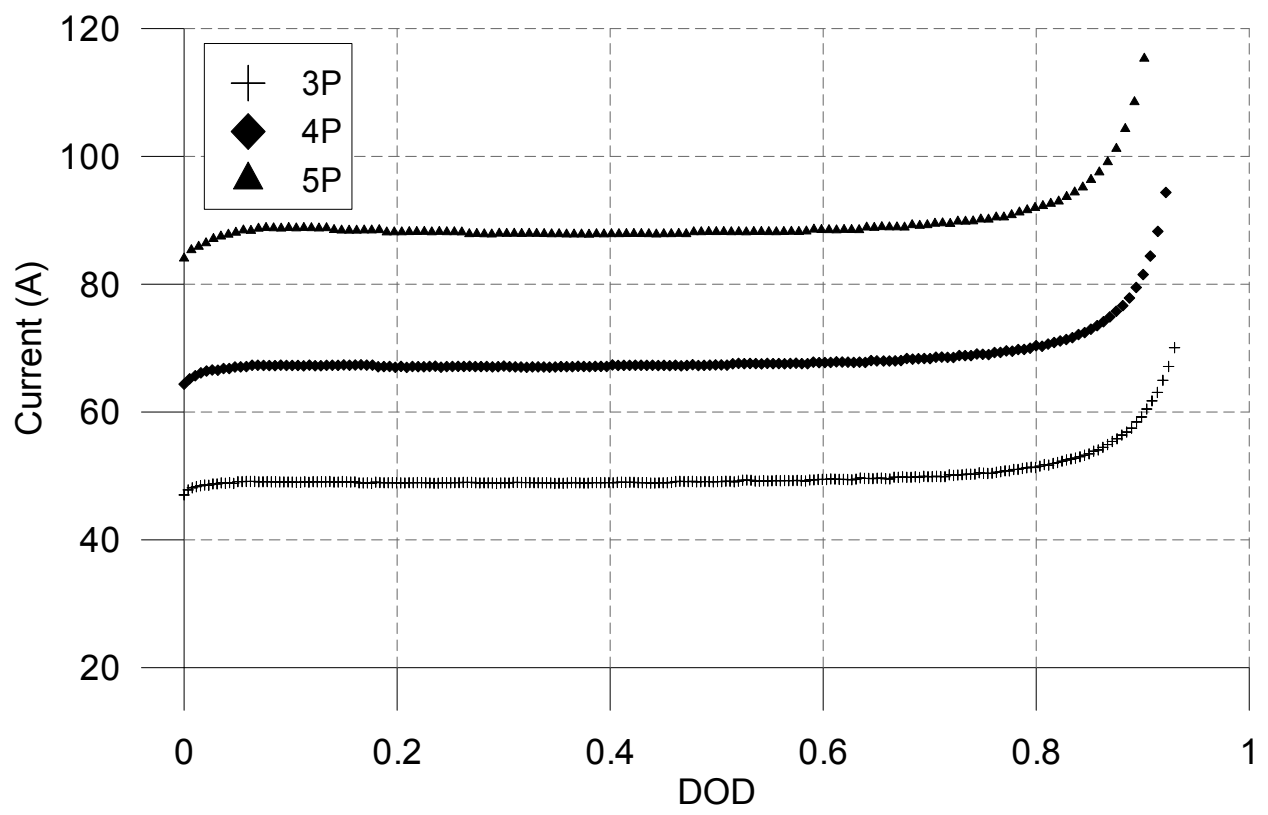

Figure 5.21: Battery current during constant power discharges. 
Table 5.2: Constant power discharge rates.

\begin{tabular}{lll}
\hline Battery Power $(\mathbf{W})$ & P-Rate & Number of runs \\
\hline 144 & $3 P$ & 3 \\
192 & $4 P$ & 3 \\
240 & $5 P$ & 3 \\
\hline
\end{tabular}

\subsubsection{Heat Generation Rates - Experimental Method}

Heat generation rates of a single battery cell were determined by performing constant power discharges of the battery at three different power levels. Plots of measured voltage and current as a function of depth of discharge (DOD) are shown in Figures 5.20 and 5.21. Two T-type thermocouples were placed on the battery and one was placed in air three feet away, as described for the previous experiments. Temperatures, voltage, and current were recorded every five seconds during each discharge experiment. In each case, heat generation rates of the battery were determined using Equation 5.2 with the previously determined $U A$ and battery heat capacity value. The heat generation rates for each discharge power level are shown in Figure 5.23. The total heat generated during each run was calculated by integrating the heat generation rate with respect to time. The highest constant power discharge rate of $5 P$, or $240 \mathrm{~W}$, was chosen to represent the maximum expected current draw, about $85 \mathrm{~A}$, required by the robotic vehicle during service. This is the power level used for subsequent simulations of the battery pack temperatures during vehicle operation.

\subsubsection{Heat Generation Rates - Entropy Method}

The theoretical heat generation rates of the battery, can be determined from Equation 5.4. The first term on the right side of Equation 5.4 represents the heat generated from ohmic heating due to current passing through internal resistance as well as other irreversible effects. The open-circuit voltage was measured as a function 


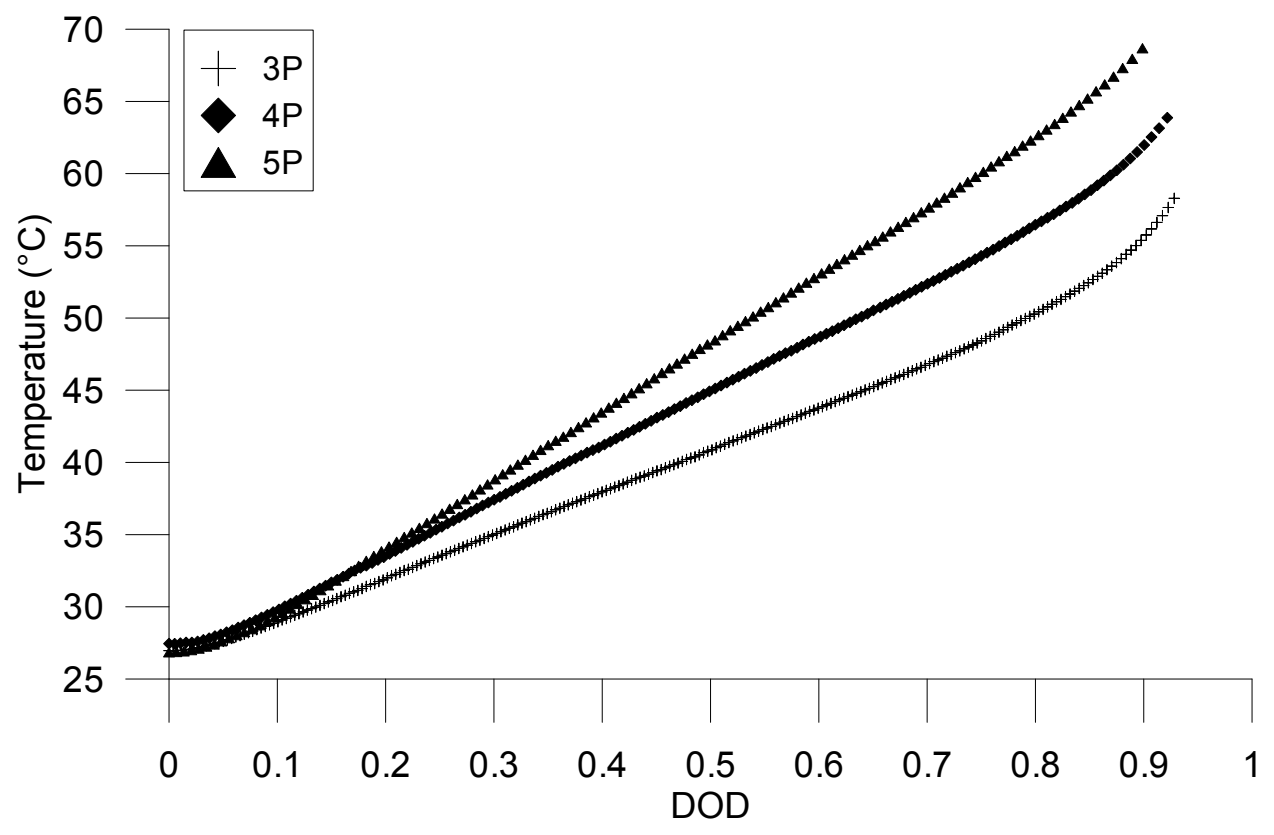

Figure 5.22: Temperature $\left({ }^{\circ} \mathrm{C}\right)$ of battery during one discharge test at each power level.

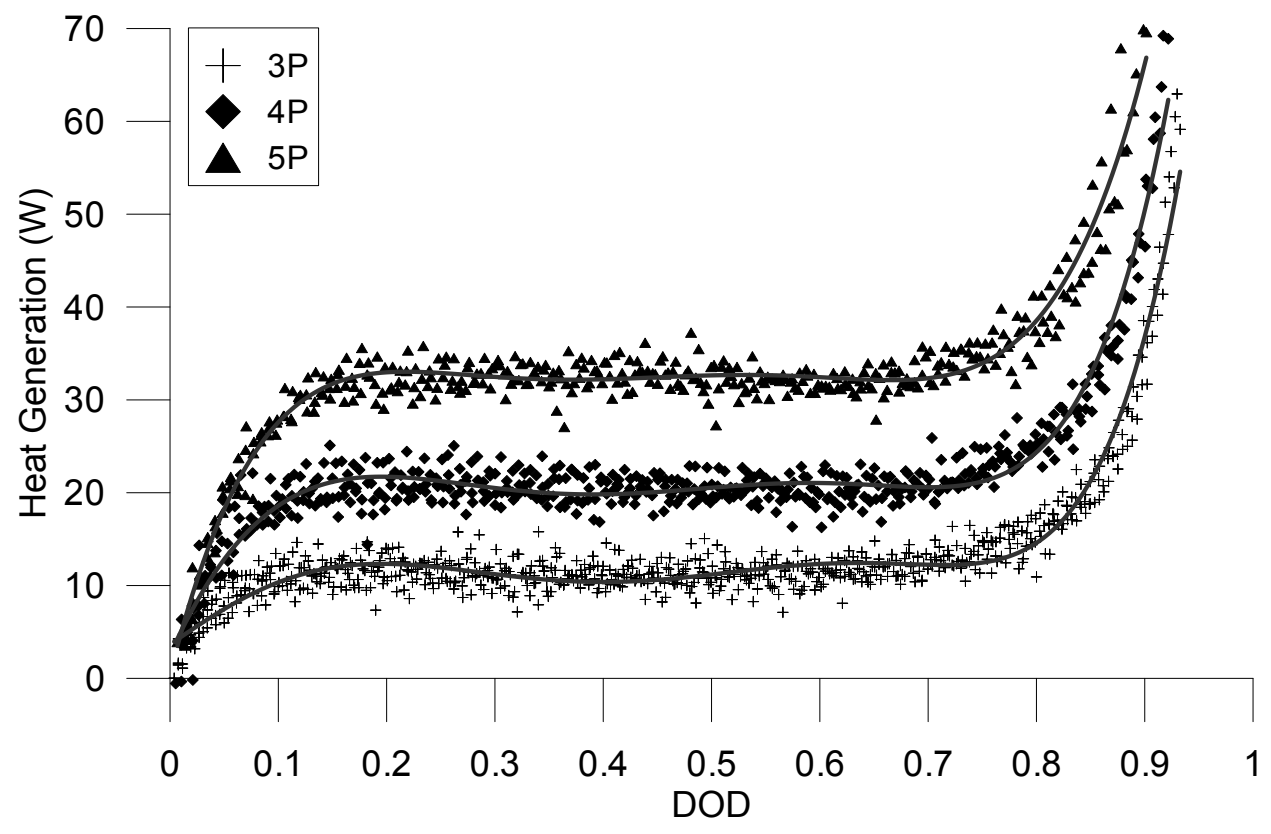

Figure 5.23: Heat generation rates (W) for all constant power discharge runs. 


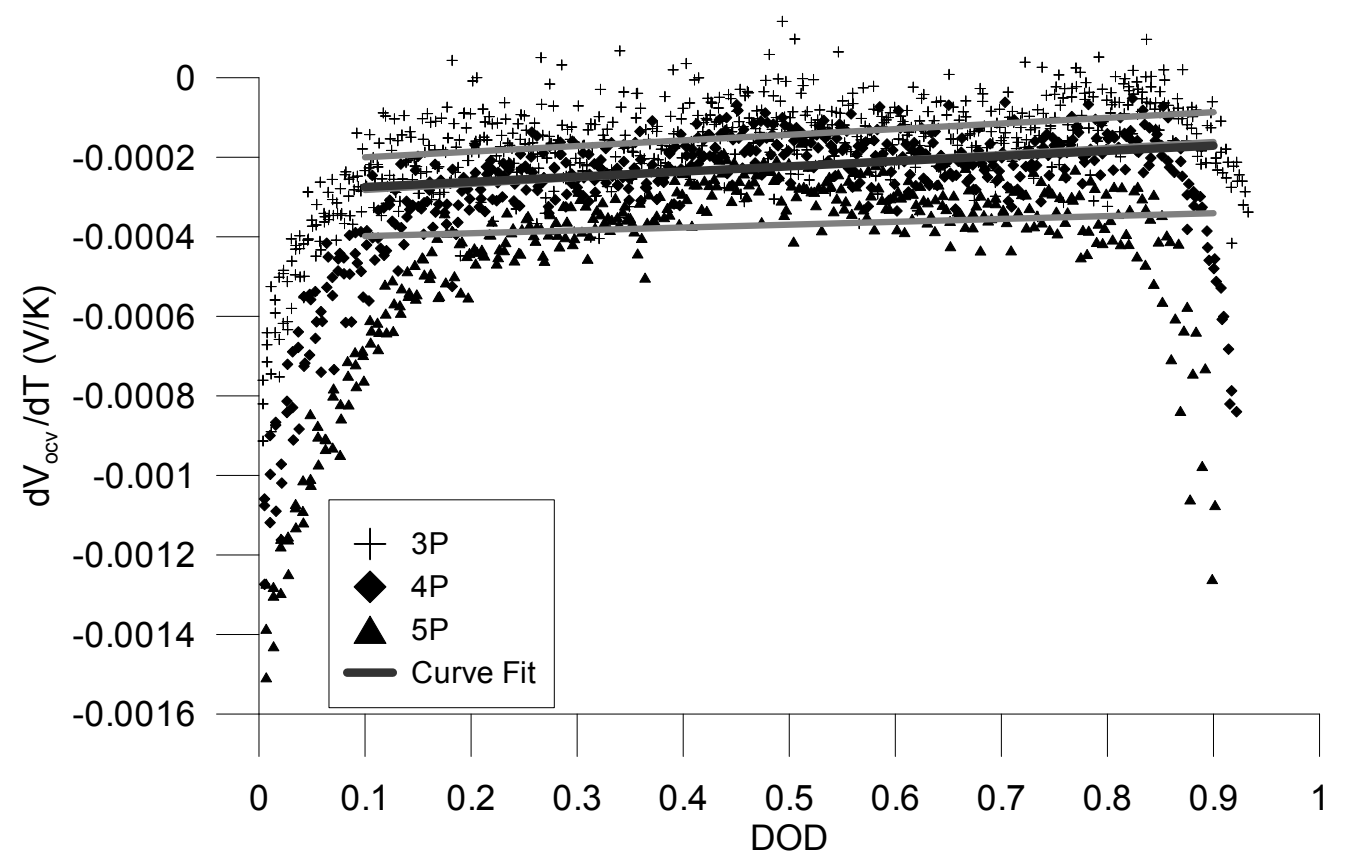

Figure 5.24: Entropy coefficient estimated from heat generation rates and battery discharge characteristics.

of depth of discharge by discharging the battery at a slow constant current rate of $C / 24$. The second term on the right side of the equation is heat generated, or consumed, by the reversible entropy change from electrochemical reactions. The relative contribution of the reversible heat generation term is expected to be lower at high charge and discharge rates [16, 20].

$$
\dot{q}_{g e n}=I\left(V_{o c v}-V_{o p}\right)-I T \frac{d V_{o c v}}{d T}
$$

The entropy coefficient of the battery, shown in Figure 5.24, was determined using the measured discharge characteristics from each run. The entropy coefficient was modeled as a linear fit of all heat generation data points between the 0.1 and 0.9 depth of discharge. The dark grey line shows the linear fit for all of the trials for all $P$ rates. Each light grey line shows the linear fit for all three trials from each respective $P$-rate. The entropy coefficient curve fit was used with Equation 5.4 to calculate the theoretical heat generation rates. A comparison of experimentally measured and 
Table 5.3: Results of calibration and heat capacity experiments.

\begin{tabular}{llllll}
\hline Material & $\begin{array}{l}\text { Mass } \\
(\mathbf{k g})\end{array}$ & $\begin{array}{l}\text { Specific } \\
\text { Heat } \\
(\mathbf{J} / \mathbf{k g K})\end{array}$ & $\begin{array}{l}U A / m C_{p} \\
(\mathbf{1} / \mathbf{m i n})\end{array}$ & $\begin{array}{l}\text { Standard } \\
\text { Error } \\
(\mathbf{1} / \mathbf{m i n})\end{array}$ & $U A(\mathbf{W} / \mathbf{K})$ \\
\hline Copper & 1.7562 & 386 & $2.59 \mathrm{E}-3$ & $\pm 2.50 \mathrm{E}-5$ & $0.0293 \pm 0.0002$ \\
Aluminum & 0.5344 & 896 & $3.41 \mathrm{E}-3$ & $\pm 2.63 \mathrm{E}-5$ & $0.0272 \pm 0.0003$ \\
Battery & 0.4936 & $950 \pm 20$ & $3.62 \mathrm{E}-3$ & $\pm 4.41 \mathrm{E}-5$ & $0.0283 \pm 0.0005$ \\
\hline
\end{tabular}

predicted heat generation rates is shown in Figure 5.25. It can be seen that there is good general agreement between the predicted and measured rates. Note that for each constant-power discharge, there is a dramatic increase in the heat generation rate at the end of the battery discharge. This arises from the drop in operating voltage and related increase in current at the end of each constant power discharge.

\subsubsection{Uncertainty}

The uncertainty in the calibration slopes and $U A$ values was reported as the standard error of the mean defined by Equation 5.5.

$$
S_{\bar{x}}=\frac{\sigma_{x}}{\sqrt{n}}
$$

Where $S, \sigma$, and $n$ represent the standard error in measuring the mean, the standard deviation, and the number of trials respectively. The uncertainty in the $U A$ value propagated to the uncertainty in the battery heat capacity following Gaussian error propagation as shown in Equation 5.6.

$$
S_{\overline{m C_{p}}}=m C_{p} \sqrt{\left(\frac{S_{\overline{U A}}}{U A}\right)^{2}+\left(\frac{S_{\overline{\text { Slope }}}}{\text { Slope }}\right)^{2}}
$$




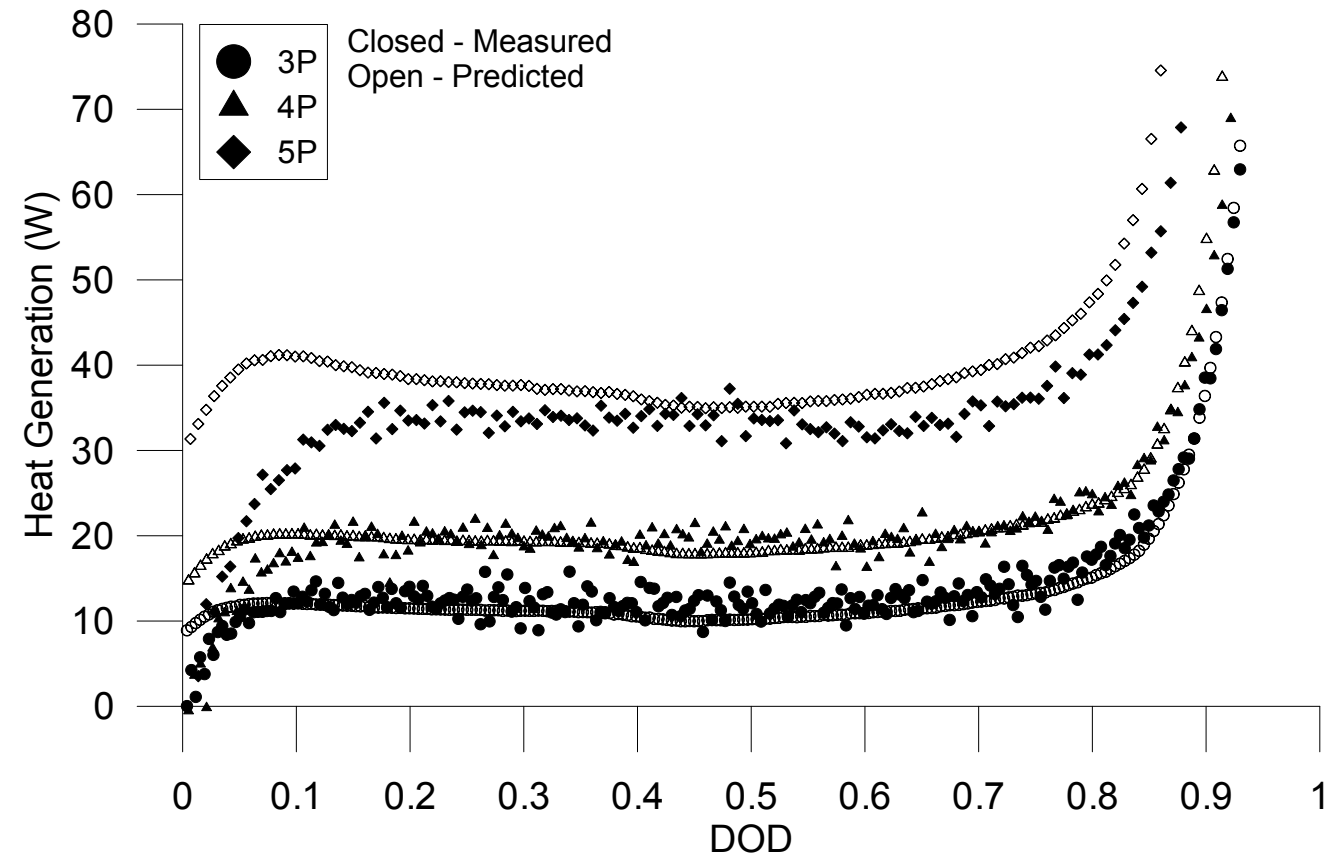

Figure 5.25: Comparison of measured and predicted heat generation rates $(\mathrm{W})$.

Table 5.4: Heat generation during constant power discharges.

\begin{tabular}{llll}
\hline$P$-rate & Average Heat Gen. $(\mathbf{W})$ & \multicolumn{2}{c}{ Heat Generated $(\mathbf{W h})$} \\
\cline { 3 - 4 } & & Measured & Predicted \\
\hline $3 P$ & 14.21 & 4.42 & 4.49 \\
$4 P$ & 20.86 & 5.55 & 5.46 \\
$5 P$ & 31.97 & 6.56 & 7.48 \\
\hline
\end{tabular}




\section{Chapter 6}

\section{Computational Fluid Dynamics Model}

\subsection{Model Development}

Fifteen cylindrical batteries measuring 0.040 meters in diameter and 0.152 meters in height were packed, as shown in Figure 1.1, in a closed aluminum box with a small air gap along the sides of the enclosure. There are small air gaps between each battery along their heights in the center portion of the box. The batteries were mounted vertically and held in place at both their base and cap by two 1.73 centimeter thick plastic spacer frames. The enclosure was fabricated from aluminum with a uniform convection boundary condition applied to the exterior walls. The entire enclosure is 0.41 meters in length, 0.13 meters in width, and 0.20 meters in height. Figures 1.1 and 6.1 show the dimensions of each component in the pack.

A model geometry of the pack was developed in SolidWorks and imported into ANSYS ICEM. Component geometry was modeled in SolidWorks since it provides better tools for part dimensioning. The assembly was saved as a step file type and imported 


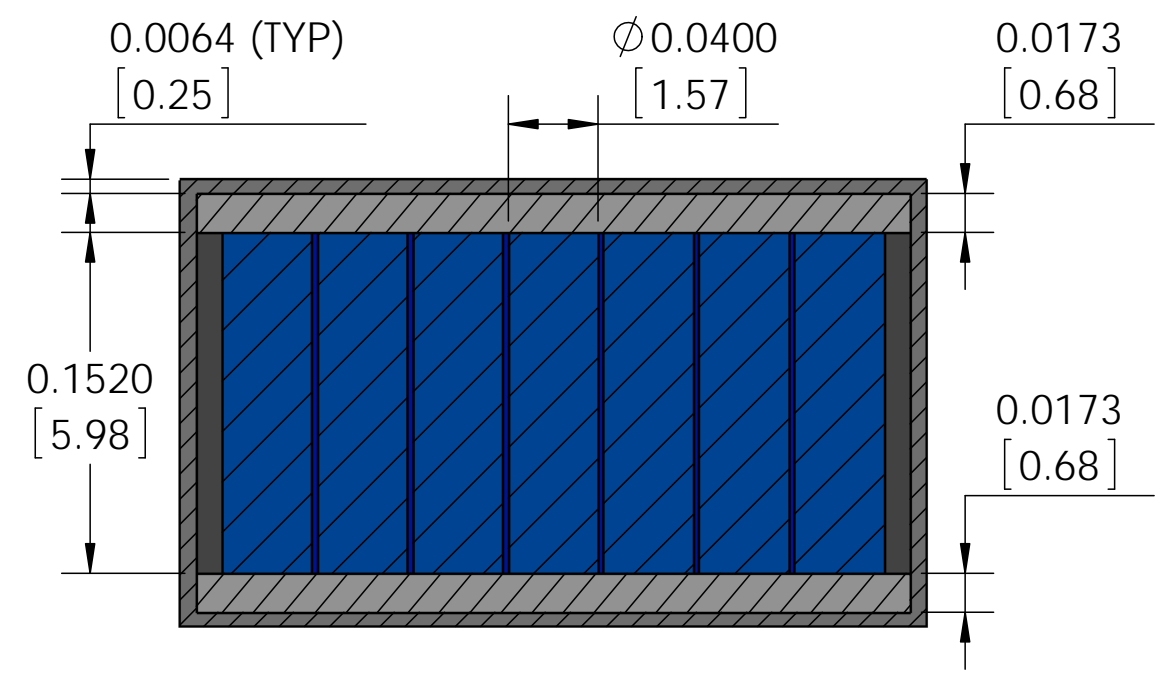

Figure 6.1: Dimensioned front section view of battery pack. Dimensions in meters [inches].

to ANSYS ICEM where it was meshed using an unstructured tetrahedral mesh. The resulting file was then imported to ANSYS Fluent were the remaining aspects of the model were developed. The air inside the battery pack is completely sealed off from the outside environment and natural convection is induced by buoyancy-driven flow.

The Rayleigh number for flow in vertical cavities, given in Equation 6.3, is based on the air gap horizontal length, the temperature difference between the two walls, and the fluid properties. The transition to turbulence for buoyancy-driven flows typically occurs over the range of Rayleigh numbers from $10^{8}$ to $10^{10}$ [23]. Flows with Rayleigh numbers below 1000 are considered to have weak buoyancy-driven flows with little advection. Therefore heat transfer is primarily by conduction and radiation across the medium. In the present case, using the maximum gap length and maximum expected temperature difference between the walls after 630 seconds at the $5 P$ power load, the Rayleigh number is well below the critical Rayleigh number for transition to turbulence and above the Rayleigh number for neglecting advection. This justifies a laminar viscous model and requires the heat transfer effects of advection to be accounted for. 


\begin{tabular}{cl} 
Table 6.1: Radiation & material properties. \\
\cline { 2 - 2 } Material & Emissivity \\
\hline Aluminum & 0.90 \\
Battery & 0.92 \\
Plastic & 0.84 \\
\hline
\end{tabular}

The Fluent model was setup so that the energy equation was enabled to calculate heat transfer within the model. Radiation heat transfer between the batteries and enclosure was accounted for by enabling the surface-to-surface radiation model. This accounted for the radiation exchange in the enclosure of gray-diffuse surfaces by calculating a view factor for each internal surface. This model assumed that all surfaces were grey and that any absorption, emission, or scatter of radiation by the air could be ignored. Emissivity properties were assigned to the internal walls of the enclosure, the plastic frames, and the batteries. The emissivity values of plastic and aluminum, shown in Table 6.1, were taken from F. P. Incropera et al. [10].

A Flir Thermacam SC300 infrared camera was used to measure the emissivity of the batteries. A piece of black electrical tape with a known emissivity of 0.97 was attached to the battery such that it had the same temperature as the battery. The camera was set to measure surface temperatures with an emissivity of 0.97 and the infrared radiation of the tape was compared to the radiation from the battery material. Figure 6.2 shows a typical infrared image of the battery. An emissivity of 0.92 was calculated for the battery coating material using this technique. Emissivity is a function of wavelength and temperature for any material. The emissivity value required by Fluent for the surface-to-surface radiation model should be a representative average of the varying emissivities for the material over all wavelengths. The infrared camera captures radiation over the 7.5 to 13 micrometer wavelength range. As such, the camera can detect a fraction of the radiation wavelengths being emitted by the battery. Wein's displacement law predicts that the wavelength of peak intensity at 


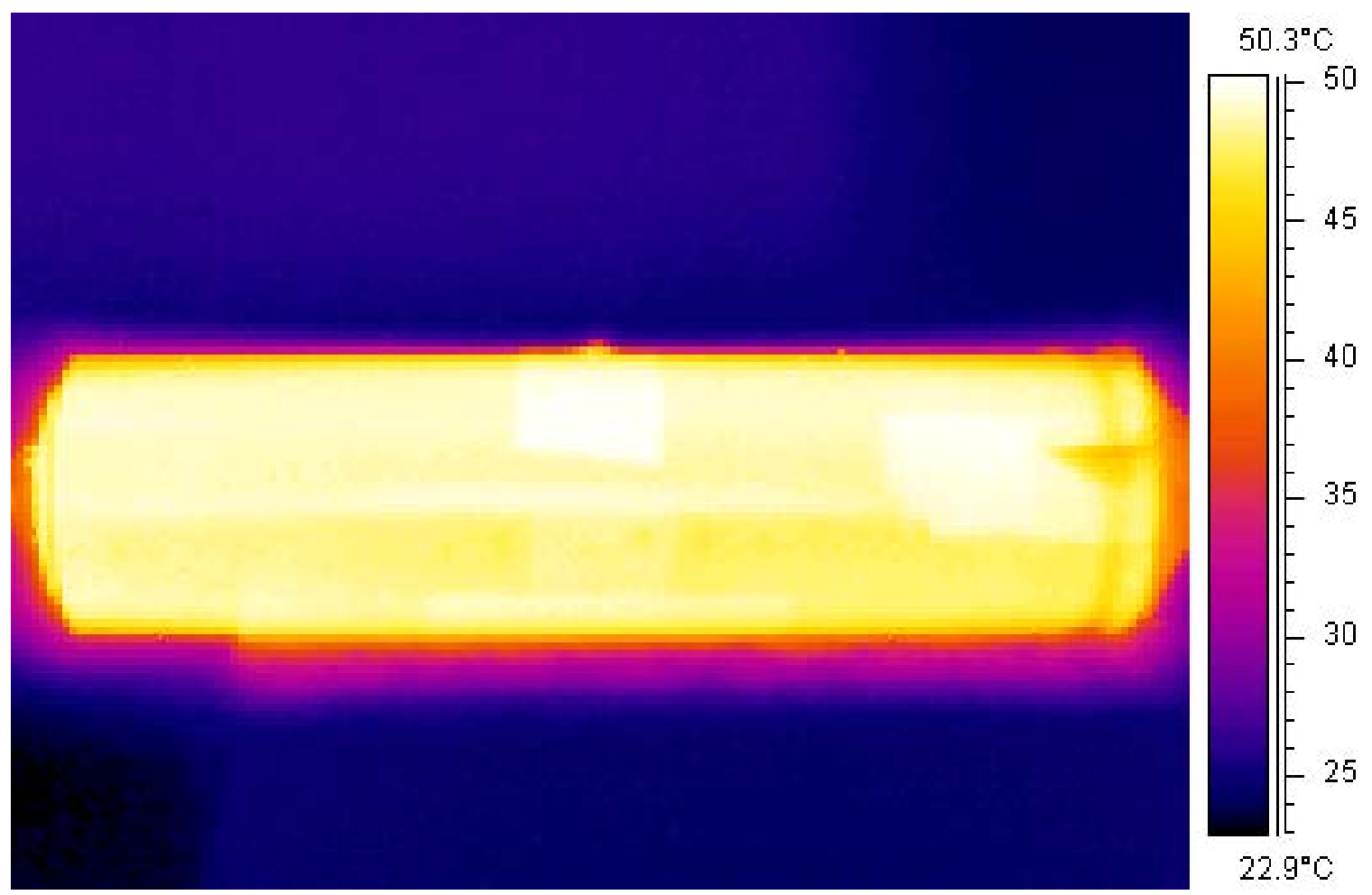

Figure 6.2: Infrared camera image of the heated battery.

a temperature of $60^{\circ} \mathrm{C}$ occurs at 8.7 micrometers which falls within the detectable range of the infrared camera. The result is an approximation for the emissivity of the battery using the detectable wavelengths and this emissivity is extended to apply to all wavelengths for the material.

Thermal properties of the batteries including specific heat, heat generation rates, and density were determined from the aforementioned experiments, while the thermal conductivity was taken from published literature [13]. The properties of each battery were assumed to be isotropic and homogeneous $[13,16]$. Table 6.2 shows the material properties for the batteries, aluminum, plastic, and air at $20^{\circ} \mathrm{C}$ [10]. In the present simulations, solid material properties were assumed to be constant, ignoring changes that occur with increasing temperature. Heat generation in the batteries was modeled as uniformly distributed $[13,4]$. The average of the experimentally measured heat generation rates for a $5 P$ discharge were divided by the volume of the battery to 
Table 6.2: Thermophysical properties for model materials.

\begin{tabular}{llllll}
\hline Material & $\begin{array}{l}\text { Density } \\
\left(\mathrm{kg} / \mathbf{m}^{3}\right)\end{array}$ & $\begin{array}{l}\text { Specific } \\
\text { Heat } \\
(\mathbf{J} / \mathbf{k g K})\end{array}$ & $\begin{array}{l}\text { Thermal } \\
\text { Conductivity } \\
(\mathbf{W} / \mathbf{m K})\end{array}$ & $\begin{array}{l}\text { Viscosity } \\
(\mathrm{kg} / \mathrm{ms})\end{array}$ & $\begin{array}{l}\text { Thermal } \\
\text { Expansion } \\
\text { Coeff. (1/K) }\end{array}$ \\
\hline Aluminum & 2700 & 896 & 167 & & \\
Battery & 2618 & 950 & 3 & & \\
Plastic & 1400 & 1050 & 0.16 & & \\
Air & 1.205 & 1005 & 0.0257 & $1.85 \mathrm{E}-05$ & 0.00343 \\
\hline
\end{tabular}

yield a curve for the average body heat flux load in $\mathrm{W} / \mathrm{m}^{3}$ over the discharge of the battery. A polynomial curve fit to the average heat generation rates was applied as a heat load to each battery in the simulation. The user-defined function for volumetric heat generation as a function of time is shown in Figure 6.3.

\subsection{Boundary and Initial Conditions}

A no-slip wall condition was imposed at the inner enclosure walls, battery walls, and plastic walls where the enclosed air comes in contact with a solid surface. At the start of the simulation all components of the system were initialized to atmospheric pressure and a temperature of $25^{\circ} \mathrm{C}$. The external free surfaces of the enclosure were given surface film boundary conditions to simulate free convection on the vertical and horizontal surfaces. The sink temperatures for the film boundary conditions were set to an ambient temperature of $25^{\circ} \mathrm{C}$. Convection coefficients were found using heat transfer correlations from F. P. Incropera et al. [10]. Though these coefficients vary with temperature, they were approximated as constant with a temperature difference of $5{ }^{\circ} \mathrm{C}$ from the ambient. The surface film approximates the convection of heat away from the battery pack as proportional to the temperature difference between the outside of the pack and the ambient. Convection coefficients determined from empirical correlations are shown in Table 6.3 and were calculated using Equations 6.2 


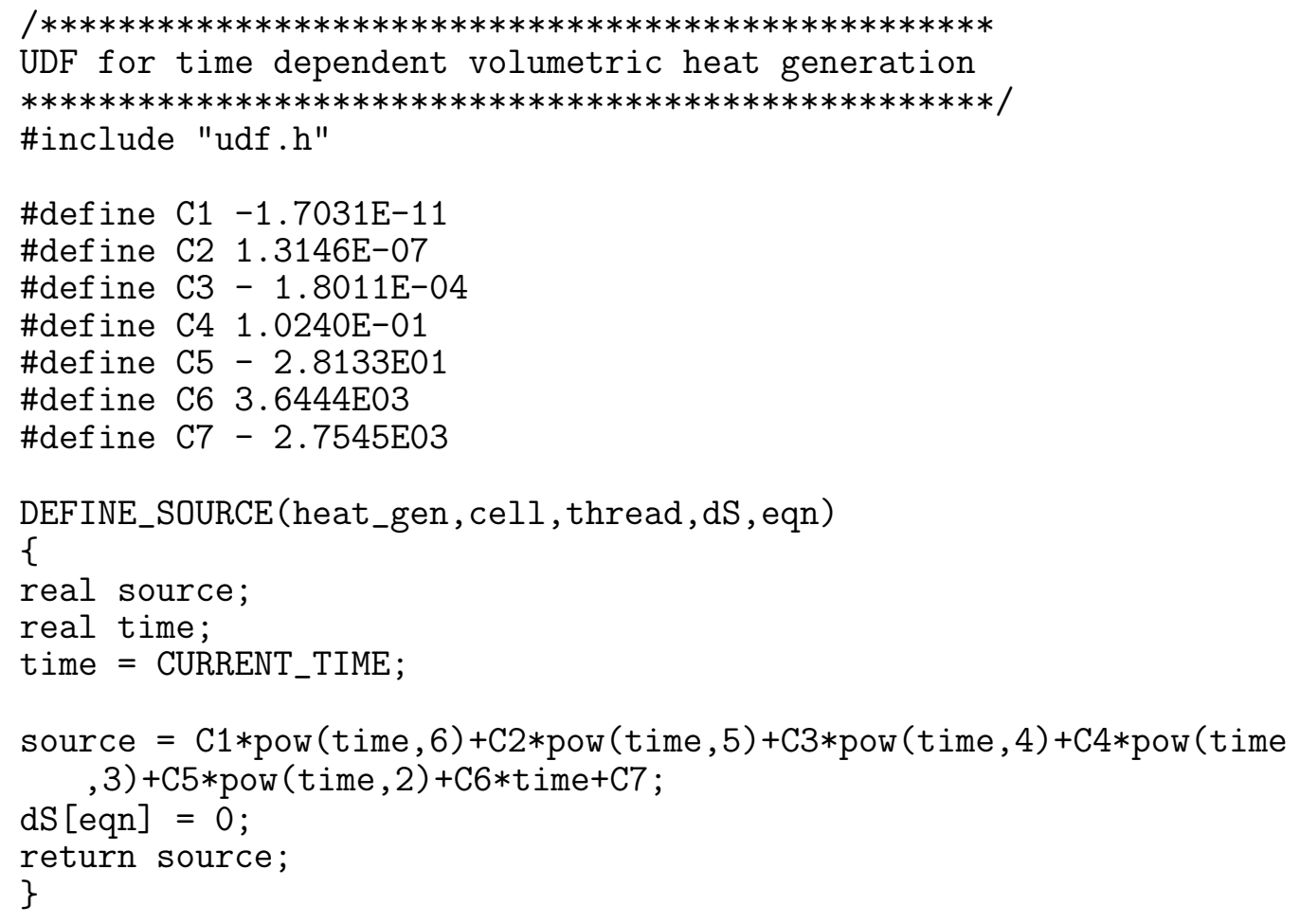

Figure 6.3: Fluent user-defined function for volumetric heat generation as a function of time from experiment results.

through 6.6. Dirt and debris are likely to settle on the pack, effectively adding a thin layer of insulation to the pack and reducing the heat convection to the ambient air. To be conservative, a smaller than predicted, uniform convection coefficient boundary condition of $2 \mathrm{~W} / \mathrm{m}^{2} \mathrm{~K}$ was applied to the exterior surfaces of the pack.

$$
\begin{gathered}
\alpha=\frac{k}{\rho c_{p}} \\
\overline{N u}_{L}=\frac{\bar{h} L}{k} \\
R a_{L}=\frac{g \beta\left(T_{1}-T_{2}\right) L^{3}}{\nu \alpha}
\end{gathered}
$$


Table 6.3: Convection film coefficients of the enclosure exterior.

\begin{tabular}{lll}
\hline Boundary Condition & Type & $\bar{h}\left(\mathbf{W} / \mathbf{m}^{2} \mathbf{K}\right)$ \\
\hline Convection Boundary 1 & Vertical Plate & 3.04 \\
Convection Boundary 2 & Horizontal Plate Bottom Hot & 4.77 \\
Convection Boundary 3 & Horizontal Plate Top Hot & 2.39 \\
\hline
\end{tabular}

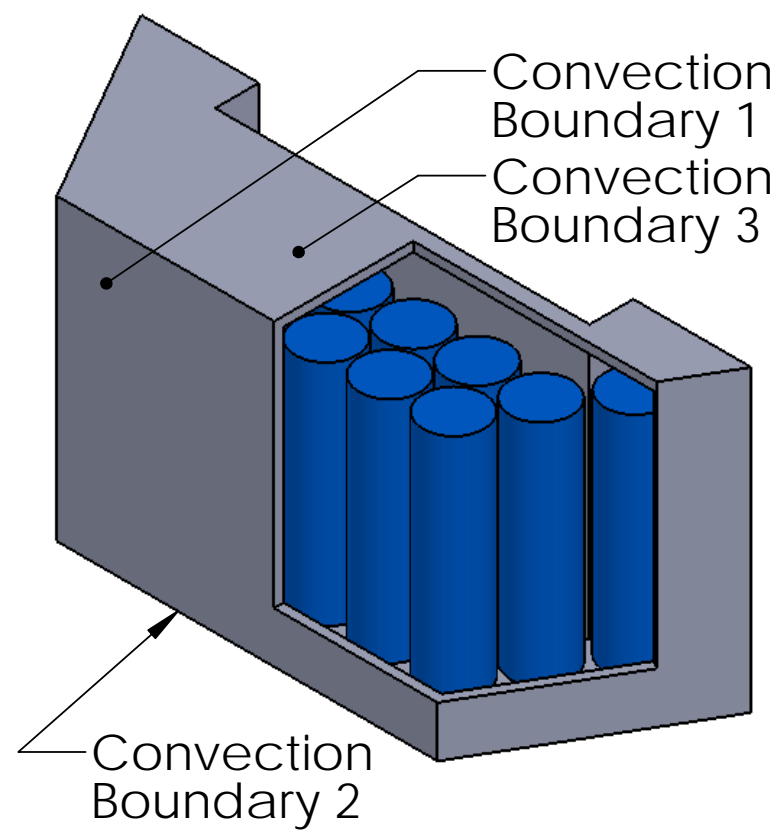

Figure 6.4: Isometric view of approximated boundary conditions.

Surface of Vertical Plate:

$$
\overline{N u}_{L}=.68+\frac{.670 R a_{L}^{1 / 4}}{\left[1+(.492 / P r)^{9 / 16}\right]^{4 / 9}} \quad\left(R a_{L} \leq 10^{9}\right)
$$

Top Surface of Hot Horizontal Plate:

$$
\overline{N u}_{L}=.54 R a_{L}^{1 / 4} \quad\left(10^{4} \leq R a_{L} \leq 10^{7}\right)
$$

Bottom Surface of Hot Horizontal Plate:

$$
\overline{N u}_{L}=.27 R a_{L}^{1 / 4} \quad\left(10^{5} \leq R a_{L} \leq 10^{10}\right)
$$




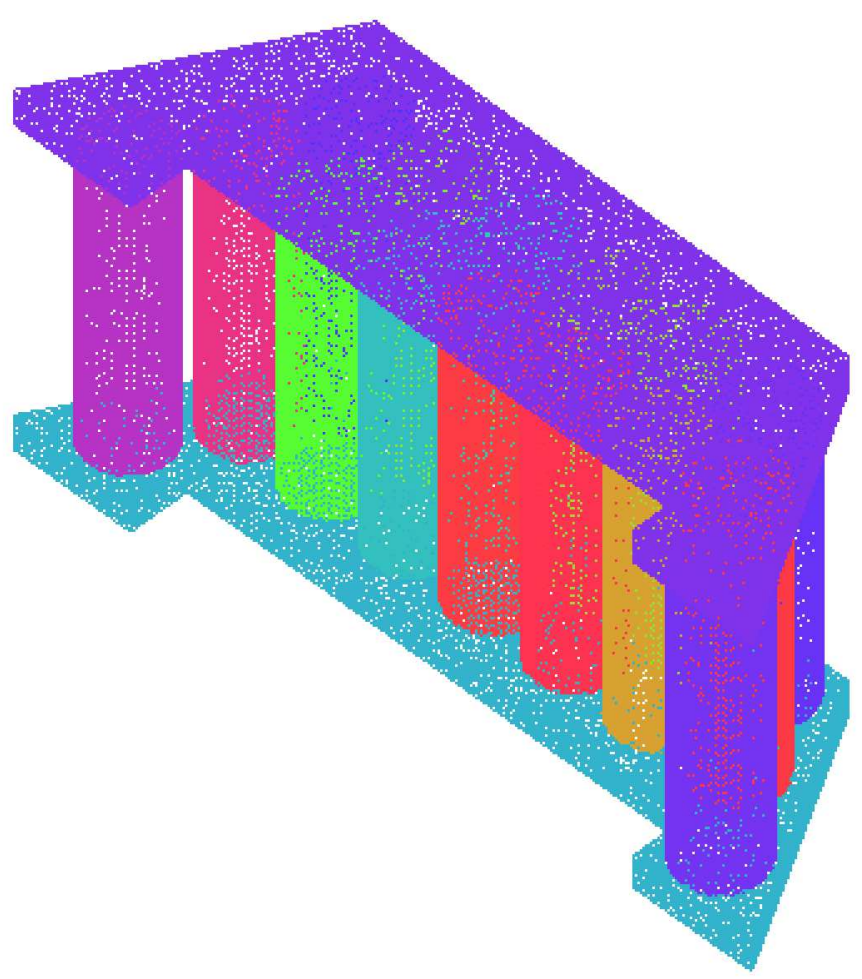

Figure 6.5: ANSYS ICEM mesh of batteries and plastic spacer frames. 6.3 Mesh Development

An unstructured mesh was generated for this study using 1,733,072 tetrahedral elements with a global maximum size measuring $4 \mathrm{~mm}$. Gravity is defined as downward in the negative y-direction in the model, corresponding to the bottom of the pack. The grid independence plot shown in Figure 6.6 illustrates that at a flow time of 630 seconds, the temperature at one point in the model converges to a specific value as the grid is refined. A $4 \mathrm{~mm}$ meter mesh spacing was chosen because it provided accurate results without substantially increasing the computational expense of the simulation. Tetrahedral elements were used throughout the entire model because they readily conform to the complex geometry of the components in the pack. 


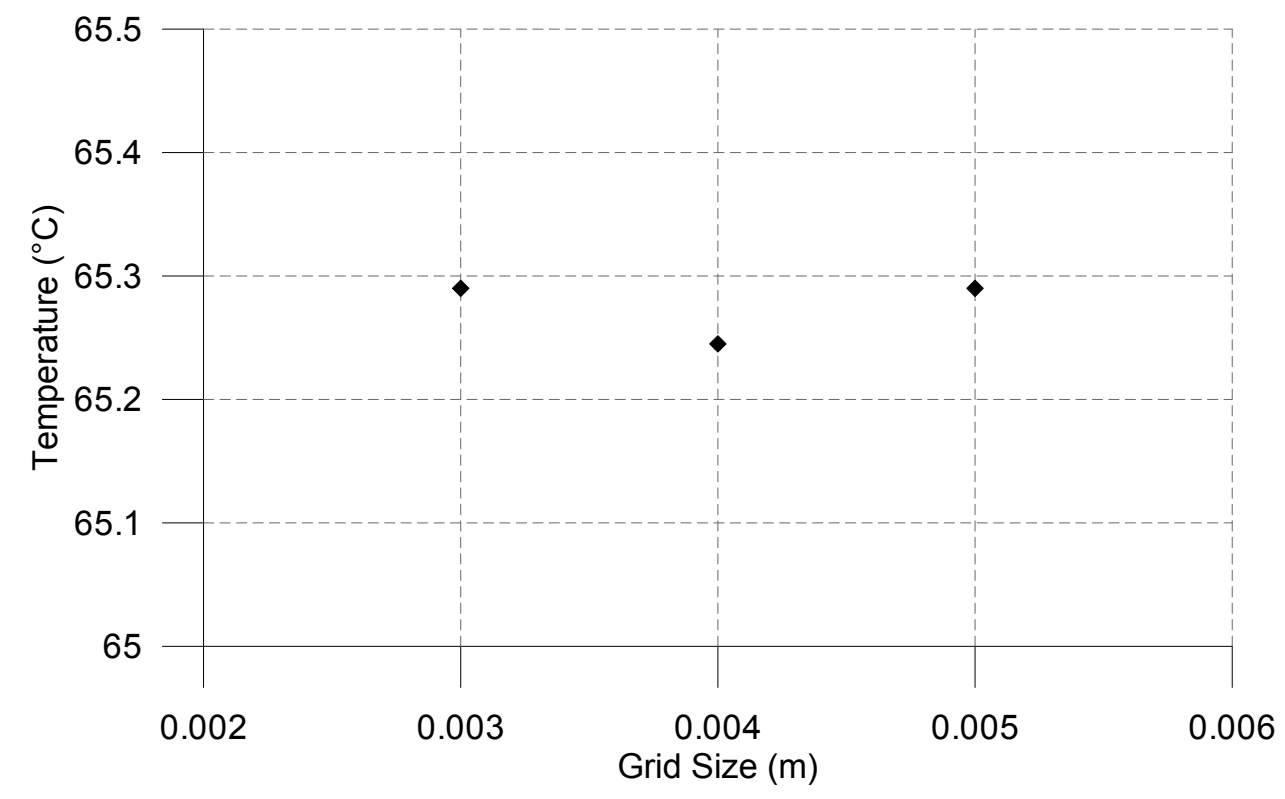

Figure 6.6: Grid independence plot of temperature $\left({ }^{\circ} \mathrm{C}\right)$ versus global mesh size $(\mathrm{m})$.

\subsection{Calculation Settings}

A transient analysis was required in the present case since the simulation only reached steady state long after the battery pack would be depleted. A fixed time step of 0.5 seconds was used to run a 630 second flow time study. This small time step ensured accuracy of the results and was based on the characteristic time of the modeled system. Due to slow heating in the battery as well as slow velocities in the air gap, larger time steps should also yield accurate results. A comparison of results using a 0.5 second time step and a 0.1 second time step showed negligible differences in the heat transfer rate and battery temperatures in the pack. All solution and model settings selected in Fluent are shown in Tables 6.4, 6.5, and 6.6. The Boussinesq approximation was used by setting the density of the air material to boussinesq in Fluent and assigning an operating density of $1.205 \mathrm{~kg} / \mathrm{m}^{3}$. The Boussinesq approximation neglects any changes in density of the fluid, except when the density terms appear multiplied by the gravity term. This leads to the conclusion that inertia dif- 
ferences are negligible while gravity is large enough to create a buoyancy-driven flow. The second-order upwind scheme was used for momentum, energy, and the transient formulation.

\begin{tabular}{ll} 
Table 6.4: General settings in Fluent \\
\hline Category & Option \\
\hline Velocity Formulation & Absolute \\
Time & Transient \\
Space & $3 \mathrm{D}$ \\
\hline
\end{tabular}

\begin{tabular}{ll} 
Table 6.5: Model settings in Fluent. \\
\hline Category & Option \\
\hline Energy & On \\
Viscous & Laminar \\
Radiation & S2S \\
\hline
\end{tabular}

Table 6.6: Solution method settings in Fluent.

\begin{tabular}{ll}
\hline Category & Option \\
\hline Pressure-Velocity Coupling & Pressure-Implicit with Splitting Operators (PISO) \\
Gradient Calculation & Least Squares Cell Based \\
Pressure Equation & Body Force Weighted, 0.5 Relaxation \\
Momentum Equation & Second Order Upwind, 0.5 Relaxation \\
Energy Equation & Second Order Upwind, 0.5 Relaxation \\
Transient Formulation & Second Order Implicit \\
& Non-Iterative Time Advancement (NITA) \\
\hline
\end{tabular}

\subsection{CFD Results}

The temperature distribution after 630 seconds at a $5 P$ discharge rate is shown in Figure 6.8. The batteries were initialized to a starting temperature of $25^{\circ} \mathrm{C}$ and were found to increase to $65.6^{\circ} \mathrm{C}$ in 630 seconds under a $5 P$ discharge. This exceeded the 
maximum design operating temperature of $60^{\circ} \mathrm{C}$ for these batteries. These elevated temperatures lead to degraded battery life and can create unsafe operating conditions. Figure 6.8 illustrates that the aluminum enclosure stayed at a relatively uniform and near ambient temperature throughout the battery discharge. This result is significant as it illustrates the lack of heat flow to the enclosure that would have transferred thermal energy away from the batteries.

Figure 6.10 shows an image of the buoyancy-driven flow in the pack, plotted as colored vectors. For the sake of clarity, the batteries are removed from this image. One can see a plume of hot air collecting at the top of the enclosure and relatively cooler air at the bottom. Additionally, as one would expect, this figure shows that the air rises along the battery walls and flows downward along the relatively cool inside walls of the enclosure. This forms thin convection cells along the enclosure walls with the air circling in the space at the top of the batteries and falling down as it cools from convection with the colder aluminum enclosure walls. Figure 6.12 shows that the vertical component of air speed is largest near the walls of the batteries and enclosure. In contrast, the center of the convection cell between the vertical walls is nearly stagnant. The columns of air between the two rows of batteries heat up similarly to the batteries due to close proximity with them.

Figure 6.13 illustrates that the temperature is relatively uniform along a horizontal line, perpendicular to the longitudinal axis of the batteries, through the center of the back row of batteries. This trend continues throughout the battery discharge with only small temperature gradients through the pack interior along the horizontal line. Figure 6.14 shows how the temperature changes with vertical position along the longitudinal axis of the middle back row battery. Significant temperature gradients appear over a short distance at the top and bottom of the pack, connected by a gentle concave-down temperature distribution between them. Maximum temperatures in the batteries occur at roughly the vertical midpoint of the pack, with relatively 


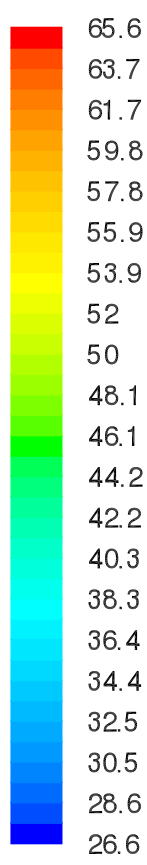

Figure 6.7: View of battery temperatures $\left({ }^{\circ} \mathrm{C}\right)$ after 630 seconds at $5 P$ rate.

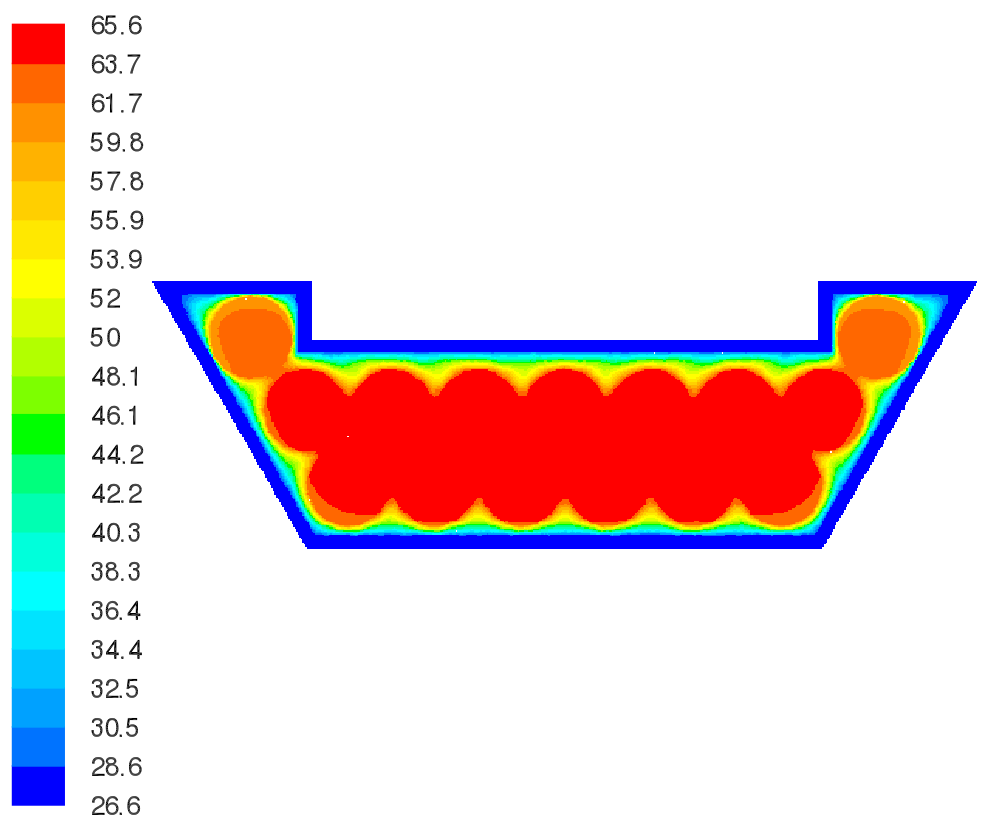

Figure 6.8: Section view of temperature $\left({ }^{\circ} \mathrm{C}\right)$ contours at vertical middle of battery pack after 630 seconds at $5 P$ discharge rate. 


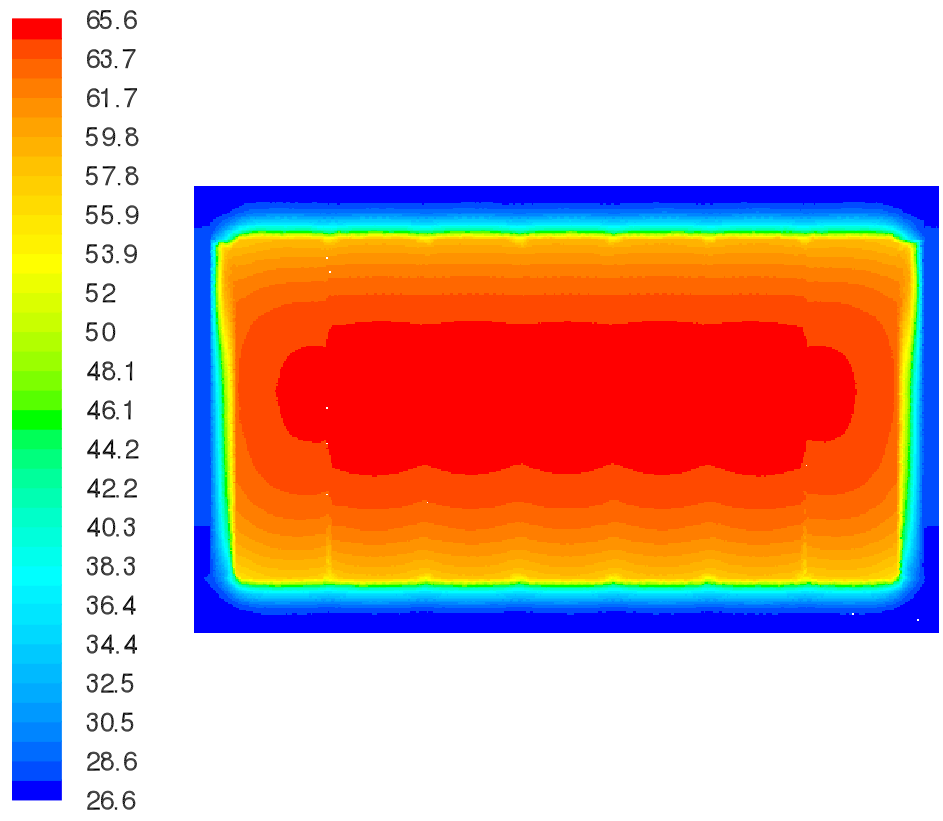

Figure 6.9: Front section view through center of front row of batteries showing temperature $\left({ }^{\circ} \mathrm{C}\right)$ contours at end of discharge at $5 P$ rate.

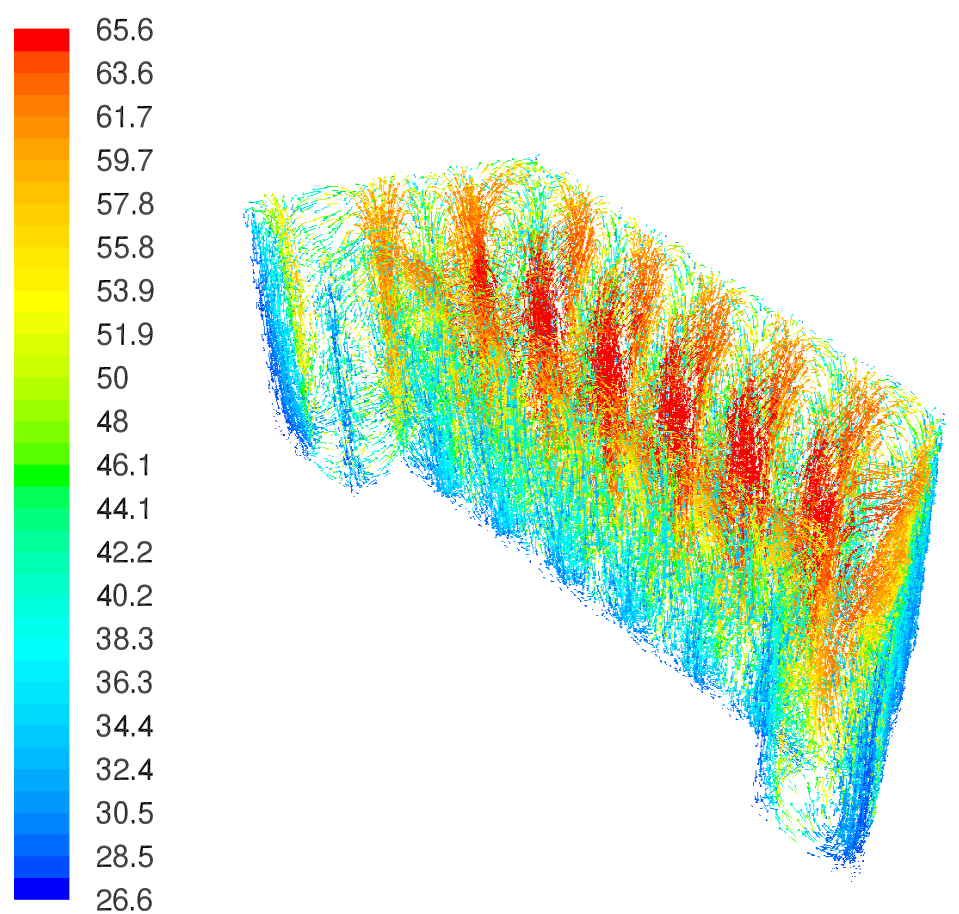

Figure 6.10: Isometric view of velocity vectors colored by temperature $\left({ }^{\circ} \mathrm{C}\right)$ for air in the enclosure after 630 seconds under $5 P$ load. 

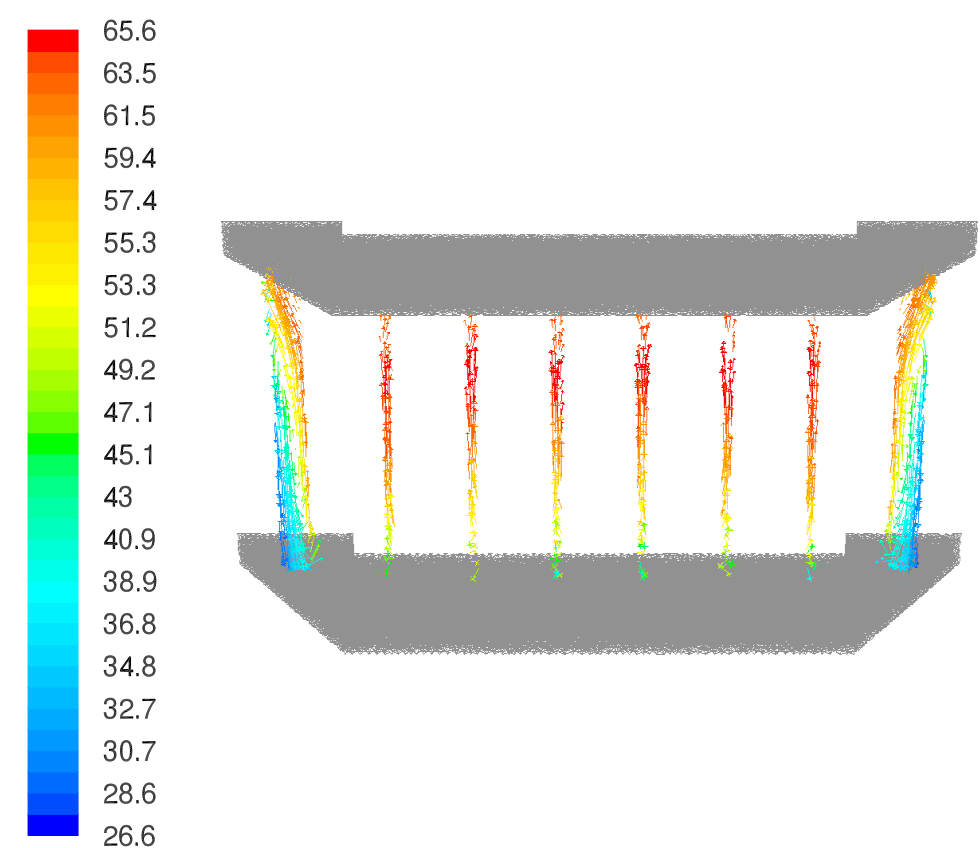

Figure 6.11: Vertical plane of velocity vectors colored by temperature $\left({ }^{\circ} \mathrm{C}\right)$ for air in the enclosure after 630 seconds at $5 P$.

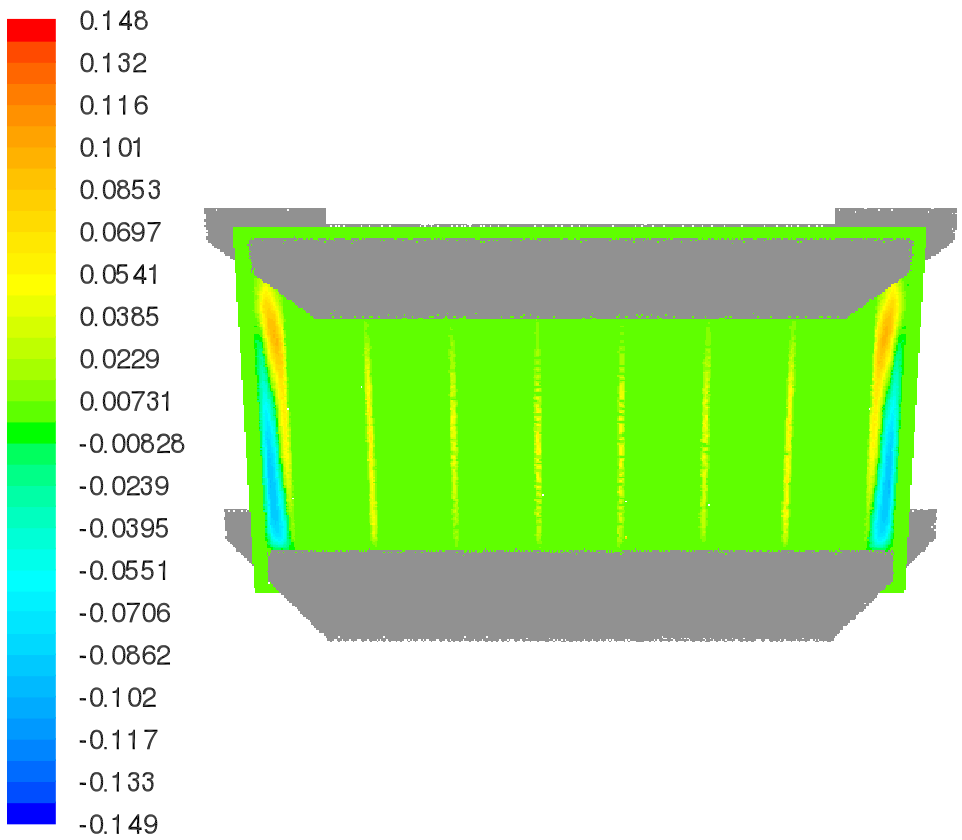

Figure 6.12: Contours of vertical component of velocity $(\mathrm{m} / \mathrm{s})$ for air in the enclosure after 630 seconds under $5 P$ discharge. 


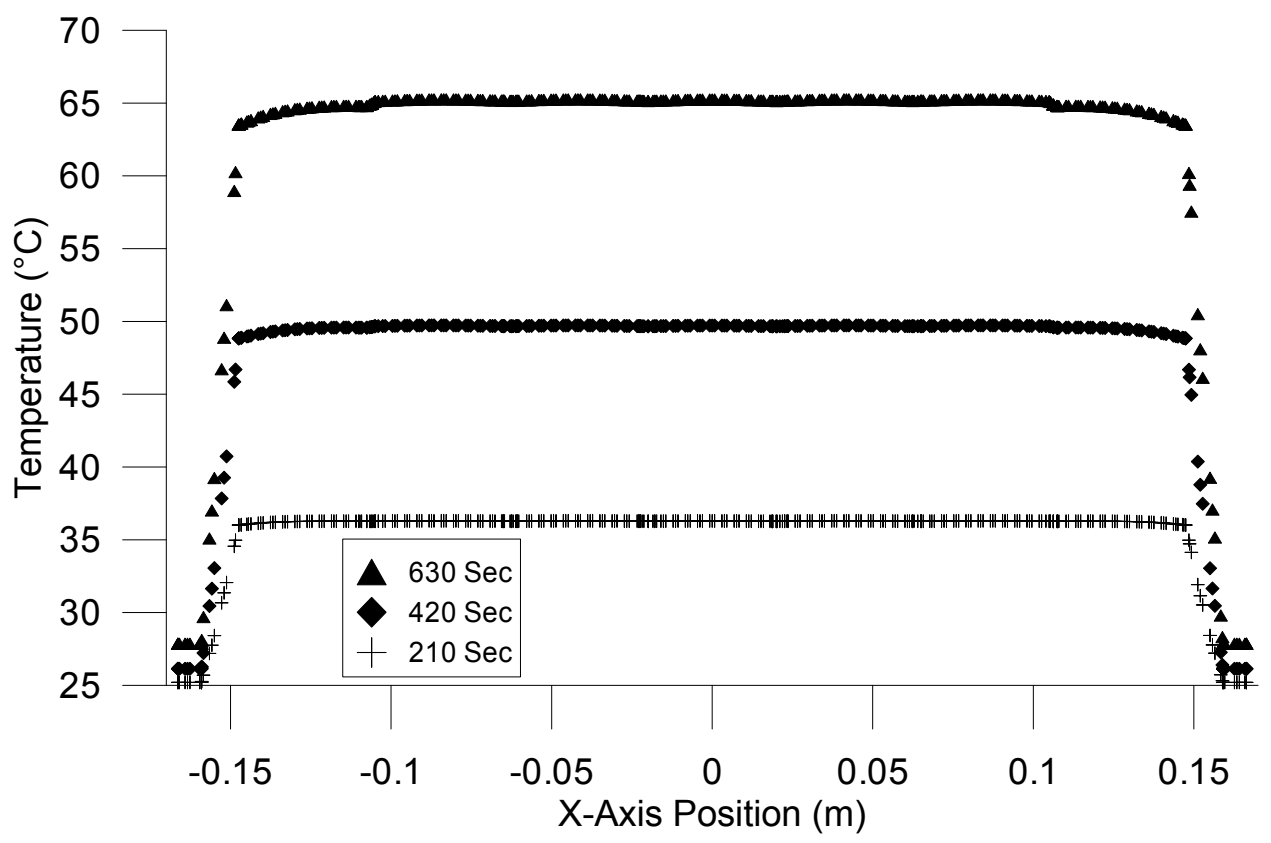

Figure 6.13: Temperature $\left({ }^{\circ} \mathrm{C}\right)$ evolution along horizontal axis through the center of the back row of batteries without PCM/EG.

milder temperatures at the top and bottom. Temperature through the center battery varies axially by over $7{ }^{\circ} \mathrm{C}$ after 630 seconds under $5 P$ loading. This temperature evolution plot also shows an increasing curvature in the mid-span temperatures as time progresses, indicating that axial temperature gradients increase with depth of discharge.

\subsection{Validation}

The CFD model was validated by comparing the surface temperature of the battery at the center of the pack to the experimentally measured surface temperature of the battery performing the same discharge profile while insulated by polyurethane. The temperature of the model followed the same trend and had a slightly smaller magnitude compared to the experimentally measured temperature. The temperature rise at the end of the simulation was $1.2^{\circ} \mathrm{C}$ smaller for the model surface than 


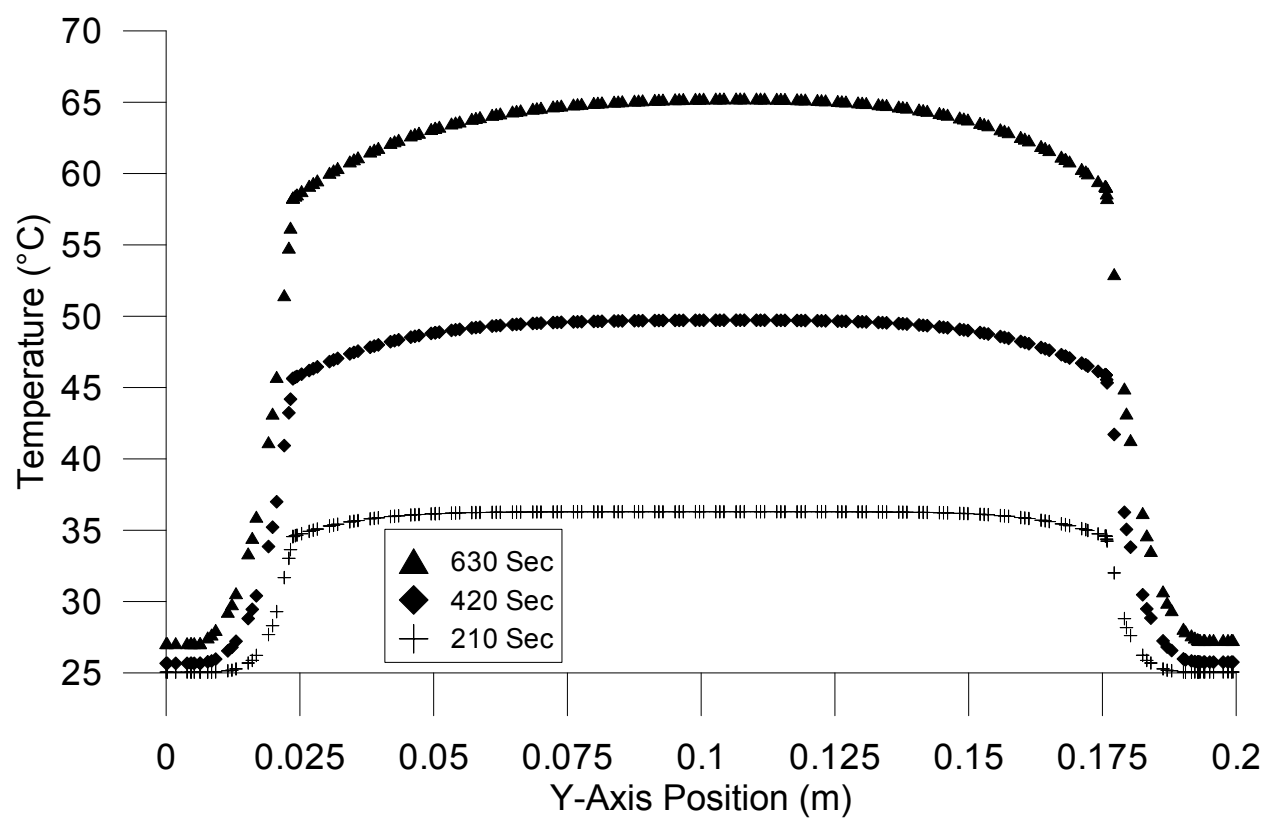

Figure 6.14: Temperature $\left({ }^{\circ} \mathrm{C}\right)$ evolution along longitudinal axis of the middle battery in the back row without PCM/EG.

the insulated experimentally measured surface. The results matched closely as expected since the modeled battery pack has near insulating conditions due to the close proximity of other batteries and the weak buoyancy-driven flow predicted by the low Rayleigh number. 


\section{Chapter 7}

\section{Phase Change Material and Expanded Graphite Model}

\subsection{Model Development}

Since the current pack design is not sufficient to protect the batteries from thermal damage during worst-case loading, a passive thermal management system was designed to exploit the energy absorption of a phase change material (PCM). Following pioneering work on the use of phase-change materials for thermal management in batteries $[13,2]$, a paraffin wax with an expanded graphite matrix was chosen for this study. This design for a passive cooling system allows the battery pack to be fully sealed from the environment without any intruding cooling elements [2].

High performing phase change materials are characterized by their high latent heat of fusion, but typically suffer from low thermal conductivity $[19,6]$. The thermal conductivity of the PCM has been improved by creating an expanded graphite (EG) matrix impregnated with a PCM $[18,7]$. This composite PCM/EG material combines the high specific latent heat of fusion of the PCM and the high thermal conductivity of 
the expanded graphite to create a highly thermally conductive and energy absorptive composite material.

The PCM absorbs the heat generated from the batteries while minimizing temperature changes in the pack. The effectiveness of the PCM is governed by the melting point and latent heat of the material. Paraffin wax (Rubitherm RT-42) was used as the PCM in this study due to its high specific latent heat of fusion and its melting point in the operating temperature range of the battery pack.

The expanded graphite matrix is formed from flake graphite by a heat treatment process [14]. The process increases the porosity of the graphite and thus decreases the bulk density. The expanded graphite particles are then compacted to form a graphite matrix. Compacting the particles increases the thermal conductivity, both perpendicular and parallel to the compaction while decreasing the porosity of the resulting matrix [3]. Figure 7.1 shows the thermal conductivity as a function of bulk density from previous research [14]. The expanded graphite matrix is submerged into liquid PCM to form the PCM/EG composite material. Capillary forces draw the liquid PCM into the matrix where it remains after the matrix is removed. The mass of PCM left in the matrix is a function of soaking time and is characterized in the work of [14].

Modeling the phase change process of materials can be complicated and computationally expensive. A modeling method developed by Farid et al. [5] was used to treat the phase change process of the paraffin as a temperature dependent change in the specific heat of the composite material. A differential scanning calorimetry (DSC) curve fit of the paraffin is shown in Figure 7.2 from the method described in [14]. The curve was used to convert the latent heat of fusion of the paraffin to an effective specific heat over the melting temperature range. The curve shown in Figure 7.2 has been normalized so that the area under the large peak, from $35^{\circ} \mathrm{C}$ to 


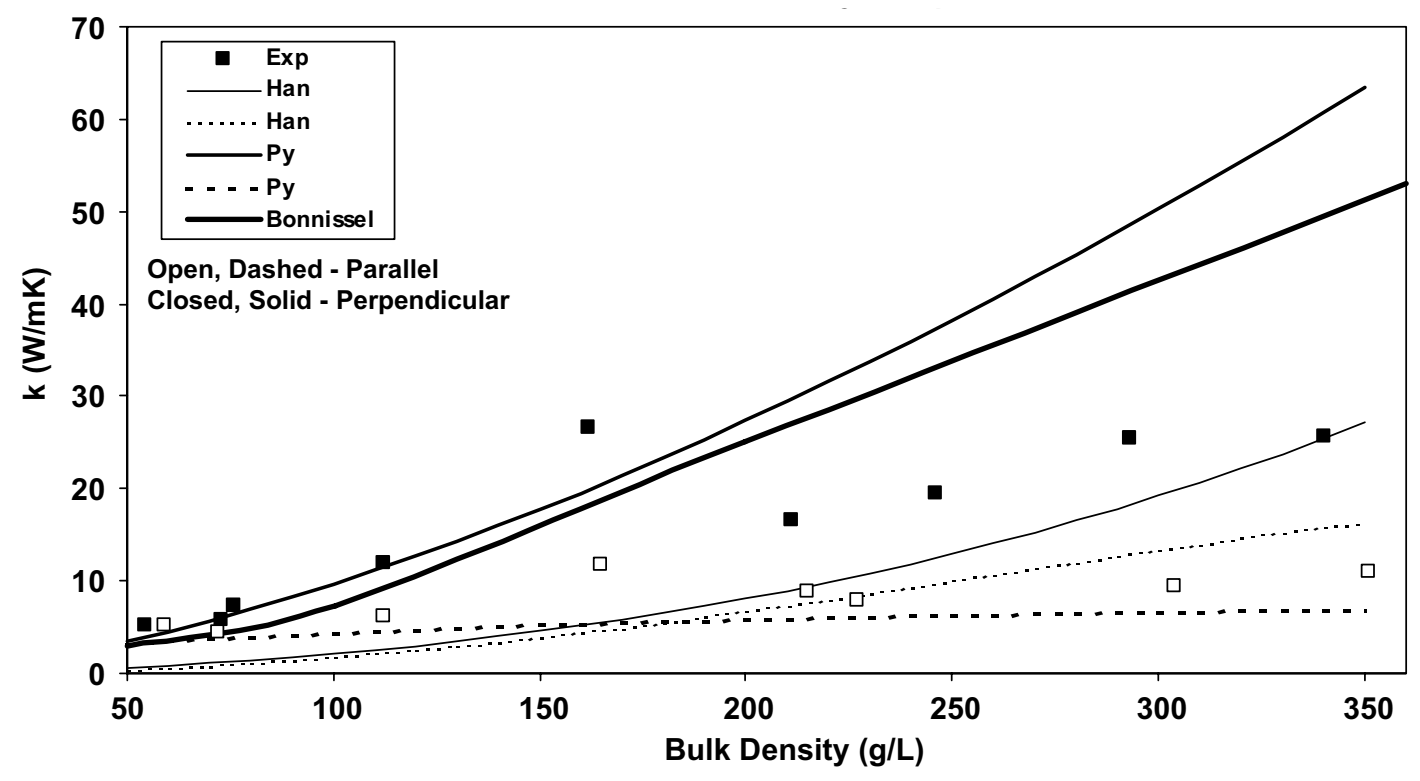

Figure 7.1: Thermal conductivity of PCM/EG composite for various graphite densities (ref. [14]).

Table 7.1: Thermodynamic and physical properties of PCM/EG composite material used in simulation.

\begin{tabular}{ll}
\hline Property & Value \\
\hline Thermal conductivity $(\mathrm{W} / \mathrm{mK})$ & 16.6 \\
Latent heat $(\mathrm{J} / \mathrm{kg})$ & 127,000 \\
Specific heat $(\mathrm{J} / \mathrm{kgK})$ & 2,250 \\
Bulk density of composite $\left(\mathrm{kg} / \mathrm{m}^{3}\right)$ & 789 \\
Bulk density of graphite $\left(\mathrm{kg} / \mathrm{m}^{3}\right)$ & 210 \\
\hline
\end{tabular}

$55^{\circ} \mathrm{C}$, is equal to one so that the curve can be scaled to the latent heat of fusion of the paraffin. The specific heat of the PCM/EG composite material, shown in Figure 7.3, was input to the Fluent model as a piecewise linear function and is the sum of the effective specific heat due to the latent heat of the paraffin and the specific heat of the composite material. Any density change of the phase change material from the solid to liquid phase was neglected. Realistically achievable thermophysical properties for the PCM/EG composite [13] used in the Fluent simulation are shown in Table 7.1. 


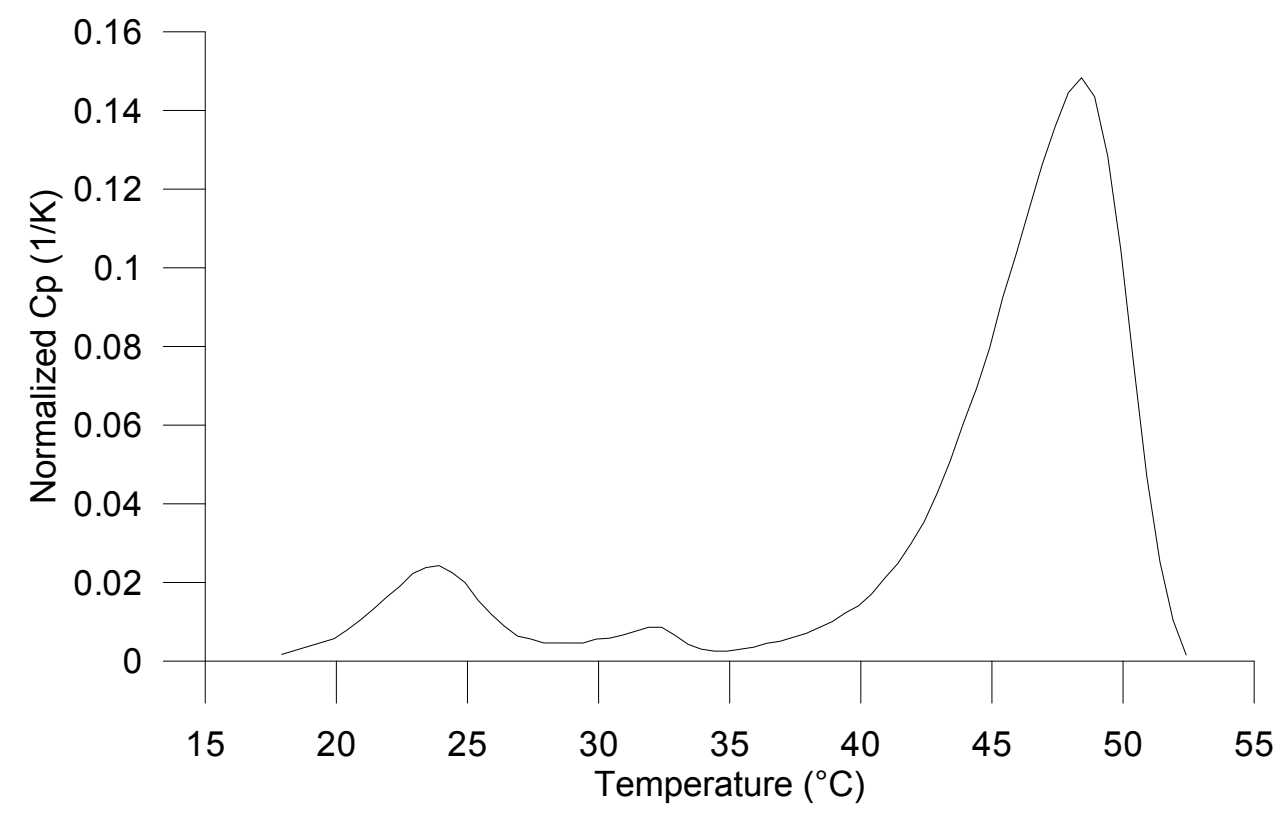

Figure 7.2: Normalized differential scanning calorimetry curve for Rubitherm RT-42 paraffin (ref. [14]).

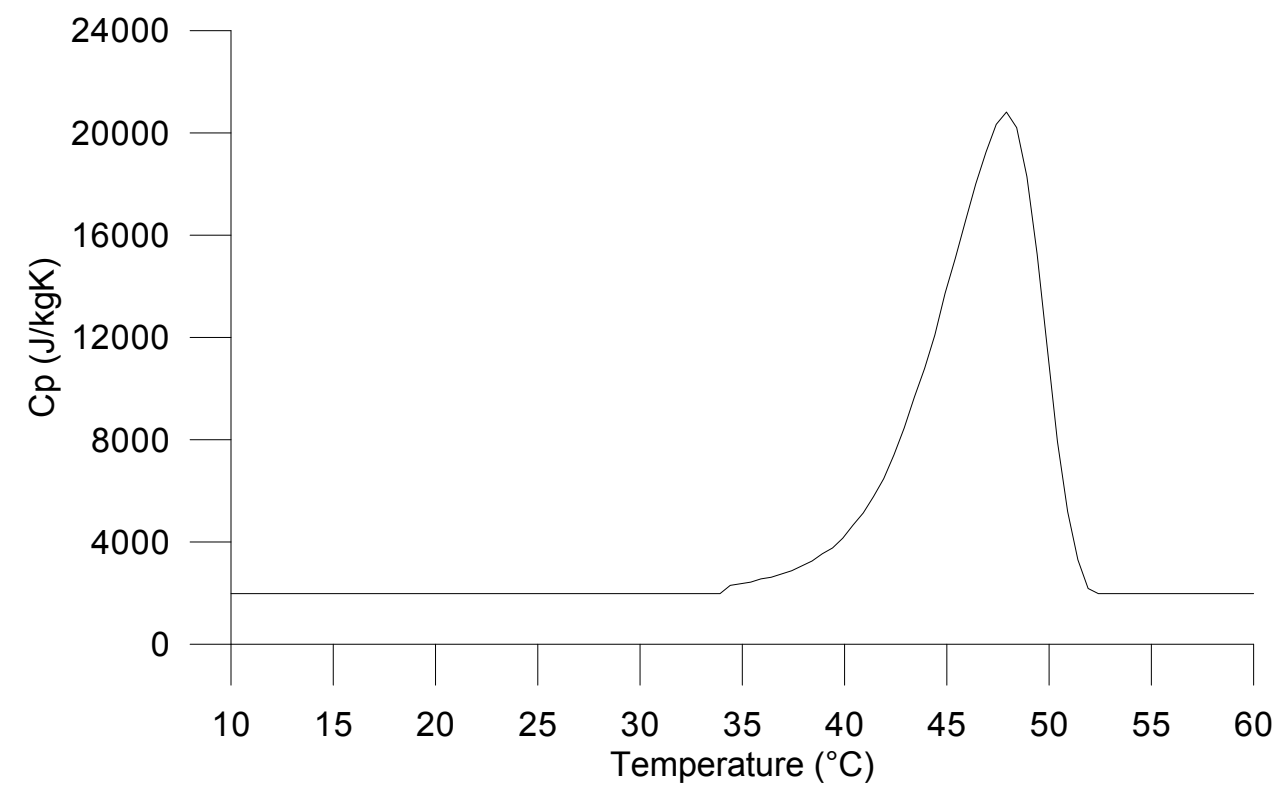

Figure 7.3: Specific heat $(\mathrm{J} / \mathrm{kgK})$ of the composite combined with effective specific heat due to latent heat of fusion of the paraffin. 


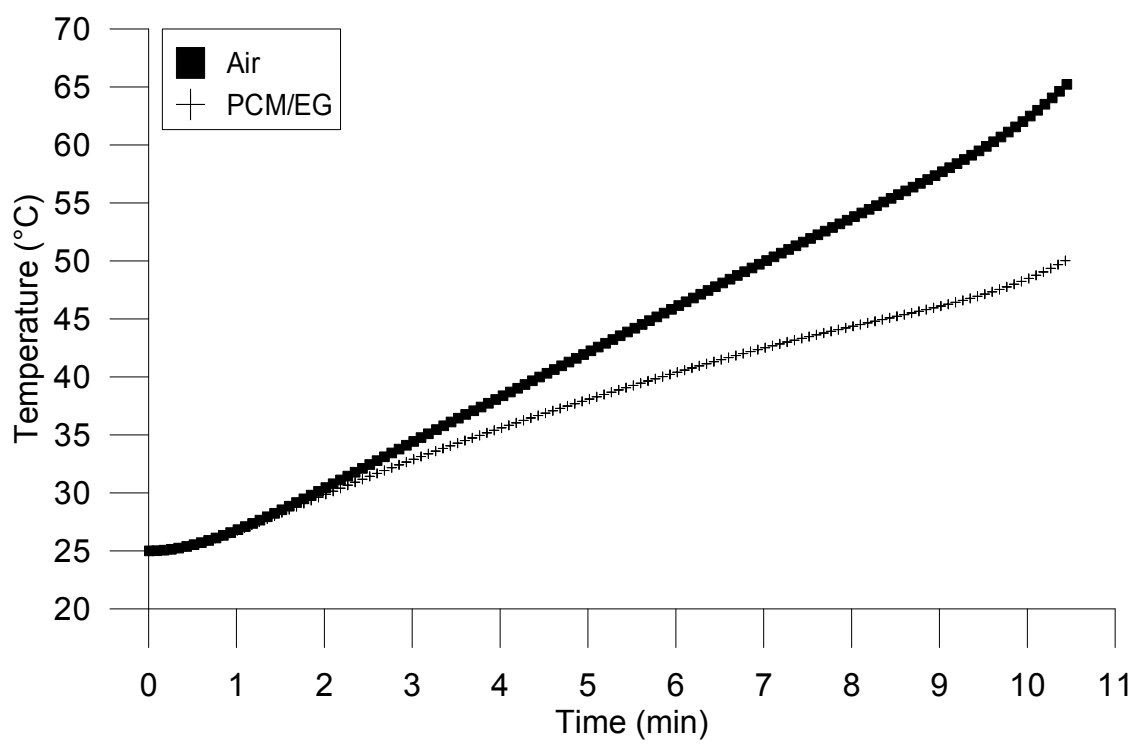

Figure 7.4: Maximum temperature $\left({ }^{\circ} \mathrm{C}\right)$ of the batteries in the enclosure over time.

\section{$7.2 \quad$ Results}

Figure 7.4 shows how the PCM/EG passive thermal management system substantially reduced the maximum temperature of the batteries compared to the original pack with natural convection cooling. Without the passive thermal management system the maximum temperature of the batteries rose beyond the $60^{\circ} \mathrm{C}$ threshold to $65.6^{\circ} \mathrm{C}$. In stark contrast, the passive thermal management system reduced the maximum temperature of the batteries to $50.3{ }^{\circ} \mathrm{C}$, keeping all of the batteries within the design operating temperature range. Figure 7.7 shows the temperature fluctuations across the width of the pack through the back row of batteries. This plot shows clearly the radial temperature fluctuation across each individual battery. The highest temperature occurs in the radial center of the middle back row battery. Temperature deviations between the centermost cell and the outermost cells are minor, less than $3{ }^{\circ} \mathrm{C}$. Figure 7.8 shows the temperature fluctuations from the bottom to the top of the pack through the middle back row battery. Axial temperature fluctuation is minor, varying less than $3{ }^{\circ} \mathrm{C}$ along the length of the battery. 


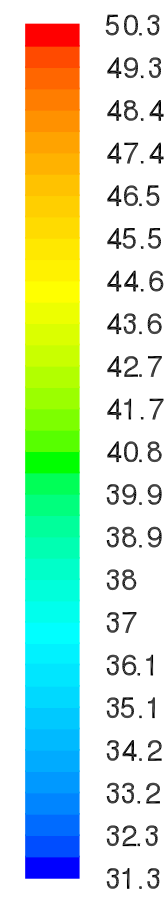

Figure 7.5: Section view of temperature $\left({ }^{\circ} \mathrm{C}\right)$ contours at vertical middle of battery pack after 630 seconds at $5 P$ rate with the $\mathrm{PCM} / \mathrm{EG}$.

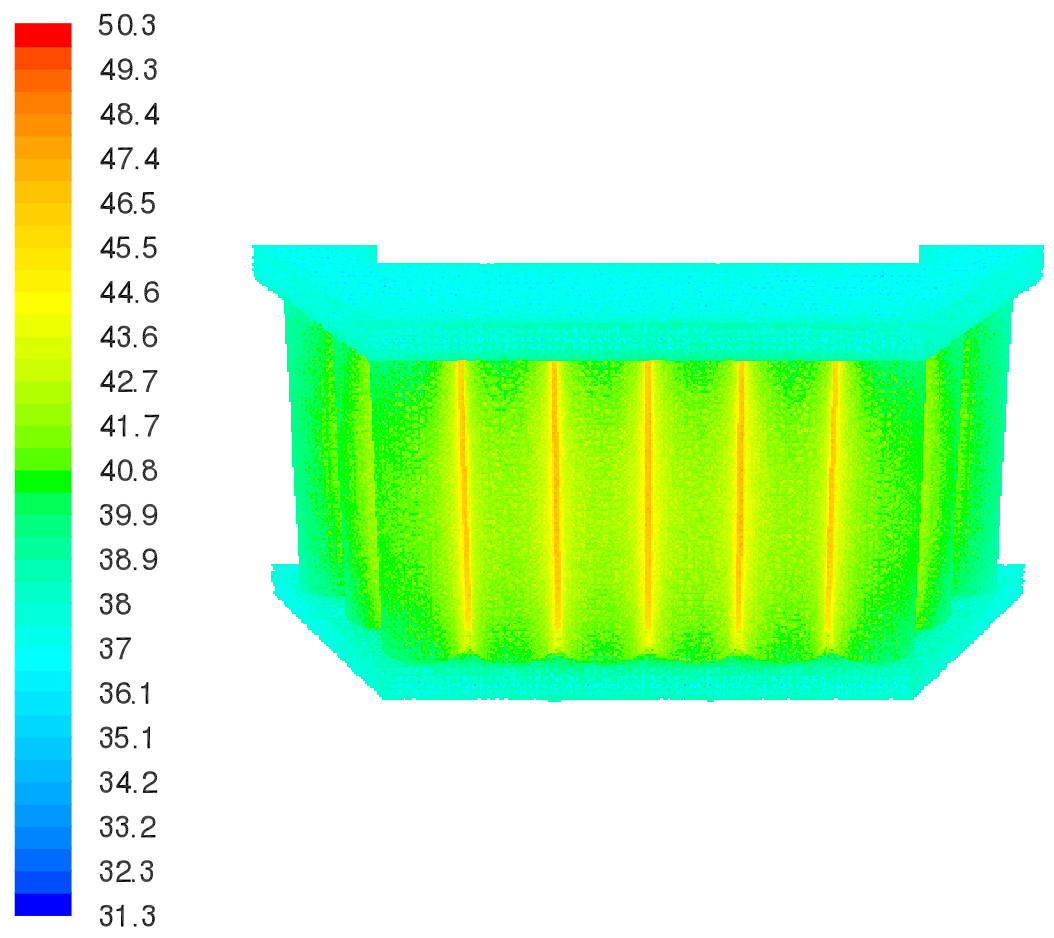

Figure 7.6: View of battery temperatures $\left({ }^{\circ} \mathrm{C}\right)$ after 630 seconds at $5 P$ rate with the $\mathrm{PCM} / \mathrm{EG}$. 


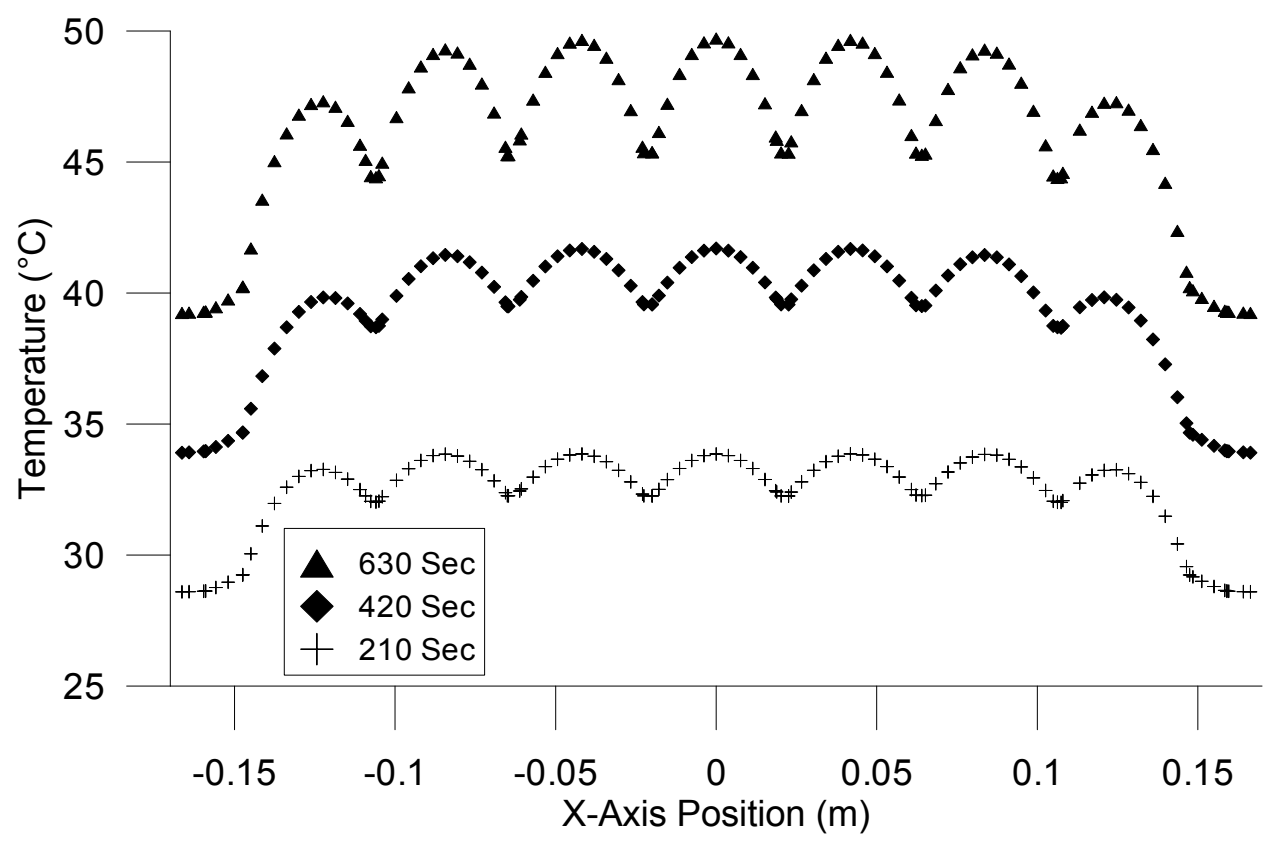

Figure 7.7: Temperature $\left({ }^{\circ} \mathrm{C}\right)$ evolution along horizontal axis through the center of the back row of batteries with PCM/EG.

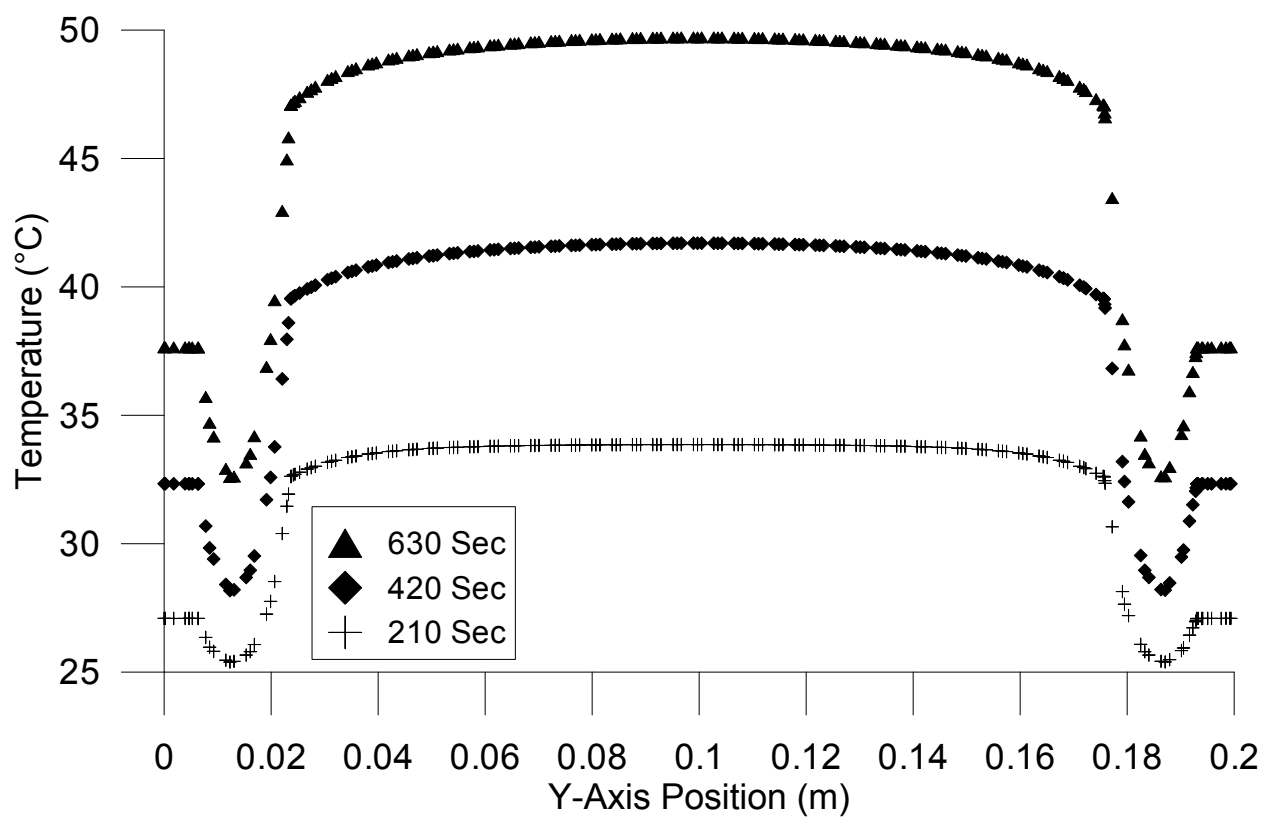

Figure 7.8: Temperature $\left({ }^{\circ} \mathrm{C}\right)$ evolution along longitudinal axis of the middle battery in the back row with PCM/EG. 


\section{Chapter 8}

\section{Discussion, Conclusions, and}

\section{Future Research}

\subsection{Discussion}

The temperature comparison for the two models under the worst-case loading condition of 3,600 W or roughly $85 \mathrm{~A}$ for 630 seconds is shown in Figure 7.4. For the case of air-convection cooling, the maximum battery temperature reaches $65.6^{\circ} \mathrm{C}$ and exceeds the maximum design operating temperature of $60^{\circ} \mathrm{C}$. This analysis indicates that the batteries in the pack are likely operating outside of their optimal temperature range if the UGV is drawing a sustained $85 \mathrm{~A}$ or more for 630 seconds. This increase in operating temperature does lead to an increase in the electrical performance of the batteries arising from the increased rate of chemical reactions, but decreases the life

Table 8.1: Temperature comparison of PCM/EG and air simulations.

\begin{tabular}{llll}
\hline Model & Heat Generated $(\mathbf{W h})$ & Max Temp. $\left({ }^{\circ} \mathbf{C}\right)$ & Temp. Rise $\left({ }^{\circ} \mathbf{C}\right)$ \\
\hline Air & 98.4 & 65.60 & 40.60 \\
PCM/EG & 98.4 & 50.32 & 25.32 \\
\hline
\end{tabular}


expectancy of the battery due to increased corrosion rates [16, 17]. Furthermore, if overheated, li-ion batteries may suffer from thermal runaway and, in extreme cases, cell rupture or combustion.

The temperature distribution results presented here provide insight into how the pack performs under maximum loading, what the maximum temperatures are, and how evenly distributed the heat is throughout the battery. This is an important and useful check to ensure that the current design can implement safety protocols to prevent thermal runaway in the batteries. Ideally, the temperature of each battery should be identical to all others so the batteries remain balanced. It is known that cells within the pack will be charged or discharged slightly differently during each cycle if they are at different temperatures. Under these conditions, the cells eventually become unbalanced with cycles, which degrades pack performance [16, 17]. Temperature variation among the cells in the pack can cause differences in impedance which can amplify capacity differences between the cells. Capacity differences can cause some cells to become over-charged or over-discharged which can lead to accelerated capacity fading or thermal runaway [2]. Thermal balancing ensures that the batteries wear out as evenly as possible and certain batteries do not need to be replaced prematurely. In short, battery management is simpler if thermal management is controlled and uniform.

In the passive thermal management model, the air surrounding the batteries was replaced with a composite expanded graphite matrix embedded with paraffin wax. This configuration exploits the large heat capacity and latent heat of fusion of the wax as well as the high thermal conductivity of the graphite matrix. This increase in conductivity around the batteries conducted heat more effectively to the exterior of the pack. Most importantly, the wax provided significant heat storage through its latent heat of fusion during phase change. The PCM/EG system provided significant heat storage and reduced the temperature of the batteries substantially as shown in 
Figure 7.4. Table 8.1 shows that the maximum temperature of the batteries was reduced from $65.6^{\circ} \mathrm{C}$ to $50.3^{\circ} \mathrm{C}$ by this passive thermal management system. Figure 7.5 shows that the PCM/EG itself did not get hot enough to completely melt the wax. The temperature reduction performance would be improved further by starting the battery discharge at a higher ambient temperature or alternatively, by lowering the melting temperature of the PCM.

From the results in Figure 6.7 it can be seen that the two batteries isolated in the 'wings' of the pack are at a lower average temperature than the batteries at the center. This is due to two effects: the increased separation distance from the majority of the batteries; and the close proximity to the relatively cool walls of the enclosure. The close proximity to the enclosure sides leads to an increase in the amount of heat that is conducted away to the enclosure and ultimately through the convection boundary condition to the ambient. This temperature discrepancy with these two batteries is not ideal, as they will likely have lower performance compared to the other batteries in the pack, leading to an enhanced chance of thermally induced imbalance. At the very least, this study suggests that future packs group the batteries in a manner that provides a more uniform battery temperature distribution.

These simulation results indicate that the air in the pack acts as an insulator due to its low thermal conductivity. The spaces for the air to circulate between the batteries and the enclosure are small and lead to significant friction, which limits advection. Replacing the air space with a highly conductive material with a high heat capacity and high latent heat, such as the expanded graphite phase change material, proved to significantly improve the thermal performance of the pack. The bulk density of the composite PCM/EG material is low compared to other highly conductive materials and will only add $1.4 \mathrm{~kg}$ of mass per battery pack to the vehicle while still providing substantial thermal performance enhancement. The passive system modeled here provides excellent thermal performance improvements without siphoning any of the 
battery pack power as would an active thermal management solution. The temperature reduction of the system allows the UGV to operate in hotter environments and draw higher currents, if necessary, without the risk of thermal runaway.

\subsection{Conclusions}

Fluent was used to run simulations of the transient temperatures in a 15-cell lithium iron phosphate battery pack for an unmanned ground vehicle under worstcase power draw conditions. These simulations were conducted to determine the risk of thermal runaway and to explore what changes might be made to better manage the battery pack temperatures. The CFD simulation adequately modeled the worstcase heat generation scenario with a power draw of 3,600 watts at roughly 85 amps and determined the temperature distribution in the pack over time. The analysis revealed that the batteries reached $65.6^{\circ} \mathrm{C}$ after 630 seconds of peak power usage. This temperature exceeds the maximum recommended operating temperature of $60^{\circ} \mathrm{C}$. Input for the simulation came from a series of experiments to determine individual cell heat generation as a function of depth of discharge over a broad range of current draws. After finding that the air-convection cooled pack would not properly protect the batteries, the model was adapted to simulate a passive cooling system utilizing an expanded graphite phase change material composite. The PCM/EG system provided a substantial maximum temperature reduction of $15.3^{\circ} \mathrm{C}$, a $37.7 \%$ reduction in temperature rise. The maximum battery temperature was reduced to $50.3^{\circ} \mathrm{C}$ for the largest expected power draw during UGV operation. The simulated passive thermal management system restored the batteries to the design operating temperature range and allowed for a sealed battery pack without intrusive cooling elements. 


\subsection{Recommendations for Future Research}

An expanded graphite phase change material with desirable, but achievable properties was chosen for this study. A design study investigating the trade-off between latent heat and thermal conductivity would be beneficial for future passive thermal management designs. Further research into advanced manufacturing techniques may lead to development of a higher performing composite phase change material with higher bulk thermal conductivity and latent heat of fusion. The paraffin material chosen could be altered to have an optimized melting temperature range such that the entire latent heat of the paraffin is utilized during a full battery discharge under the worst-case expected power draw.

A Foster network model could be created for this specific application similar to the one employed by Hu et al. [8]. This model could be coupled to an electrical heat generation model using the previously mentioned heat generation equation for batteries. The network model could create an equivalent circuit for the thermal performance of this specific battery pack which could be tuned using results from the Fluent CFD model. Once tuned, a current-voltage power profile could be plugged into the network model and the model could be used to calculate the resulting temperatures that the batteries would experience over time. This solution would take a mere fraction of the time that would be needed to solve a CFD problem and could quickly be used for each power profile of interest. 


\section{Bibliography}

[1] S. Al Hallaj, R. Venkatachalapathy, J. Prakash, and J. R. Selman, "Entropy changes due to structural transformation in the graphite anode and phase change of the $\mathrm{LiCoO}_{2}$ cathode," Journal of The Electrochemical Society 147 (2000): $2432-2436$.

[2] S. Al-Hallaj and J. R. Selman, "Thermal modeling of secondary lithium batteries for electric vehicle/hybrid electric vehicle applications," Journal of Power Sources 110 (2002): 341-348.

[3] M. Bonnissel, L. Lou, and D. Tondeur, "Compacted exfoliated natural graphite as a heat conduction medium," Carbon 39 (2001): 2151-2161.

[4] D. H. Doughty, P. C. Butler, R. G. Jungst, and E. P. Roth, "Lithium battery thermal models," Journal of Power Sources 110 (2002): 357-363.

[5] M. Farid, F. Hamad, and M. Abu-Arabi, "Melting and solidification in multidimensional geometry and presence of more than one interface," Energy Conversion and Management 39 (1998): 809-818.

[6] M. M. Farid, A. M. Kuhdair, S. A. K. Razack, and S. Al-Hallaj, "A review on phase change energy storage: materials and applications," Energy Conversion and Management 45 (2004): 1597-1615. 
[7] J. H. Han, K. W. Cho, K. H. Lee, and H. Kim, "Porous graphite matrix for chemical heat pumps," Carbon 36 (1998): 1801-1810.

[8] X. Hu, S. Lin, and S. Stanton, "A novel thermal model for HEV/EV battery modeling based on CFD calculation," Energy Conversion Congress and Exposition (2010): 893-900.

[9] IEEE Spectrum, "Lithium Batteries Take to the Road," http://spectrum.ieee.org/green-tech/advanced-cars/lithium-batteries-taketo-the-road, 2007.

[10] F. P. Incropera, D. P. DeWitt, T. L. Bergman, and A. S. Lavine, Introduction to Heat Transfer, 5th ed., New Jersey: John Wiley \& Sons, (2007).

[11] G. Kim, A. Pesaran, and R. Spotnitz, "A three-dimensional thermal abuse model for lithium-ion cells," Journal of Power Sources 170 (2007): 476-489.

[12] H. Maleki and A. K. Shamsuri, "Thermal analysis and modeling of a notebook computer battery," Journal of Power Sources 115 (2003): 131-136.

[13] A. Mills and S. Al-Hallaj, "Simulation of passive thermal management system for lithium-ion battery packs," Journal of Power Sources 141 (2005): 307-315.

[14] A. Mills, M. Farid, J. R. Selman, and S. Al-Hallaj, "Thermal conductivity enhancement of phase change materials using a graphite matrix," Journal of Applied Thermal Engineering 26 (2006): 1652-1661.

[15] K. Onda, T. Ohshima, M. Nakayama, K. Fukuda, and T. Araki, "Thermal behavior of small lithium-ion battery during rapid charge and discharge cycles," Journal of Power Sources 158 (2005): 535-542.

[16] A. Pesaran, A. Vlahinos, and S. Burch, "Thermal performance of EV and HEV battery modules and packs," National Renewable Energy Laboratory (1997). 
[17] A. A. Pesaran, "Battery thermal management in EVs and HEVs: Issues and solutions," Battery Management 43 (2001): 34-49.

[18] X. Py, R. Olives, and S. Mauran, "Paraffin/porous-graphite-matrix composite as a high and constant power thermal storage material," International Journal of Heat and Mass Transfer 44 (2001): 2727-2737.

[19] Z. Rao, S. Wang, and G. Zhang, "Simulation and experiment of thermal energy management with phase change material for ageing $\mathrm{LiFePO}_{4}$ power battery," Energy Conversion and Management 52 (2011): 3408-3414.

[20] V. V. Viswanathan, D. Choi, D. Wang, W. Xu, S. Towne, R. E. Williford, J. Zhang, J. Liu, and Z. Yang, "Effect of entropy change of lithium intercalation in cathodes and anodes on Li-ion battery thermal management," Journal of Power Sources 195 (2010): 3720-3729.

[21] ANSYS, FLUENT 12.0 Theory Guide, (2009).

[22] ANSYS, FLUENT 12.0 UDF Manual, (2009).

[23] ANSYS, FLUENT 12.0 User's Guide, (2009). 


\section{Appendix A}

\section{ANSYS Fluent Model Input}

\section{Summary}

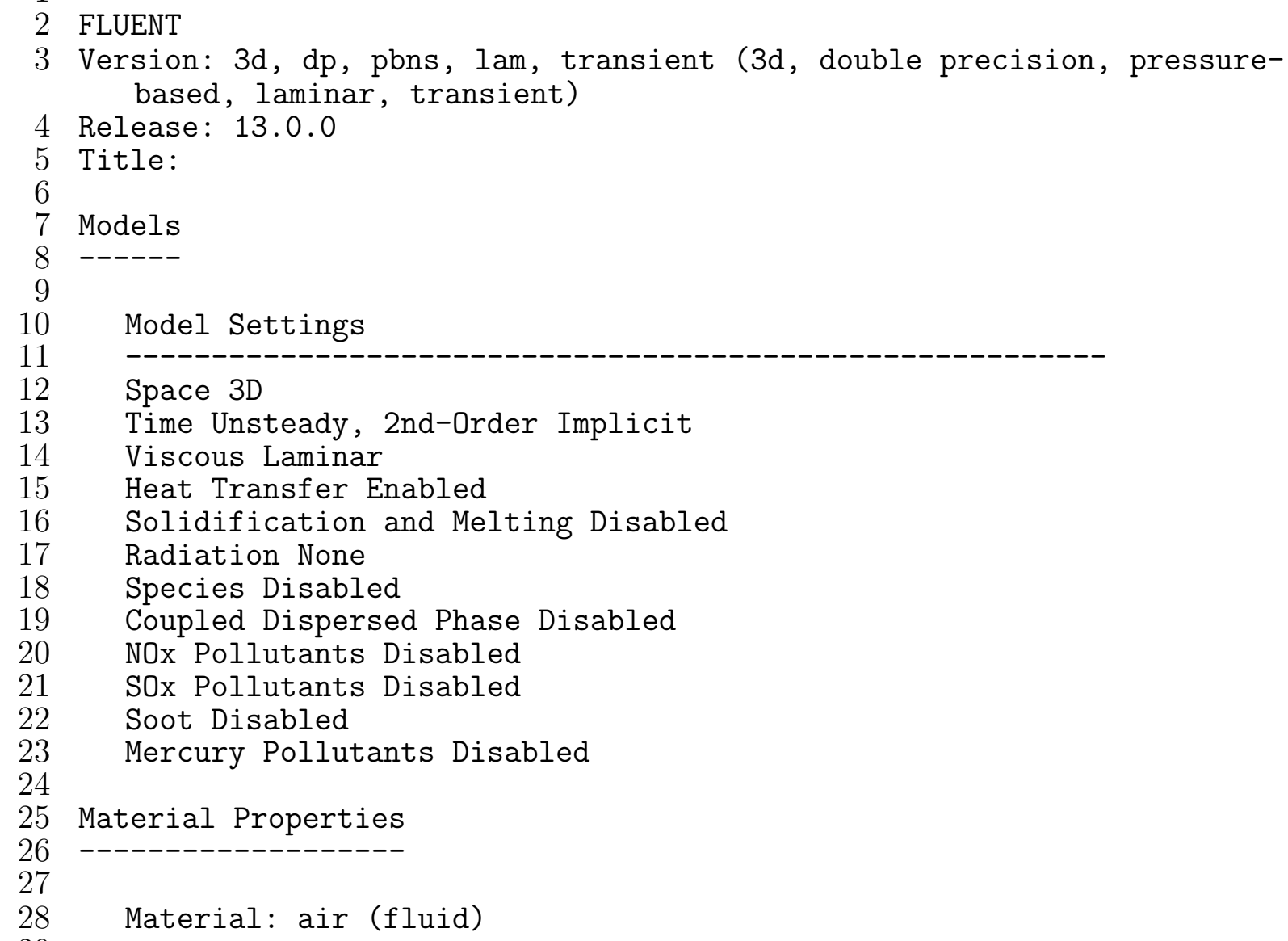

25 Material Properties

26 ------------------- 
Property Units Method Value(s)

Density $\mathrm{kg} / \mathrm{m} 3$ boussinesq 1.205

Cp (Specific Heat) $\mathrm{j} / \mathrm{kg}-\mathrm{k}$ constant 1005

Thermal Conductivity $\mathrm{w} / \mathrm{m}-\mathrm{k}$ constant 0.025699999

Viscosity $\mathrm{kg} / \mathrm{m}-\mathrm{s}$ constant $1.8500001 \mathrm{e}-05$

Molecular Weight $\mathrm{kg} / \mathrm{kgmol}$ constant 28.966

Thermal Expansion Coefficient $1 / \mathrm{k}$ constant 0.00343

Speed of Sound $\mathrm{m} / \mathrm{s}$ none \#f

Material: plastic (solid)

Property Units Method Value(s)

Density $\mathrm{kg} / \mathrm{m} 3$ constant 1400

Cp (Specific Heat) $\mathrm{j} / \mathrm{kg}-\mathrm{k}$ constant 1050

Thermal Conductivity $\mathrm{w} / \mathrm{m}-\mathrm{k}$ constant 0.16

Material: pcm (solid)

Property Units Method Value(s)

Density $\mathrm{kg} / \mathrm{m} 3$ constant 1010

Cp (Specific Heat) $\mathrm{j} / \mathrm{kg}-\mathrm{k}$ polynomial (283 1980) (307.39999 1980) (307.89999 2303) (308.39999 2366) (308.89999 2430) $\begin{array}{llllll}(309.39999 & 2557)(309.89999 & 2620) & (310.39999 & 2747) & (310.89999\end{array}$ 2874) (311.39999 3065) (311.89999 3257) (312.39999 3540)

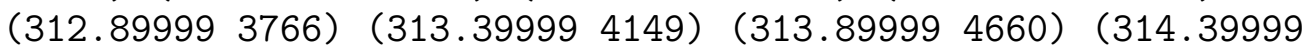
5135) (314.89999 5773) (315.39999 6475) (315.89999 7405) (316.39999 9668) (316.89999 9668) (317.39999 10790) (317.89999 12095) (3184 13728) (318.89999 15097) (319.39999 16566) (319.89999 18007) (320.39999 19249) (320.89999 20335) (321.39999 20817) (321.89999 20205) (322.39999 18288) $\begin{array}{llllll}(322.89999 & 15256) & (323.39999 & 11549) & (323.89999 & 7934)\end{array}$

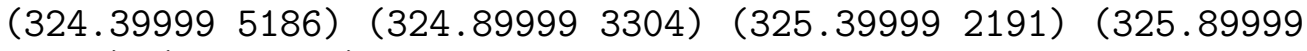
1980) (373 1980)

Thermal Conductivity $\mathrm{w} / \mathrm{m}-\mathrm{k}$ constant 16.6

Material: battery (solid)

Property Units Method Value(s)

Density $\mathrm{kg} / \mathrm{m} 3$ constant 2618.3999

Cp (Specific Heat) $\mathrm{j} / \mathrm{kg}-\mathrm{k}$ constant 950

Thermal Conductivity $\mathrm{w} / \mathrm{m}-\mathrm{k}$ constant 3

Material: aluminum (solid)

Property Units Method Value(s)

Density $\mathrm{kg} / \mathrm{m} 3$ constant 2700

Cp (Specific Heat) $\mathrm{j} / \mathrm{kg}-\mathrm{k}$ constant 896 


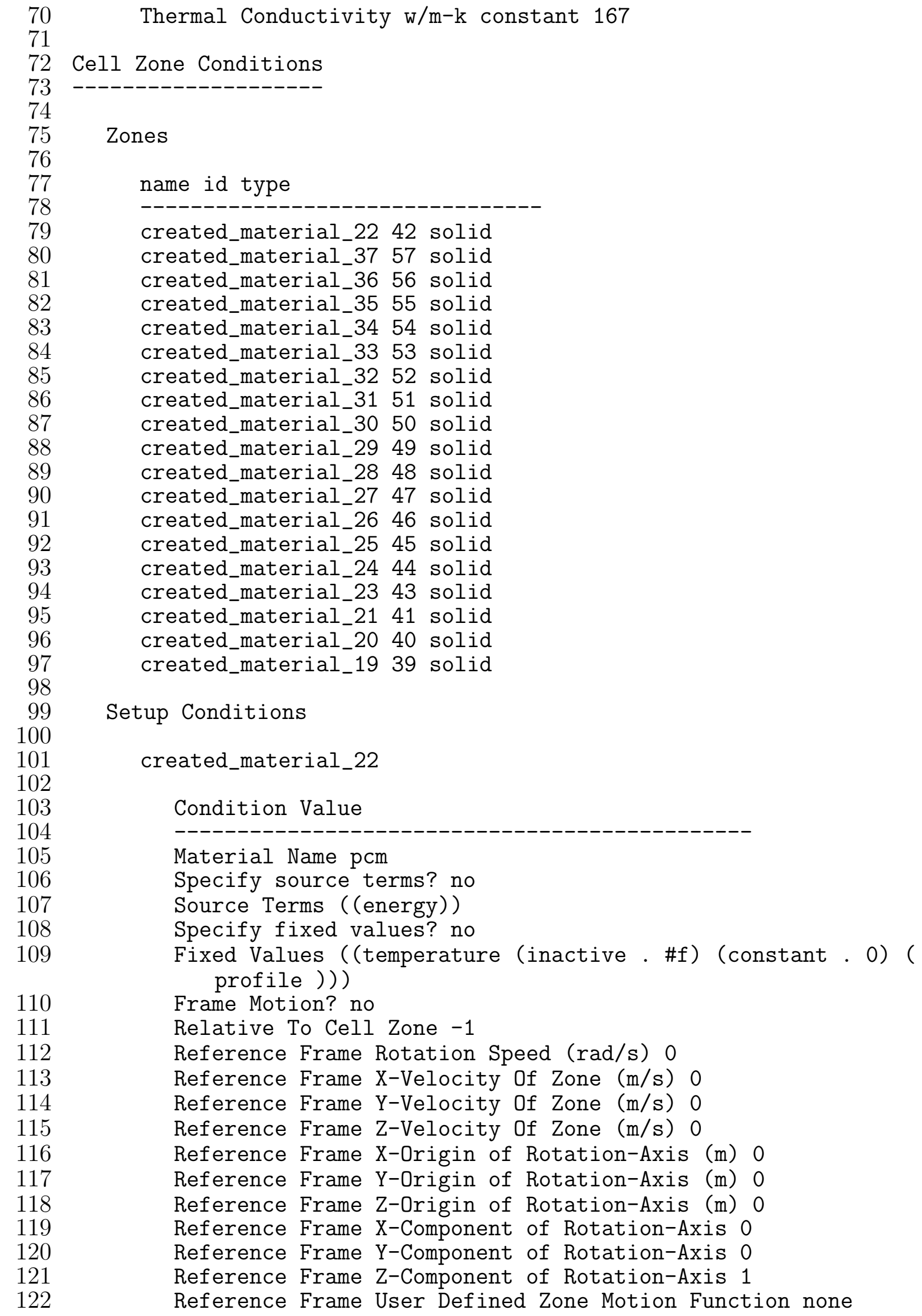


Mesh Motion? no

Relative To Cell Zone -1

Moving Mesh Rotation Speed ( $\mathrm{rad} / \mathrm{s}) 0$

Moving Mesh X-Velocity Of Zone (m/s) 0

Moving Mesh Y-Velocity Of Zone $(\mathrm{m} / \mathrm{s}) 0$

Moving Mesh Z-Velocity Of Zone (m/s) 0

Moving Mesh X-Origin of Rotation-Axis (m) 0

Moving Mesh Y-Origin of Rotation-Axis (m) 0

Moving Mesh Z-Origin of Rotation-Axis (m) 0

Moving Mesh X-Component of Rotation-Axis 0

Moving Mesh Y-Component of Rotation-Axis 0

Moving Mesh Z-Component of Rotation-Axis 1

Moving Mesh User Defined Zone Motion Function none

Deactivated Thread no

created_material_37

Condition Value

Material Name battery

Specify source terms? yes

Source Terms ((energy ((profile udf heat_gen) (inactive .\#f) (constant . 0))))

Specify fixed values? no

Fixed Values ((temperature (inactive . \#f) (constant . 0) ( profile )))

Frame Motion? no

Relative To Cell Zone -1

Reference Frame Rotation Speed (rad/s) 0

Reference Frame X-Velocity Of Zone (m/s) 0

Reference Frame Y-Velocity of Zone $(\mathrm{m} / \mathrm{s}) 0$

Reference Frame Z-Velocity of Zone (m/s) 0

Reference Frame X-Origin of Rotation-Axis (m) 0

Reference Frame Y-Origin of Rotation-Axis (m) 0

Reference Frame Z-Origin of Rotation-Axis (m) 0

Reference Frame X-Component of Rotation-Axis 0

Reference Frame Y-Component of Rotation-Axis 0

Reference Frame Z-Component of Rotation-Axis 1

Reference Frame User Defined Zone Motion Function none

Mesh Motion? no

Relative To Cell Zone -1

Moving Mesh Rotation Speed ( $\mathrm{rad} / \mathrm{s}) 0$

Moving Mesh X-Velocity Of Zone $(\mathrm{m} / \mathrm{s}) 0$

Moving Mesh Y-Velocity Of Zone $(\mathrm{m} / \mathrm{s}) 0$

Moving Mesh Z-Velocity Of Zone (m/s) 0

Moving Mesh X-Origin of Rotation-Axis (m) 0

Moving Mesh Y-Origin of Rotation-Axis (m) 0

Moving Mesh Z-Origin of Rotation-Axis (m) 0

Moving Mesh X-Component of Rotation-Axis 0

Moving Mesh Y-Component of Rotation-Axis 0

Moving Mesh Z-Component of Rotation-Axis 1

Moving Mesh User Defined Zone Motion Function none

Deactivated Thread no 
created_material_36

Condition Value

Material Name battery

Specify source terms? yes

Source Terms ((energy ((profile udf heat_gen) (inactive.\#f) (constant . 0))))

Specify fixed values? no

Fixed Values ((temperature (inactive . \#f) (constant . 0) ( profile )))

Frame Motion? no

Relative To Cell Zone -1

Reference Frame Rotation Speed (rad/s) 0

Reference Frame X-Velocity Of Zone (m/s) 0

Reference Frame Y-Velocity of Zone $(\mathrm{m} / \mathrm{s}) 0$

Reference Frame Z-Velocity Of Zone (m/s) 0

Reference Frame X-Origin of Rotation-Axis (m) 0

Reference Frame Y-Origin of Rotation-Axis (m) 0

Reference Frame Z-Origin of Rotation-Axis (m) 0

Reference Frame X-Component of Rotation-Axis 0

Reference Frame Y-Component of Rotation-Axis 0

Reference Frame Z-Component of Rotation-Axis 1

Reference Frame User Defined Zone Motion Function none

Mesh Motion? no

Relative To Cell Zone -1

Moving Mesh Rotation Speed (rad/s) 0

Moving Mesh X-Velocity Of Zone $(\mathrm{m} / \mathrm{s}) 0$

Moving Mesh Y-Velocity Of Zone $(\mathrm{m} / \mathrm{s}) 0$

Moving Mesh Z-Velocity Of Zone (m/s) 0

Moving Mesh X-Origin of Rotation-Axis (m) 0

Moving Mesh Y-Origin of Rotation-Axis (m) 0

Moving Mesh Z-Origin of Rotation-Axis (m) 0

Moving Mesh $\mathrm{X}$-Component of Rotation-Axis 0

Moving Mesh Y-Component of Rotation-Axis 0

Moving Mesh Z-Component of Rotation-Axis 1

Moving Mesh User Defined Zone Motion Function none

Deactivated Thread no

created_material_35

Condition Value

Material Name battery

Specify source terms? yes

Source Terms ((energy ((profile udf heat_gen) (inactive.\#f) (constant . 0))))

Specify fixed values? no

Fixed Values ((temperature (inactive . \#f) (constant . 0) ( profile )))

Frame Motion? no

Relative To Cell Zone -1

Reference Frame Rotation Speed (rad/s) 0 
224

Reference Frame X-Velocity Of Zone (m/s) 0

Reference Frame Y-Velocity of Zone $(\mathrm{m} / \mathrm{s}) 0$

Reference Frame Z-Velocity of Zone (m/s) 0

Reference Frame X-Origin of Rotation-Axis (m) 0

Reference Frame Y-Origin of Rotation-Axis (m) 0

Reference Frame Z-Origin of Rotation-Axis (m) 0

Reference Frame X-Component of Rotation-Axis 0

Reference Frame Y-Component of Rotation-Axis 0

Reference Frame Z-Component of Rotation-Axis 1

Reference Frame User Defined Zone Motion Function none

Mesh Motion? no

Relative To Cell Zone -1

Moving Mesh Rotation Speed (rad/s) 0

Moving Mesh X-Velocity Of Zone (m/s) 0

Moving Mesh Y-Velocity Of Zone $(\mathrm{m} / \mathrm{s}) 0$

Moving Mesh Z-Velocity Of Zone (m/s) 0

Moving Mesh X-Origin of Rotation-Axis (m) 0

Moving Mesh Y-Origin of Rotation-Axis (m) 0

Moving Mesh Z-Origin of Rotation-Axis (m) 0

Moving Mesh X-Component of Rotation-Axis 0

Moving Mesh Y-Component of Rotation-Axis 0

Moving Mesh Z-Component of Rotation-Axis 1

Moving Mesh User Defined Zone Motion Function none

Deactivated Thread no

created_material_34

Condition Value

Material Name battery

Specify source terms? yes

Source Terms ((energy ((profile udf heat_gen) (inactive.\#f) (constant . 0))))

Specify fixed values? no

Fixed Values ((temperature (inactive . \#f) (constant . 0) ( profile )))

Frame Motion? no

Relative To Cell Zone -1

Reference Frame Rotation Speed (rad/s) 0

Reference Frame X-Velocity Of Zone (m/s) 0

Reference Frame Y-Velocity Of Zone (m/s) 0

Reference Frame Z-Velocity Of Zone (m/s) 0

Reference Frame X-Origin of Rotation-Axis (m) 0

Reference Frame Y-Origin of Rotation-Axis (m) 0

Reference Frame Z-Origin of Rotation-Axis (m) 0

Reference Frame X-Component of Rotation-Axis 0

Reference Frame Y-Component of Rotation-Axis 0

Reference Frame Z-Component of Rotation-Axis 1

Reference Frame User Defined Zone Motion Function none

Mesh Motion? no

Relative To Cell Zone -1

Moving Mesh Rotation Speed ( $\mathrm{rad} / \mathrm{s}) 0$

Moving Mesh X-Velocity Of Zone $(\mathrm{m} / \mathrm{s}) 0$ 
Moving Mesh Y-Velocity Of Zone (m/s) 0

Moving Mesh Z-Velocity Of Zone $(\mathrm{m} / \mathrm{s}) 0$

Moving Mesh X-Origin of Rotation-Axis (m) 0

Moving Mesh Y-Origin of Rotation-Axis (m) 0

Moving Mesh Z-Origin of Rotation-Axis (m) 0

Moving Mesh X-Component of Rotation-Axis 0

Moving Mesh Y-Component of Rotation-Axis 0

Moving Mesh Z-Component of Rotation-Axis 1

Moving Mesh User Defined Zone Motion Function none

Deactivated Thread no

created_material_33

Condition Value

Material Name battery

Specify source terms? yes

Source Terms ((energy ((profile udf heat_gen) (inactive . \#f) (constant . 0))))

Specify fixed values? no

Fixed Values ((temperature (inactive . \#f) (constant . 0) ( profile )))

Frame Motion? no

Relative To Cell Zone -1

Reference Frame Rotation Speed (rad/s) 0

Reference Frame X-Velocity Of Zone (m/s) 0

Reference Frame Y-Velocity Of Zone $(\mathrm{m} / \mathrm{s}) 0$

Reference Frame Z-Velocity Of Zone (m/s) 0

Reference Frame X-Origin of Rotation-Axis (m) 0

Reference Frame Y-Origin of Rotation-Axis (m) 0

Reference Frame Z-Origin of Rotation-Axis (m) 0

Reference Frame X-Component of Rotation-Axis 0

Reference Frame Y-Component of Rotation-Axis 0

Reference Frame Z-Component of Rotation-Axis 1

Reference Frame User Defined Zone Motion Function none

Mesh Motion? no

Relative To Cell Zone -1

Moving Mesh Rotation Speed (rad/s) 0

Moving Mesh X-Velocity Of Zone $(\mathrm{m} / \mathrm{s}) 0$

Moving Mesh Y-Velocity Of Zone $(\mathrm{m} / \mathrm{s}) 0$

Moving Mesh Z-Velocity Of Zone (m/s) 0

Moving Mesh X-Origin of Rotation-Axis (m) 0

Moving Mesh Y-Origin of Rotation-Axis (m) 0

Moving Mesh Z-Origin of Rotation-Axis (m) 0

Moving Mesh X-Component of Rotation-Axis 0

Moving Mesh Y-Component of Rotation-Axis 0

Moving Mesh Z-Component of Rotation-Axis 1

Moving Mesh User Defined Zone Motion Function none

Deactivated Thread no

created_material_32

Condition Value 


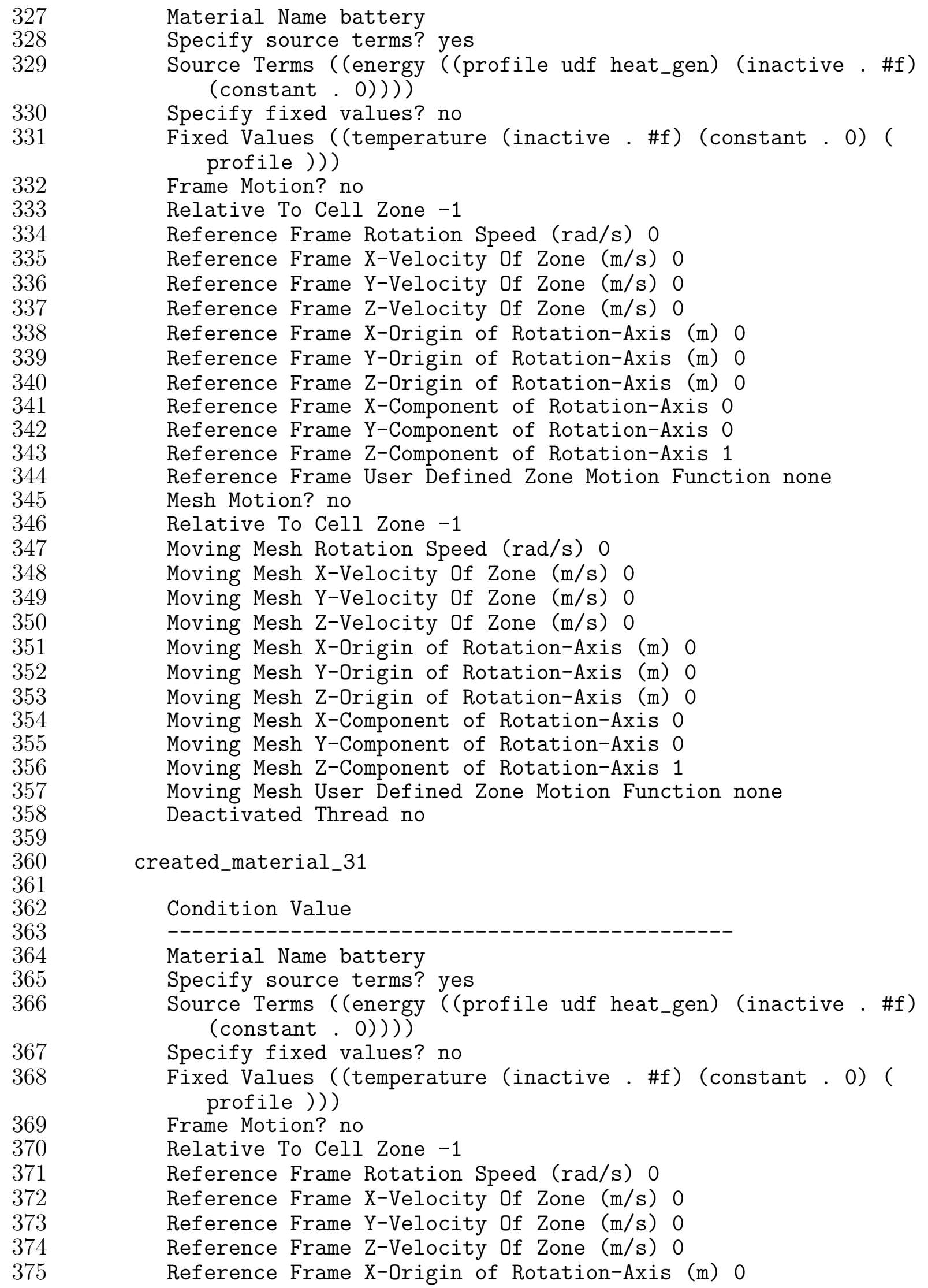


Reference Frame Y-Origin of Rotation-Axis (m) 0

Reference Frame Z-Origin of Rotation-Axis (m) 0

Reference Frame X-Component of Rotation-Axis 0

Reference Frame Y-Component of Rotation-Axis 0

Reference Frame Z-Component of Rotation-Axis 1

Reference Frame User Defined Zone Motion Function none

Mesh Motion? no

Relative To Cell Zone -1

Moving Mesh Rotation Speed (rad/s) 0

Moving Mesh X-Velocity Of Zone $(\mathrm{m} / \mathrm{s}) 0$

Moving Mesh Y-Velocity Of Zone $(\mathrm{m} / \mathrm{s}) 0$

Moving Mesh Z-Velocity Of Zone $(\mathrm{m} / \mathrm{s}) 0$

Moving Mesh X-Origin of Rotation-Axis (m) 0

Moving Mesh Y-Origin of Rotation-Axis (m) 0

Moving Mesh Z-Origin of Rotation-Axis (m) 0

Moving Mesh X-Component of Rotation-Axis 0

Moving Mesh Y-Component of Rotation-Axis 0

Moving Mesh Z-Component of Rotation-Axis 1

Moving Mesh User Defined Zone Motion Function none

Deactivated Thread no

created_material_30

Condition Value

Material Name battery

Specify source terms? yes

Source Terms ((energy ((profile udf heat_gen) (inactive . \#f) (constant . 0))))

Specify fixed values? no

Fixed Values ((temperature (inactive . \#f) (constant . 0) ( profile )))

Frame Motion? no

Relative To Cell Zone -1

Reference Frame Rotation Speed (rad/s) 0

Reference Frame X-Velocity Of Zone $(\mathrm{m} / \mathrm{s}) 0$

Reference Frame Y-Velocity Of Zone (m/s) 0

Reference Frame Z-Velocity Of Zone (m/s) 0

Reference Frame X-Origin of Rotation-Axis (m) 0

Reference Frame Y-Origin of Rotation-Axis (m) 0

Reference Frame Z-Origin of Rotation-Axis (m) 0

Reference Frame X-Component of Rotation-Axis 0

Reference Frame Y-Component of Rotation-Axis 0

Reference Frame Z-Component of Rotation-Axis 1

Reference Frame User Defined Zone Motion Function none

Mesh Motion? no

Relative To Cell Zone -1

Moving Mesh Rotation Speed (rad/s) 0

Moving Mesh X-Velocity Of Zone $(\mathrm{m} / \mathrm{s}) 0$

Moving Mesh Y-Velocity Of Zone $(\mathrm{m} / \mathrm{s}) 0$

Moving Mesh Z-Velocity Of Zone (m/s) 0

Moving Mesh X-Origin of Rotation-Axis (m) 0

Moving Mesh Y-Origin of Rotation-Axis (m) 0 
Moving Mesh Z-Origin of Rotation-Axis (m) 0 Moving Mesh X-Component of Rotation-Axis 0 Moving Mesh Y-Component of Rotation-Axis 0 Moving Mesh Z-Component of Rotation-Axis 1 Moving Mesh User Defined Zone Motion Function none Deactivated Thread no

created_material_29

Condition Value

Material Name plastic

Specify source terms? no

Source Terms ((energy))

Specify fixed values? no

Fixed Values ((temperature (inactive . \#f) (constant . 0) ( profile )))

Frame Motion? no

Relative To Cell Zone -1

Reference Frame Rotation Speed (rad/s) 0

Reference Frame X-Velocity Of Zone (m/s) 0

Reference Frame Y-Velocity Of Zone (m/s) 0

Reference Frame Z-Velocity Of Zone (m/s) 0

Reference Frame X-Origin of Rotation-Axis (m) 0

Reference Frame Y-Origin of Rotation-Axis (m) 0

Reference Frame Z-Origin of Rotation-Axis (m) 0

Reference Frame X-Component of Rotation-Axis 0

Reference Frame Y-Component of Rotation-Axis 0

Reference Frame Z-Component of Rotation-Axis 1

Reference Frame User Defined Zone Motion Function none

Mesh Motion? no

Relative To Cell Zone -1

Moving Mesh Rotation Speed (rad/s) 0

Moving Mesh X-Velocity Of Zone (m/s) 0

Moving Mesh Y-Velocity Of Zone $(\mathrm{m} / \mathrm{s}) 0$

Moving Mesh Z-Velocity Of Zone (m/s) 0

Moving Mesh X-Origin of Rotation-Axis (m) 0

Moving Mesh Y-Origin of Rotation-Axis (m) 0

Moving Mesh Z-Origin of Rotation-Axis (m) 0

Moving Mesh X-Component of Rotation-Axis 0

Moving Mesh Y-Component of Rotation-Axis 0

Moving Mesh Z-Component of Rotation-Axis 1

Moving Mesh User Defined Zone Motion Function none

Deactivated Thread no

created_material_28

Condition Value

Material Name battery

Specify source terms? yes

Source Terms ((energy ((profile udf heat_gen) (inactive.\#f) (constant . 0))))

Specify fixed values? no 
Fixed Values ((temperature (inactive . \#f) (constant . 0) ( profile ))) 
Mesh Motion? no

Relative To Cell Zone -1

Moving Mesh Rotation Speed (rad/s) 0

Moving Mesh X-Velocity Of Zone (m/s) 0

Moving Mesh Y-Velocity Of Zone (m/s) 0

Moving Mesh Z-Velocity Of Zone (m/s) 0

Moving Mesh X-Origin of Rotation-Axis (m) 0

Moving Mesh Y-Origin of Rotation-Axis (m) 0

Moving Mesh Z-Origin of Rotation-Axis (m) 0

Moving Mesh $\mathrm{X}$-Component of Rotation-Axis 0

Moving Mesh Y-Component of Rotation-Axis 0

Moving Mesh Z-Component of Rotation-Axis 1

Moving Mesh User Defined Zone Motion Function none

Deactivated Thread no

created_material_26

Condition Value

Material Name battery

Specify source terms? yes

Source Terms ((energy ((profile udf heat_gen) (inactive.\#f) (constant . 0))))

Specify fixed values? no

Fixed Values ((temperature (inactive . \#f) (constant . 0) ( profile )))

Frame Motion? no

Relative To Cell Zone -1

Reference Frame Rotation Speed ( $\mathrm{rad} / \mathrm{s}) 0$

Reference Frame X-Velocity Of Zone (m/s) 0

Reference Frame Y-Velocity Of Zone $(\mathrm{m} / \mathrm{s}) 0$

Reference Frame Z-Velocity Of Zone (m/s) 0

Reference Frame X-Origin of Rotation-Axis (m) 0

Reference Frame Y-Origin of Rotation-Axis (m) 0

Reference Frame Z-Origin of Rotation-Axis (m) 0

Reference Frame X-Component of Rotation-Axis 0

Reference Frame Y-Component of Rotation-Axis 0

Reference Frame Z-Component of Rotation-Axis 1

Reference Frame User Defined Zone Motion Function none

Mesh Motion? no

Relative To Cell Zone -1

Moving Mesh Rotation Speed ( $\mathrm{rad} / \mathrm{s}) 0$

Moving Mesh X-Velocity Of Zone (m/s) 0

Moving Mesh Y-Velocity Of Zone $(\mathrm{m} / \mathrm{s}) 0$

Moving Mesh Z-Velocity Of Zone (m/s) 0

Moving Mesh X-Origin of Rotation-Axis (m) 0

Moving Mesh Y-Origin of Rotation-Axis (m) 0

Moving Mesh Z-Origin of Rotation-Axis (m) 0

Moving Mesh $\mathrm{X}$-Component of Rotation-Axis 0

Moving Mesh Y-Component of Rotation-Axis 0

Moving Mesh Z-Component of Rotation-Axis 1

Moving Mesh User Defined Zone Motion Function none

Deactivated Thread no 
created_material_25 


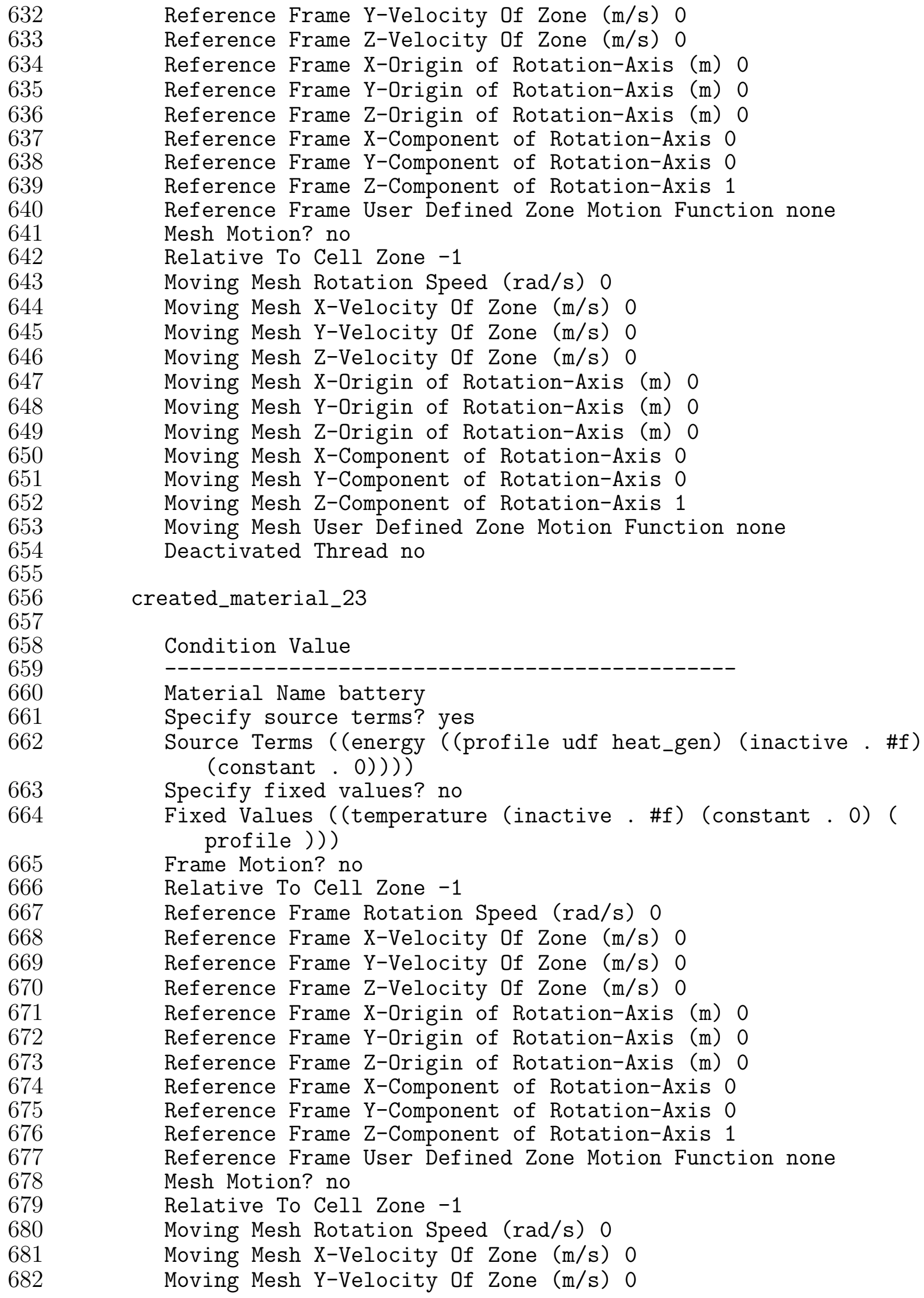

Reference Frame Y-Velocity Of Zone (m/s) 0

Reference Frame Z-Velocity Of Zone (m/s) 0

Reference Frame X-Origin of Rotation-Axis (m) 0

Reference Frame Y-Origin of Rotation-Axis (m) 0

Reference Frame Z-Origin of Rotation-Axis (m) 0

Reference Frame X-Component of Rotation-Axis 0

Reference Frame Y-Component of Rotation-Axis 0

Reference Frame Z-Component of Rotation-Axis 1

Reference Frame User Defined Zone Motion Function none Mesh Motion? no

Relative To Cell Zone -1

Moving Mesh Rotation Speed (rad/s) 0

Moving Mesh X-Velocity Of Zone (m/s) 0

Moving Mesh Y-Velocity Of Zone $(\mathrm{m} / \mathrm{s}) 0$

Moving Mesh Z-Velocity Of Zone (m/s) 0

Moving Mesh X-Origin of Rotation-Axis (m) 0

Moving Mesh Y-Origin of Rotation-Axis (m) 0

Moving Mesh Z-Origin of Rotation-Axis (m) 0

Moving Mesh X-Component of Rotation-Axis 0

Moving Mesh Y-Component of Rotation-Axis 0

Moving Mesh Z-Component of Rotation-Axis 1

Moving Mesh User Defined Zone Motion Function none

Deactivated Thread no

created_material_23

Condition Value

Material Name battery

Specify source terms? yes

Source Terms ((energy ((profile udf heat_gen) (inactive.\#f) (constant . 0))))

Specify fixed values? no

Fixed Values ((temperature (inactive . \#f) (constant . 0) ( profile )))

Frame Motion? no

Relative To Cell Zone -1

Reference Frame Rotation Speed (rad/s) 0

Reference Frame X-Velocity Of Zone (m/s) 0

Reference Frame Y-Velocity Of Zone (m/s) 0

Reference Frame Z-Velocity Of Zone (m/s) 0

Reference Frame X-Origin of Rotation-Axis (m) 0

Reference Frame Y-Origin of Rotation-Axis (m) 0

Reference Frame Z-Origin of Rotation-Axis (m) 0

Reference Frame X-Component of Rotation-Axis 0

Reference Frame Y-Component of Rotation-Axis 0

Reference Frame Z-Component of Rotation-Axis 1

Reference Frame User Defined Zone Motion Function none

Mesh Motion? no

Relative To Cell Zone -1

Moving Mesh Rotation Speed ( $\mathrm{rad} / \mathrm{s}) 0$

Moving Mesh X-Velocity Of Zone $(\mathrm{m} / \mathrm{s}) 0$

Moving Mesh Y-Velocity Of Zone (m/s) 0 
683

684

685

686

687

688

689

690

691

692

693

694

695

696

697

698

699

700

701

702

703

704

705

706

707

708

709

710

711

712

713

714

715

716

717

718

719

720

721

722

723

724

725

726

727

728

729

730

731

732

733

734

Moving Mesh Z-Velocity Of Zone (m/s) 0

Moving Mesh X-Origin of Rotation-Axis (m) 0

Moving Mesh Y-Origin of Rotation-Axis (m) 0

Moving Mesh Z-Origin of Rotation-Axis (m) 0

Moving Mesh X-Component of Rotation-Axis 0

Moving Mesh Y-Component of Rotation-Axis 0

Moving Mesh Z-Component of Rotation-Axis 1

Moving Mesh User Defined Zone Motion Function none

Deactivated Thread no

created_material_21

Condition Value

Material Name battery

Specify source terms? yes

Source Terms ((energy ((profile udf heat_gen) (inactive. \#f) (constant . 0))))

Specify fixed values? no

Fixed Values ((temperature (inactive . \#f) (constant . 0) ( profile )))

Frame Motion? no

Relative To Cell Zone -1

Reference Frame Rotation Speed (rad/s) 0

Reference Frame X-Velocity Of Zone (m/s) 0

Reference Frame Y-Velocity Of Zone (m/s) 0

Reference Frame Z-Velocity Of Zone (m/s) 0

Reference Frame X-Origin of Rotation-Axis (m) 0

Reference Frame Y-Origin of Rotation-Axis (m) 0

Reference Frame Z-Origin of Rotation-Axis (m) 0

Reference Frame X-Component of Rotation-Axis 0

Reference Frame Y-Component of Rotation-Axis 0

Reference Frame Z-Component of Rotation-Axis 1

Reference Frame User Defined Zone Motion Function none

Mesh Motion? no

Relative To Cell Zone -1

Moving Mesh Rotation Speed (rad/s) 0

Moving Mesh X-Velocity Of Zone (m/s) 0

Moving Mesh Y-Velocity Of Zone (m/s) 0

Moving Mesh Z-Velocity Of Zone (m/s) 0

Moving Mesh X-Origin of Rotation-Axis (m) 0

Moving Mesh Y-Origin of Rotation-Axis (m) 0

Moving Mesh Z-Origin of Rotation-Axis (m) 0

Moving Mesh $\mathrm{X}$-Component of Rotation-Axis 0

Moving Mesh Y-Component of Rotation-Axis 0

Moving Mesh Z-Component of Rotation-Axis 1

Moving Mesh User Defined Zone Motion Function none

Deactivated Thread no

created_material_20

Condition Value

Material Name battery 
735

736

737

738

739

740

741

742

743

744

745

746

747

748

749

750

751

752

753

754

755

756

757

758

759

760

761

762

763

764

765

766

767

768

769

770

771

772

773

774

775

776

777

778

779

780

781

782

783

Specify source terms? yes

Source Terms ((energy ((profile udf heat_gen) (inactive. \#f) (constant . 0))))

Specify fixed values? no

Fixed Values ((temperature (inactive . \#f) (constant . 0) ( profile )))

Frame Motion? no

Relative To Cell Zone -1

Reference Frame Rotation Speed (rad/s) 0

Reference Frame X-Velocity Of Zone $(\mathrm{m} / \mathrm{s}) 0$

Reference Frame Y-Velocity Of Zone $(\mathrm{m} / \mathrm{s}) 0$

Reference Frame Z-Velocity Of Zone (m/s) 0

Reference Frame X-Origin of Rotation-Axis (m) 0

Reference Frame Y-Origin of Rotation-Axis (m) 0

Reference Frame Z-Origin of Rotation-Axis (m) 0

Reference Frame X-Component of Rotation-Axis 0

Reference Frame Y-Component of Rotation-Axis 0

Reference Frame Z-Component of Rotation-Axis 1

Reference Frame User Defined Zone Motion Function none

Mesh Motion? no

Relative To Cell Zone -1

Moving Mesh Rotation Speed ( $\mathrm{rad} / \mathrm{s}) 0$

Moving Mesh X-Velocity Of Zone (m/s) 0

Moving Mesh Y-Velocity Of Zone $(\mathrm{m} / \mathrm{s}) 0$

Moving Mesh Z-Velocity Of Zone (m/s) 0

Moving Mesh X-Origin of Rotation-Axis (m) 0

Moving Mesh Y-Origin of Rotation-Axis (m) 0

Moving Mesh Z-Origin of Rotation-Axis (m) 0

Moving Mesh X-Component of Rotation-Axis 0

Moving Mesh Y-Component of Rotation-Axis 0

Moving Mesh Z-Component of Rotation-Axis 1

Moving Mesh User Defined Zone Motion Function none

Deactivated Thread no

created_material_19

Condition Value

Material Name battery

Specify source terms? yes

Source Terms ((energy ((profile udf heat_gen) (inactive.\#f) (constant . 0))))

Specify fixed values? no

Fixed Values ((temperature (inactive . \#f) (constant . 0) ( profile )))

Frame Motion? no

Relative To Cell Zone -1

Reference Frame Rotation Speed (rad/s) 0

Reference Frame X-Velocity Of Zone (m/s) 0

Reference Frame Y-Velocity Of Zone $(\mathrm{m} / \mathrm{s}) 0$

Reference Frame Z-Velocity Of Zone (m/s) 0

Reference Frame X-Origin of Rotation-Axis (m) 0

Reference Frame Y-Origin of Rotation-Axis (m) 0 


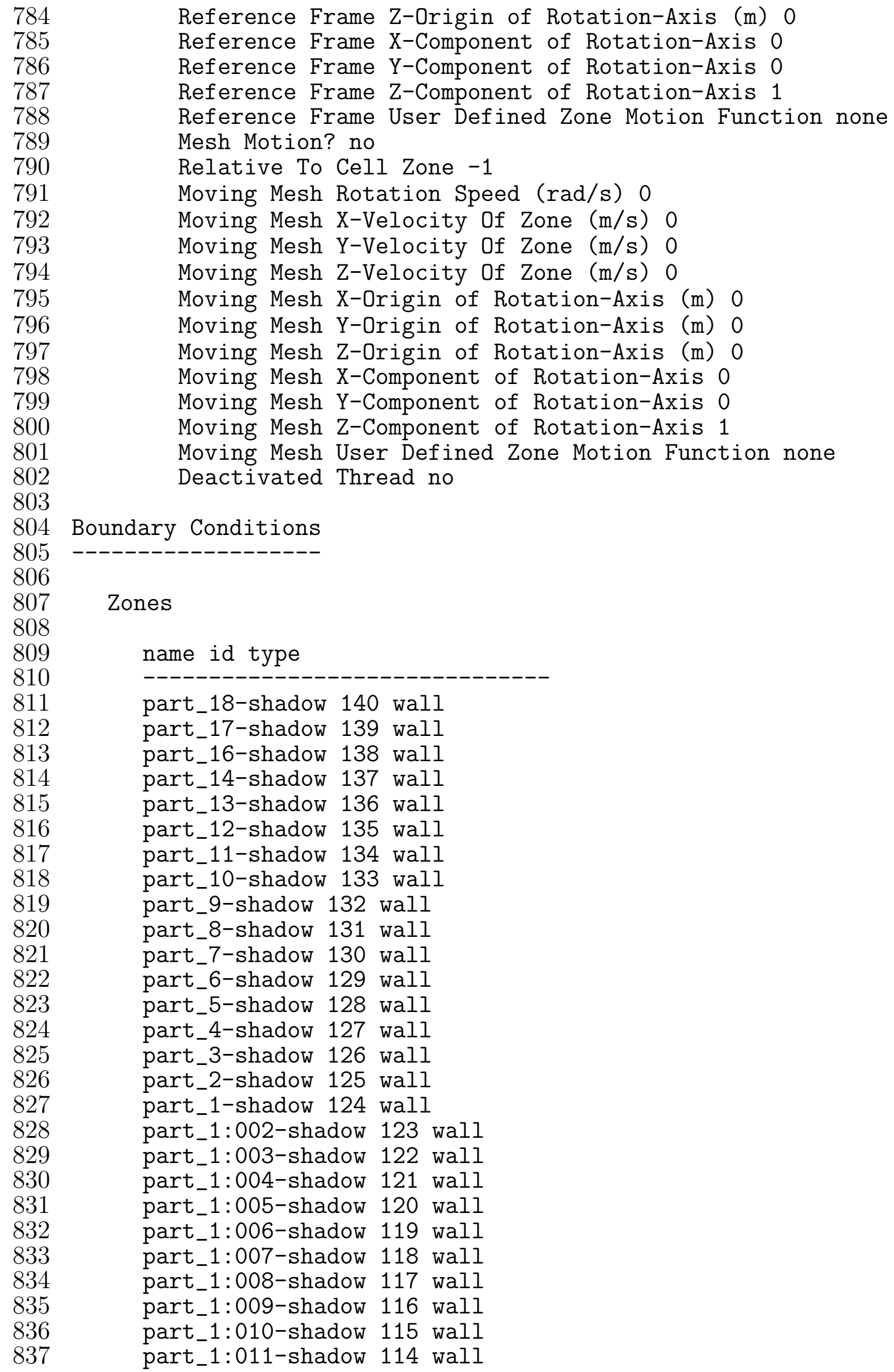




\begin{tabular}{|c|c|c|}
\hline 838 & part_1:012-shadow 113 & 3 wal \\
\hline 839 & part_1:013-shadow 112 & 2 wal \\
\hline 840 & part_1:014-shadow 111 & 1 wal \\
\hline 841 & part_1:015-shadow 110 & wal \\
\hline 842 & part_1:016-shadow 109 & 9 wal \\
\hline 843 & part_1:017-shadow 108 & wal \\
\hline 844 & part_2:018-shadow 107 & \\
\hline 845 & part_3:019-shadow 106 & wa] \\
\hline 846 & part_4:020-shadow 105 & wa] \\
\hline 847 & part_5:021-shadow 104 & wal \\
\hline 848 & part_6:022-shadow & wal \\
\hline 849 & part_7:023-shadow & $\mathrm{w}$ \\
\hline 850 & part_8:024-shadow 101 & $\mathrm{w}$ \\
\hline 851 & part_9:025-shadow 100 & al \\
\hline 852 & part_10:026-shadow 99 & wal \\
\hline 853 & part_11:027-shadow 98 & wal \\
\hline 854 & part_12:028-shadow 97 & wal \\
\hline 855 & part_12:029-shadow 96 & wal \\
\hline 856 & part_12:030-shadow 95 & \\
\hline 857 & part_12:031-shadow 38 & wal \\
\hline 858 & part_12:032-shadow 37 & 7 wal \\
\hline 859 & part_12:033-shadow 36 & wal \\
\hline 860 & part_15:034-shadow 35 & \\
\hline 861 & part_1 77 wall & \\
\hline 862 & part_2 78 wall & \\
\hline 863 & part_3 79 wall & \\
\hline 864 & part_4 80 wall & \\
\hline 865 & part_5 81 wall & \\
\hline 866 & part_6 82 wall & \\
\hline 867 & part_7 83 wall & \\
\hline 868 & part_8 84 wall & \\
\hline 869 & part_9 85 wall & \\
\hline 870 & part_10 86 wall & \\
\hline 871 & part_11 87 wall & \\
\hline 872 & part_12 88 wall & \\
\hline 873 & part_13 89 wall & \\
\hline 874 & part_14 90 wall & \\
\hline 875 & part_15 91 wall & \\
\hline 876 & part_16 92 wall & \\
\hline 877 & part_17 93 wall & \\
\hline 878 & part_18 94 wall & \\
\hline 879 & part_1:002 2 wall & \\
\hline 880 & part_1:003 3 wall & \\
\hline 881 & part_1:004 4 wall & \\
\hline 882 & part_1:005 5 wall & \\
\hline 883 & part_1:006 6 wall & \\
\hline 884 & part_1:007 7 wall & \\
\hline 885 & part_1:008 8 wall & \\
\hline 886 & part_1:009 9 wall & \\
\hline 887 & part_1:010 10 wall & \\
\hline 888 & part_1:011 11 wall & \\
\hline 889 & part_1:012 12 wall & \\
\hline 890 & part_1:013 13 wall & \\
\hline 891 & part_1:014 14 wall & \\
\hline 892 & part_1:015 15 wall & \\
\hline
\end{tabular}




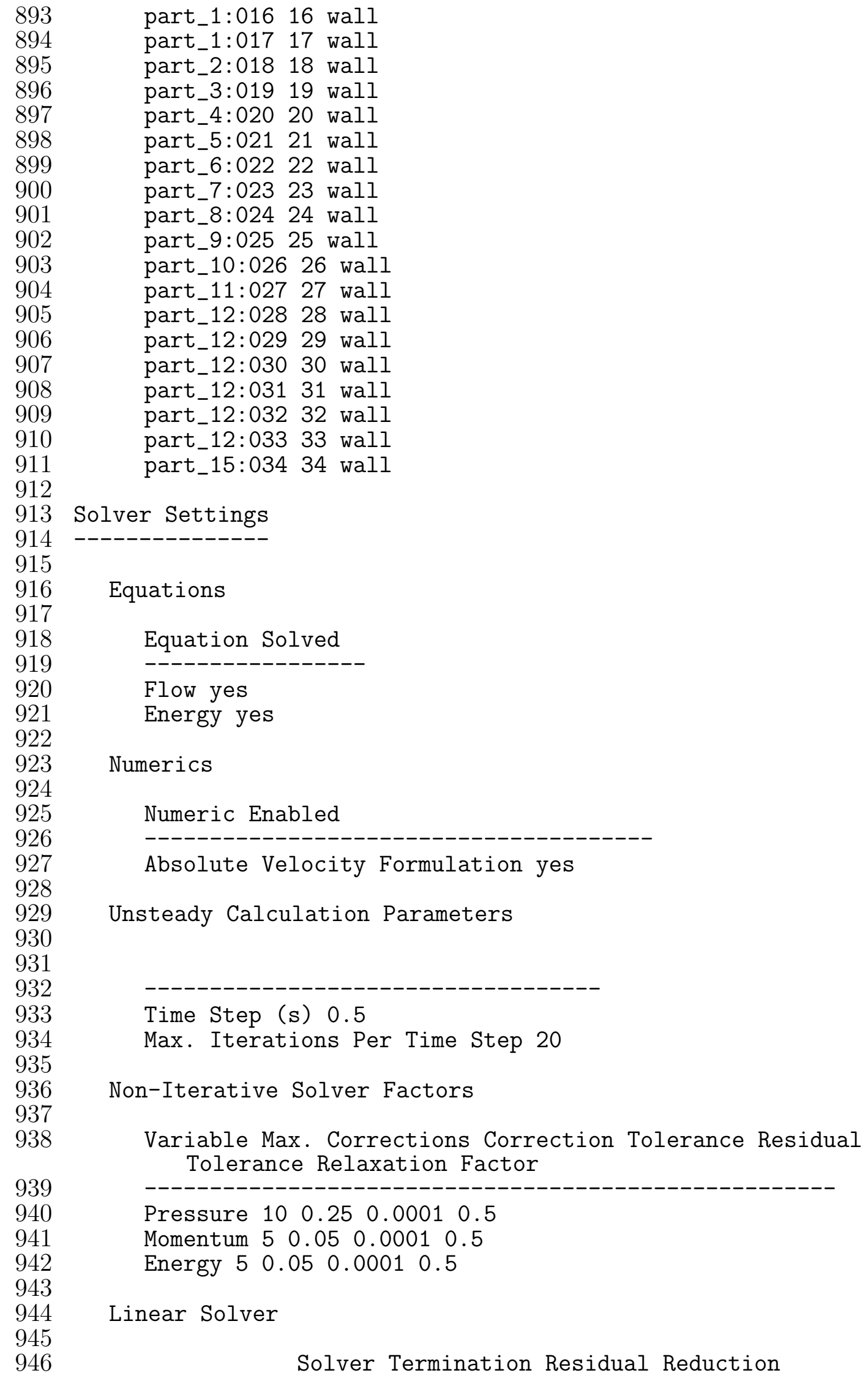

Equations

Equation Solved

Flow yes

Energy yes

Numerics

Numeric Enabled

Absolute Velocity Formulation yes

Unsteady Calculation Parameters

Time Step (s) 0.5

Max. Iterations Per Time Step 20

Non-Iterative Solver Factors

Variable Max. Corrections Correction Tolerance Residual Tolerance Relaxation Factor

Pressure $\begin{array}{llll}10 & 0.25 & 0.0001 & 0.5\end{array}$

Momentum $50.05 \quad 0.00010 .5$

Energy $5 \quad 0.05 \quad 0.0001 \quad 0.5$

Linear Solver

Solver Termination Residual Reduction 


$\begin{array}{ll}947 & \text { Variable Type Criterion Tolerance } \\ 948 & \text {------ } \\ 949 & \text { Pressure F-Cycle 0.1 } \\ 950 & \text { X-Momentum Flexible 0.1 } 0.7 \\ 951 & \text { Y-Momentum Flexible } 0.10 .7 \\ 952 & \text { Z-Momentum Flexible } 0.10 .7 \\ 953 & \text { Energy Flexible 0.1 0.7 } \\ 954 & \\ 955 & \text { Pressure-Velocity Coupling } \\ 956 & \\ 957 & \text { Parameter Value } \\ 958 & \text {-------------------- } \\ 959 & \text { Type PISO } \\ 960 & \text { Neighbour Correction 1 } \\ 961 & \\ 962 & \text { Discretization Scheme } \\ 963 & \\ 964 & \text { Variable Scheme } \\ 965 & \text {------------------- } \\ 966 & \text { Pressure Body Force Weighted } \\ 967 & \text { Momentum Second Order Upwind } \\ 968 & \text { Energy Second Order Upwind } \\ 969 & \\ 970 & \text { Solution Limits } \\ 971 & \text { Quantity Limit } \\ 972 & \text {-------------------------- } \\ 973 & \text { Minimum Absolute Pressure 1 } \\ 974 & \text { Maximum Absolute Pressure 5e+10 } \\ 975 & \text { Minimum Temperature 1 } \\ 976 & \text { Maximum Temperature 5000 } \\ 977 & \end{array}$

